INSTITUTO DE PESQUISAS ENERGÉTICAS E NUCLEARES Autarquia associada à Universidade de São Paulo

\title{
VIDRO COMERCIAL COMO DETECTOR E MEDIDOR DE RADIAÇÃO NUM IRRADIADOR DE GRANDE PORTE
}

Ary de Araújo Rodrigues Júnior

Dissertação apresentada como parte dos requisitos para obtenção do grau de Mestre em Ciências na Área de Tecnologia Nuclear Aplicações.

Orientadora:

Dra. Linda V. Ehlin Caldas

SÃO PAULO 
A minha esposa Sueli, por todo seu amor, apoio e compreensão 


\section{$\underline{\text { Agradecimentos }}$}

À Dra. Linda Caldas, por me convidar a realizar este trabalho e pela grande e dedicada orientação na execução desta dissertação.

À Diretoria da EMBRARAD, em especial ao Dr. Dirceu M. Vizeu, pelo apoio fundamental à realização deste trabalho.

A todos os funcionários da EMBRARAD, que direta ou indiretamente colaboraram na realização deste trabalho.

Ao Sr. Marcos Xavier, por me ensinar a usar o termopar digital.

Ao MSc. Orlando Rodrigues Júnior, pela paciente leitura das amostras de vidro no espectrofotômetro.

À Dra. Maria da Penha A. Potiens, pela valiosa ajuda na utilização do programa Excel. 
À Sra. Adriana C. A. Lima, pela confecção das excelentes transparências.

À Supervisão de Radioquímica do IPEN, pela análise das amostras por ativação com nêutrons.

Ao Instituto de Pesquisas Energéticas e Nucleares (IPEN), pela possibilidade oferecida para a realização deste trabalho.

A todos os amigos que direta ou indiretamente colaboraram na realização deste trabalho.

E especialmente ao meu pai Ary, à minha mãe Alayde e a minha irmã Simone, pela compreensão e apoio, que foram de grande ajuda na realização deste trabalho. 


\title{
VIDRO COMERCIAL COMO DETECTOR E MEDIDOR DE RADIAÇÃO NUM IRRADIADOR DE GRANDE PORTE
}

\author{
Ary de Araújo Rodrigues Júnior
}

\section{RESUMO}

Amostras de vidro comercial para janelas de fabricação nacional foram testadas como dosímetros de rotina para doses altas em um irradiador de grande porte que utiliza uma fonte de ${ }^{60} \mathrm{Co}$. Estas amostras foram estudadas em termos da uniformidade do lote, repetibilidade, desvanecimento, resposta à dose absorvida entre 5 e $30 \mathrm{kGy}$, de processamentos rotineiros. A técnica da absorção óptica foi usada para medir-se as amostras de vidro. Todos os resultados obtidos mostram a viabilidade do uso de amostras de placas de vidro para janelas como um sistema dosimétrico de rotina, assim como indicador de irradiação Sim/Não para doses altas em irradiadores de grande porte que utilizam fontes de ${ }^{60} \mathrm{Co}$. 


\title{
COMMERCIAL PLATE WINDOW GLASS AS DETECTOR AND RADIATION METER AT A TOTE BOX IRRADIATOR
}

\author{
Ary de Araújo Rodrigues Júnior
}

\begin{abstract}
Commercial window glass samples were tested as routine high dose dosimeters at a ${ }^{60}$ Co tote box irradiator. These samples were studied in terms of their batch uniformity, response repeatibility, fading and absorbed dose response from 5 until $30 \mathrm{kGy}$ in typical irradiation procedures. The optical absorption technique was used to measure the glass samples. All the obtained results show the feasibility of using plate window glass samples as a routine high dose dosimetry system and as a Yes/No irradiation indicator for a ${ }^{60} \mathrm{Co}$ tote box irradiator.
\end{abstract}




\section{SUMÁRIO}

RESUMO_.................................................................................... i

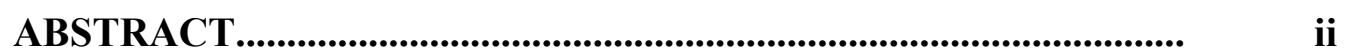

Página

1 INTRODUÇÃO............................................................................ 1

2 FUNDAMENTOS TEÓRICOS......................................................... 5

2.1 Tratamento por radiação............................................................. 5

2.1.1 Introdução ao processamento gama....................................... 5

2.1.2 Tecnologias Alternativas de Esterilização............................... 6

2.1.2.1 Esterilização por Óxido de Etileno.............................. 7

2.1.2.2 Irradiação com Acelerador de Elétrons......................... 8

2.1.2.3 Esterilização por Irradiação Gama............................. 9

2.1.3 Outras aplicações do processamento gama.............................. 11

2.1.4 Irradiação de alimentos......................................................... 12

2.1.5 Irradiação de pedras preciosas............................................... 15

2.1.6 Química de radiação em polímeros........................................ 17

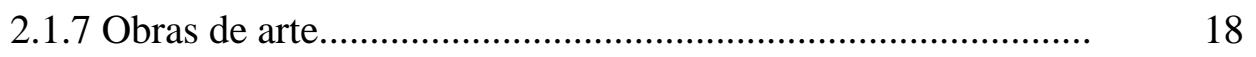

2.2 Dosimetria de altas doses.......................................................... 19

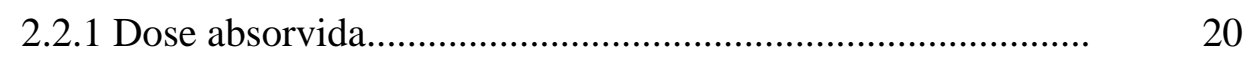

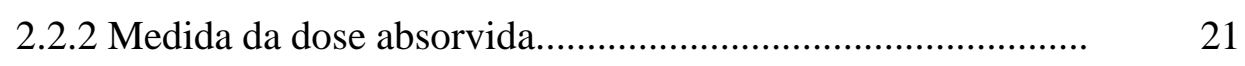

2.2.3 Métodos de dosimetria de altas doses................................... 22

2.2.3.1 Calorímetros........................................................... 22

2.2.3.2 Câmaras de ionização................................................ 23

2.2.3.3 Dosímetros químicos............................................... 24

2.2.3.4 Sistemas dosimétricos sólidos................................... 26

2.2.3.5 Sistemas dosimétricos gasosos................................ 27

2.2.4 Influência de fatores externos sobre dosímetros de doses

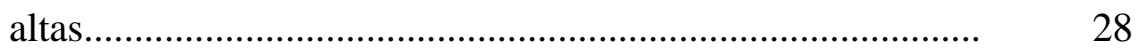

2.2.5 Incertezas nas análises das leituras de dose........................... $\quad 30$ 
2.3 Calibração

2.3.1 Calibrações, rastreabilidade e intercomparação da dose absorvida...

2.3.2 Calibração em laboratório padrão...........................................

2.3.3 Calibração na instalação do usuário...................................... 32

2.3.4 Padronização da avaliação da dose absorvida em produtos.... $\quad 33$

2.3.5 Calibração no local............................................................. 34

2.4 Fenômenos observados nos vidros durante a irradiação................... 34

3 MATERIAIS E MÉTODOS.............................................................. 37

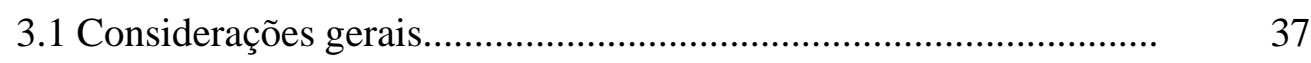

3.2 Amostras de vidro e dosímetros "red perspex"............................... 37

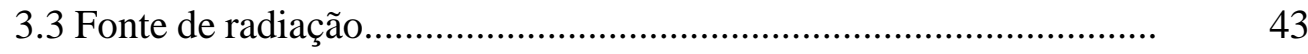

3.4 Sistema de medida.................................................................... 52

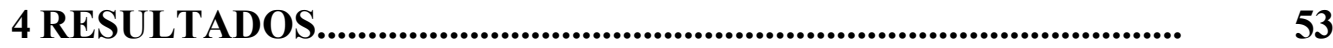

4.1 Caracterização das amostras de vidro com relação à espessura e à absorção.

4.2 Irradiação estática das amostras....................................................... 54

4.3 Curvas de calibração: irradiação estática......................................... 56

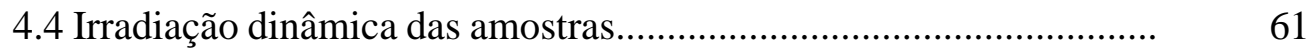

4.5 Curvas de calibração: irradiação dinâmica.......................................... 63

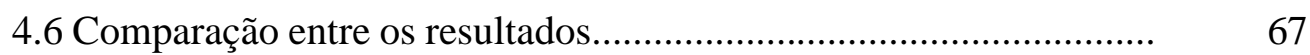

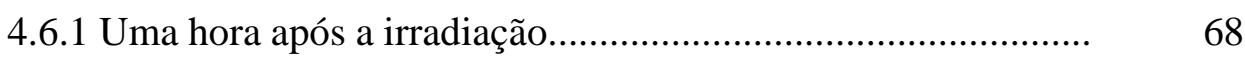

4.6.2 Duas horas após a irradiação................................................. 72

4.6.3 Um dia após a irradiação.................................................... 76

4.7 Estudo de repetibilidade............................................................. $\quad 80$

4.8 Detector de irradiação Sim / Não..................................................... 80

4.9 Proposta de um circuíto detector..................................................... 81

4.10 Análise de custo vidro versus “red perspex”................................. 82

5 CONCLUSÕES...................................................................... 84

6 REFERÊNCIAS BIBLIOGRAFICAS........................................... 85 


\section{1) INTRODUÇÃO}

A utilização de radiação em processos industriais oferece atualmente várias vantagens nos campos da esterilização de produtos médicos $\mathrm{e}$ farmacêuticos, da preservação de alimentos, do tratamento de materiais químicos e uma variedade de outros produtos largamente utilizados na sociedade moderna, todos com relevância direta à saúde e ao bem estar. A importância segura e econômica do processamento industrial já foi claramente reconhecida.

Uma dosimetria de confiança constitui um parâmetro fundamental para a garantia da qualidade do processamento por radiação e dos produtos irradiados. Além disso, é a padronização da dosimetria que pode vir a fornecer a justificativa necessária para a aprovação normativa para produtos irradiados e formar a base da autorização internacional para o seu livre comércio.

Após o início do programa de padronização de doses altas da Agência Internacional de Energia Atômica (IAEA) em 1977, foi organizado o primeiro simpósio da IAEA em dosimetria de doses altas em 1984, como resultado do aumento da necessidade de uma dosimetria de confiança não apenas nos processos da comunidade científica mas também na indústria de processamento por radiação. $\mathrm{O}$ décimo encontro internacional sobre Processamento por Radiação ocorreu em Anaheim (EUA) em 1997, com o objetivo de oferecer um fórum internacional para o intercâmbio de informações técnicas em desenvolvimentos recentes neste campo específico. Nos trabalhos apresentados neste evento foram discutidos o desenvolvimento 
de novas técnicas, o aperfeiçoamento de sistemas dosimétricos rotineiros e de referência, o controle e a garantia da qualidade em dosimetria.

Três intervalos diferentes de doses têm sido definidos na área industrial: o intervalo de doses "baixas" entre 10 Gy e 3 kGy; o intervalo de doses "médias" entre 1 e $10 \mathrm{kGy}$; e o intervalo de doses "altas" entre 5 e 100kGy. As doses "baixas" são utilizadas para inibir a germinação de cebolas e batatas, no tratamento de grãos e para permitir a armazenagem de vários produtos alimentícios. As doses "médias" são utilizadas na pasteurização de produtos alimentícios e desinfecção de rejeitos sólidos e líquidos, enquanto que as doses "altas" são aplicadas aos processos de esterilização de produtos alimentares e médicos, além de vários tratamentos de plásticos.

A dosimetria de doses altas vem despertando muita atenção, como se pode observar também nos anais dos simpósios internacionais. Os sistemas mais utilizados têm sido os calorímetros, as câmaras de ionização, os plásticos, as alaninas e os dosímetros de Fricke ${ }^{[1]}$.

Mas há outros sistemas já desenvolvidos e outros sendo desenvolvidos para atender a necessidades específicas de medidas e de custo. Neste campo tem-se os sistemas de medida de doses altas que fazem uso de soluções aquosas $^{[2-8]}$, semicondutores ${ }^{[9-11]}$, substâncias termoluminescentes ${ }^{[12-15]}$ (como o $\mathrm{LiF}$ e o $\mathrm{CaSO}_{4}$ ) ou outros tipos de materiais, cuja finalidade primeira não era se prestar à dosimetria de radiações, como a celulose $\mathrm{e}^{[16]}$.

Há ainda a linha de desenvolvimento de indicadores qualitativos de detecção de doses altas, cuja única finalidade é indicar se o material foi ou não irradiado por uma mudança de coloração ${ }^{[17]}$. 
Os irradiadores de grande porte começaram a ser instalados no Brasil há mais de duas décadas. Atualmente o sistema dosimétrico mais utilizado em nível mundial neste campo é o que envolve a utilização do dosímetro de rotina de polimetacrilato ("red perspex"), devido a várias características vantajosas apresentadas: independência de resposta com a taxa de dose e com a temperatura, reprodutibilidade, estabilidade pós-irradiação e, principalmente, a praticidade com que este pode ser utilizado ${ }^{[18-21]}$, mas apresenta a grande desvantagem de ser importado.

Existem vários tipos de dosímetros utilizados para doses altas, com características e custos diferentes ${ }^{[1]}$. Uma alternativa aos dosímetros de polimetacrilato é o vidro comercial transparente, pois este apresenta um escurecimento proporcional e reprodutível à dose após irradiação. Mas o desvanecimento inicial de sua resposta é muito acentuado, o que dificulta a sua utilização como dosímetro. Para tentar contornar esta desvantagem é utilizado um procedimento posterior à irradiação, avaliando-se as amostras sempre após um mesmo intervalo de tempo.

Vários estudos vêm sendo realizados com o objetivo de possibilitar o uso de vidro comercial, nacional e transparente como dosímetro de rotina para doses altas em fontes de radiação gama ${ }^{[22-27]}$, em aceleradores de elétrons $^{[28]}$, em irradiadores de grande porte $^{[29-31]}$ e em aceleradores síncrotron $^{[32]}$, assim como de alguns tipos de quartzo ${ }^{[33-35]}$ e vidro fosfatado ${ }^{[36]}$.

Há uma crença generalizada entre estudantes e membros da comunidade científica de que os vidros podem fluir à temperatura ambiente e que após vários anos este efeito se tornaria visível. Como "prova" alegam que os vitrais de antigas catedrais são mais espessos nas partes inferiores. Mas isto não passa de um mito pois o tempo necessário para ocorrer uma deformação 
espontânea nestes vitrais seria maior que $10^{32}$ anos ( a idade do universo é da ordem de $10^{10}$ anos). Antigamente os vidros de janela eram soprados na forma de cilindros e, a seguir, partidos e moldados manualmente; dessa forma a espessura das peças não era uniforme e algumas partes inferiores podiam ser mais espessas do que as partes superiores ${ }^{[37]}$.

O objetivo deste trabalho é o de verificar a possibilidade de utilização de amostras de vidro tanto como detectores de irradiação do tipo "Sim/Não" como dosímetros, a serem empregados nos procedimentos rotineiros de dosimetria num irradiador de grande porte, que opera com radiação gama de ${ }^{60} \mathrm{Co}$, utilizando-se para avaliação o mesmo equipamento que para a leitura dos dosímetros de polimetacrilato.

Foram estudadas as características dosimétricas mais importantes dos vidros como a reprodutibilidade, resposta à dose (curvas de calibração) e estabilidade à temperatura ambiente do irradiador. 


\section{2) FUNDAMENTOS TEÓRICOS}

\subsection{Tratamento por radiação}

\subsubsection{Introdução ao processamento gama}

O processamento gama é uma tecnologia bem estabelecida, que vem sendo usada no Brasil em aplicações médicas e nas indústrias há mais de 20 anos. Esta tecnologia é baseada no uso cuidadosamente controlado da radiação gama.

A esterilização por irradiação gama de produtos médicos começou em 1960. O processo foi introduzido nos Estados Unidos em 1964, quando a Ethicon Inc., uma empresa integrante da companhia Johnson \& Johnson, colocou em serviço três instalações de radiação gama. A Ethicon estava interessada em esterilizar suturas de origem orgânica, que não podiam ser tratadas com as técnicas então existentes. A esterilização gama foi logo adotada por outros grandes fabricantes, tais como Beckton Dickinson, Baxter International, 3M e Sherwood Medical. No fim de 1966, 15 irradiadores de escala industrial estavam em serviço em sete países. Em 1996 havia cerca de 160 irradiadores gama em operação em mais de 40 países em todo o mundo ${ }^{[38]}$. Atualmente há cerca de 200 (segundo técnicos da MDS Nordion Canadá, o maior fabricante mundial de irradiadores de grande porte) e no Brasil existem seis.

Por causa de sua simplicidade, a esterilização gama cresceu significativamente na indústria de dispositivos médicos. A grande maioria de fabricantes está agora projetando produtos novos ou reprojetando produtos existentes e embalagens para esterilização gama. 
A indústria tem se "convertido a gama", isto é, mudando de óxido de etileno (ETO) para a esterilização gama. Esta tendência de conversão tem sido guiada por diversos fatores, incluindo: introdução de novas formulações de polímeros, com estabilizadores de radiação, vantagens competitivas baseadas na manufatura, distribuição "just-in-time", aumento de preocupação com respeito à segurança de uso de ETO, e problemas ambientais com o uso de Dicloro-difluorometano $\left(\mathrm{CCl}_{2} \mathrm{~F}_{2}\right)$, cujo nome comercial é o Freon-12 . Historicamente, o Freon-12 foi misturado com o ETO para reduzir a inflamabilidade do gás. Embora a indústria, internacionalmente, esteja se afastando de ETO, muitos produtos continuaram a ser esterilizados por este método, durante a década de 1990. O processamento por radiação está progressivamente substituindo o ETO, à medida que os fornecedores de materiais aumentam a compatibilidade dos polímeros com a radiação.

Os irradiadores industriais são projetados, construídos e operados para se adaptar a padrões de segurança estritos, estabelecidos pelas autoridades reguladoras locais, nacionais e internacionais.

\subsubsection{Tecnologias alternativas de esterilização}

Os métodos usados para a esterilização de produtos médicos de uso único estão geralmente restritos a três alternativas: irradiação gama, tratamento químico (óxido de etileno) e irradiação em aceleradores de elétrons. Vapor, calor seco e outros métodos de tratamento químico são também utilizados, mas são limitados em suas aplicações. 


\subsubsection{Esterilização por óxido de etileno}

O óxido de etileno é uma tecnologia de esterilização eficiente e usada regularmente na Europa, nos Estados Unidos e no Brasil. O ETO é um esterilizante extremamente eficiente, não degrada materiais, e para uns poucos produtos é o único método de esterilização aceitável. Entretanto, a dominância do ETO como tecnologia de esterilização está em declínio devido ao aumento dos custos e preocupações maiores sobre os níveis de resíduos, Freon-12, emissões tóxicas e segurança de operadores, ligadas ao seu uso ${ }^{[38]}$.

O ETO impõe um número grande de necessidades de projeto e de exigências técnicas. Os projetos do produto e de sua embalagem têm que permitir movimento do gás e exposição do material a uma variação de pressões e a uma temperatura elevada. As embalagens porosas têm que ser utilizadas para permitir que o gás circule através do produto. O ETO é altamente tóxico, e os artigos tratados muitas vezes requerem quarentena de 4 a 14 dias para garantir que o gás tenha se dispersado totalmente. Os testes microbiológicos também têm que ser realizados após a esterilização. $\mathrm{O}$ uso do ETO é estritamente controlado, já que ele não pode ser liberado para a atmosfera, pois isto implicaria em um possível risco para os operadores e para o ambiente.

Também o transporte, a estocagem, o manuseio e o uso do ETO ou de outros agentes químicos potencialmente nocivos são preocupações importantes, a serem analisadas para o seu uso como agente esterilizante.

A esterilização por raios gama elimina a necessidade das atividades de pré-condicionamento e de retirada de gases, necessários para o processamento por ETO. Isso não somente reduz os custos do processo e da 
estocagem, mas também libera muito espaço para a fabricação. Os produtos processados por radiação gama podem ser despachados imediatamente após o processamento, o que facilita a disponibilidade e os serviços para o consumidor. Há outros benefícios ligados à esterilização gama. Os produtos tratados por este método gama não estão sujeitos ao esforço das alterações de pressão, umidade e temperatura, e a validação da esterilização é geralmente muito mais fácil de executar.

\subsubsection{Irradiação com acelerador de elétrons}

Quando são utilizados aceleradores de elétrons para esterilização, os feixes de elétrons de energias altas podem ser diretamente dirigidos sobre 0 alvo, ou dirigidos sobre uma placa conversora, que gera raios $\mathrm{X}$ de energias altas, que por sua vez irradiam os produtos.

A esterilização de materiais por aceleradores de elétrons tem sucesso limitado, principalmente por causa de suas características de pequena penetração. A radiação gama tem uma capacidade de penetração muito maior na matéria do que os elétrons acelerados com energias altas. Além disso, quando este método é utilizado para esterilizar produtos de densidades diferentes, podem ocorrer problemas de sombreamento. Isto torna a validação e a segurança consistente de dose absorvida difíceis; pode também haver um aquecimento considerável do produto, devido à alta taxa de dose $e^{[38]}$.

A esterilização por acelerador de elétrons oferece algumas vantagens. A fonte não é composta de radionuclídeos, portanto não decai com o tempo e não precisa ser acondicionada como rejeito radioativo após a desativação da instalação. Só existe risco de exposição à radiação, quando a máquina 
está operando. Além disso, como a máquina usa energia elétrica como fonte de energia, ela pode ser desligada, quando não está em uso.

Entretanto, há necessidade de níveis altos de ocupação para ser economicamente viável, e é necessário ter à disposição peças de reposição muito caras para garantir a continuidade de operação, no caso de quebrar.

\subsubsection{Esterilização por irradiação gama}

O processo de esterilização por irradiação gama consiste em expor produtos à radiação gama, geralmente do ${ }^{60} \mathrm{Co}$, em uma instalação especialmente construída. A radiação mata os microrganismos, por romper sua estrutura de ADN (Ácido desoxirribonucléico), deixando o produto inalterado ${ }^{[38]}$.

O processo é ideal para esterilizar produtos médicos de uso único, tais como seringas, catéters, equipos para infusões endovenosas, luvas, máscaras e muitos outros materiais. Devido ao fato da radiação gama ser penetrante, os materiais são irradiados em sua embalagem final e podem ser liberados imediatamente após a esterilização. O pacote permanece selado, durante o processo de esterilização, de tal maneira que a esterilidade é mantida até que a embalagem seja aberta para o uso. A temperatura máxima gerada pelo processo é da ordem de $40^{\circ} \mathrm{C}$; assim, o tratamento é adequado para materiais termossensíveis, tais como os usados para a manufatura de válvulas cardíacas plásticas. Os materiais irradiados podem ser manuseados com segurança, imediatamente após o processamento $^{[38]}$. A Tabela 2.1 mostra as características dos métodos de esterilização mais utilizados. 
Tabela 2.1: Métodos de esterilização mais utilizados ${ }^{[38]}$

\begin{tabular}{|c|c|c|c|}
\hline Pontos considerados & Irradiação Gama & Óxido de Etileno & $\begin{array}{l}\text { Irradiação com } \\
\text { Elétrons }\end{array}$ \\
\hline Projeto do produto & Sem restrição & $\begin{array}{l}\text { Sem cavidades } \\
\text { seladas }\end{array}$ & Sem restrição \\
\hline Materiais & Maioria dos materiais & $\begin{array}{l}\text { Maioria dos materiais } \\
\text { satisfatoriamente }\end{array}$ & Poucas exceções \\
\hline $\begin{array}{l}\text { Embalagem do } \\
\text { produto }\end{array}$ & Sem restrições & $\begin{array}{l}\text { - Material } \\
\text { permeável ao } \\
\text { processo de } \\
\text { embalagem dupla. } \\
\text { - Previsão de } \\
\text { expansão da } \\
\text { embalagem } \\
\text { quando submetida } \\
\text { ao vácuo. } \\
\text { - Selagem resistente } \\
\text { à distensão do } \\
\text { vácuo. }\end{array}$ & Sem restrições \\
\hline $\begin{array}{l}\text { Parâmetros de } \\
\text { processo }\end{array}$ & Tempo & $\begin{array}{l}\text { Concentração de } \\
\text { ETO, vácuo, pressão, } \\
\text { temperatura, umidade } \\
\text { relativa e tempo }\end{array}$ & $\begin{array}{l}\text { Tempo e corrente de } \\
\text { feixe }\end{array}$ \\
\hline $\begin{array}{l}\text { Confiabilidade do } \\
\text { processo esterilizante }\end{array}$ & Excelente & Boa & Excelente \\
\hline $\begin{array}{l}\text { Necessidade de teste } \\
\text { microbiológico por } \\
\text { esterilização }\end{array}$ & Não & Exigido & Não \\
\hline Período de quarentena & Não & Exigido & Não \\
\hline $\begin{array}{l}\text { Tratamento após } \\
\text { esterilização }\end{array}$ & Não & $\begin{array}{l}\text { Arear para remover } \\
\text { resíduos tóxicos }\end{array}$ & Não \\
\hline Economia & $\begin{array}{l}\text { Boa em grandes e } \\
\text { pequenas quantidades }\end{array}$ & $\begin{array}{l}\text { Boa em grandes e } \\
\text { pequenas quantidades }\end{array}$ & $\begin{array}{l}\text { Boa em grandes } \\
\text { quantidades }\end{array}$ \\
\hline
\end{tabular}




\subsubsection{Outras aplicações do processamento gama}

Embora o processamento gama tenha sido primeiramente usado para a esterilização de dispositivos médicos, esta tecnologia pode também ser usada para eliminar microrganismos em outros produtos. Alguns medicamentos e cosméticos, tais como pós, pomadas e soluções, assim como materiais de embalagem e especiarias (e alimentos desidratados) são esterilizados ou descontaminados por processamento gama. A tecnologia pode também reforçar ou incrementar as propriedades de plásticos, e é empregada em outras aplicações especializadas ${ }^{[38]}$.

No futuro, a irradiação gama poderá também ser usada como tratamento alternativo em relação a agentes químicos e pesticidas, para aumentar a qualidade de certos alimentos. A irradiação pode controlar microrganismos de origem alimentar, tais como Salmonelas em aves, destruir insetos e seus ovos ou larvas em especiarias e grãos, e ainda estender a vida de prateleira de alguns vegetais e frutas. $\mathrm{O}$ processo foi avaliado pela Organização Mundial de Saúde (“Codex Alimentarius") e foi aprovado para alguns alimentos pelo Food and Drug Administration (FDA), dos Estados Unidos.

Outra aplicação potencial da radiação gama, alternativa aos métodos existentes, é o tratamento de lixo, de grande interesse ambiental. Irradiadores especialmente projetados podem ser utilizados para esterilizar lixo de várias fontes, incluindo hospitais, aviões, navios e redes municipais de esgotos. 
Também a matéria prima, importante na indústria farmacêutica e de cosméticos, pode ser irradiada para esterilização ou desinfestação ${ }^{[39]}$.

A radiação gama vem assumindo um papel cada vez mais importante neste aspecto. Temos atualmente, em todo o mundo, várias instalações que podem processar os mais diversos tipos de produtos, esterilizando-os ou desinfestando-os sem nenhum efeito secundário. Este processo não deixa resíduos que possam afetar a saúde dos usuários ou das pessoas que manuseiam estes produtos.

Já foram determinadas milhares de curvas-respostas à radiação para bactérias, bacteriófagos, fungos e vírus, o que permite estabelecer uma adequação exata da dose para se conseguir o efeito desejado ${ }^{[39]}$.

\subsubsection{Irradiação de alimentos}

$\mathrm{O}$ tratamento de alimentos com elétrons (energias até $10 \mathrm{MeV}$ ) ou raios gama e raios $\mathrm{X}$ (energias até $5 \mathrm{MeV}$ ) não produz radioatividade nos alimentos assim tratados. A necessidade da avaliação toxicológica de produtos alimentares nasce do fato de que a aplicação da radiação provoca alterações químicas. A natureza dos compostos induzidos por radiação depende da composição química do alimento. A concentração de compostos induzidos por radiação geralmente aumenta com o aumento das doses de radiação, mas pode ser modificada durante o processo por fatores como temperatura, presença ou ausência de ar e conteúdo aquoso da amostra. A energia absorvida por alimentos irradiados é muito menor que aquela absorvida por alimentos aquecidos. Portanto, não deve surpreender o fato de que as modificações químicas causadas pela irradiação são muito menores 
quantitativamente, que aquelas causadas pelo aquecimento. Por exemplo: uma dose absorvida de $10 \mathrm{kGy}$ corresponde a um aumento de temperatura de apenas $2,4^{\circ} \mathrm{C}$ em um alimento que tenha a capacidade calórica da água. Isto corresponde a cerca de $3 \%$ da energia necessária para aquecer a temperatura da água de $20^{\circ} \mathrm{C}$ a $100^{\circ} \mathrm{C}^{[40]}$.

O Comitê de Peritos, reunido em 1976 (Organização Mundial de Saúde, Agência Internacional de Energia Atômica e Food and Agriculture Organization), concluiu que os produtos radiolíticos detectados na grande variedade de alimentos e em constituintes individuais de alimentos estudados não pareciam trazer nenhum perigo toxicológico nas concentrações, nas quais foram detectados. O Comitê também admitiu que, em doses abaixo de 10kGy, os dados podiam ser extrapolados de um membro de uma classe de alimentos para outros membros relacionados ${ }^{[40]}$.

A irradiação de alimentos é feita com três finalidades principais: $:^{[1,41]}$

a) Inibição de brotamento: $\mathrm{O}$ tratamento é realizado com quantidades pequenas de radiação de 150 a 250 Gy. Batata, cebola e alho são os produtos mais irradiados internacionalmente, regulando preços de entressafra e aproveitando a mercadoria que se perde em enormes quantidades.

b) Desinfestação de produtos agrícolas: $O$ tratamento elimina larvas, moscas, insetos, nematóides e ácaros. A dose de radiação varia entre 150 Gy e 1 kGy. Aqui, a radiação deverá substituir as fumigações com dibrometo de etileno, que têm se mostrado com potencial cancerígeno e mutagênico, deixando resíduos importantes nos alimentos. 
c) Descontaminação de alimentos: A radiação é um excelente germicida. No tratamento de alimentos, distinguem-se: 1) radapertização: consegue-se a esterilização de alimentos; as doses de radiação são altas, geralmente superiores a $25 \mathrm{kGy}$; 2) radurização: obtém-se aumento da vida útil dos alimentos, diminuindo-se a carga de microrganismos. As doses chegan até 1,5 kGy, e nos produtos tratados incluem-se grande número de frutas, verduras frescas, pescado, carnes, frangos, camarões; 3) radicidação: neste caso, elimina-se a maior parte dos patógenos existentes nos alimentos; as doses geralmente são de 10 kGy e os alimentos irradiados são fundamentalmente especiarias, liofilizados e desidratados. Quanto menor o conteúdo hídrico do alimento, maior é a sua tolerância à radiação.

Os constituintes de nutrientes (enzimas, vitaminas e proteínas) toleram bem a radiação. Os hidratos de carbono sofrem modificações importantes e nos lipídeos ocorrem fenômenos de oxidação, conferindo ao alimento paladar rançoso. $\mathrm{O}$ alimento ideal para ser irradiado, no sentido de comestibilidade, é o que tem baixo teor de água, glicose e gorduras.

A irradiação de alimentos não pode ser aplicada indiscriminadamente, ela está longe de ser uma panacéia. Os produtos que apresentam teor aquoso alto sofrem problemas de hidro-radiólise. As gorduras rancificam, quando em teor alto, sob a ação da radiação. Proteínas e açúcares toleram bem a radiação ${ }^{[42]}$. 


\subsubsection{Irradiação de pedras preciosas}

Há uma grande variedade de tratamentos utilizados, visando alterar a cor de gemas naturais.

Muitas técnicas de melhoramentos foram empregadas desde tempos antigos, como o "oleamento" de esmeraldas, executado pelos romanos. Outras modalidades de atuação se faziam por coberturas de filmes finos, calor e tratamentos químicos ${ }^{[43]}$.

Por razões éticas, atualmente todos os tratamentos devem ser comunicados ao comprador pelo vendedor. Contudo, alguns métodos, como o aquecimento de águas marinhas, citrino e zircônio incolor, são efetuados tão rotineiramente que só raramente são mencionados nas transações.

Estes processos, como a irradiação de topázio azul e quartzo esfumaçado, são praticamente idênticos aos que existem na natureza, de tal forma que os produtos obtidos não se distinguem dos naturais.

As modificações de cor das gemas são conseguidas por meio da ação de calor, radiação e pintura.

A irradiação de gemas, principalmente topázios, é comum no mercado internacional há mais de 15 anos. Esta prática se difundiu rapidamente entre os comerciantes brasileiros. As irradiações eram feitas no exterior, com evidentes prejuízos para o País e para os comerciantes. Essa situação se alterou com as atividades do Grupo de Centros de Cor do Instituto de Física da Universidade de São Paulo (IFUSP). O estabelecimento, em meados de 1980, do Convênio EMBRARAD-IFUSP e o repasse de tecnologia, 
representaram mudanças importantes na situação. Atualmente, quase toda a irradiação de gemas é feita, no Brasil, pela EMBRARAD, Cotia, São Paulo.

A irradiação de gemas naturais é indicada para:

1. Criar centros de cor, que também ocorrem naturalmente a partir de materiais incolores;

2. Intensificar alguns efeitos luminosos dos centros de cor;

3. Restaurar centros de cor, que tenham diminuído em número devido à exposição ao calor ou à luz;

4. Criar centros de cor que ainda não existem "in natura";

5. Introduzir mudanças que não envolvam os centros de cor.

A causa física exata da modificação de cor, induzida pela radiação, em muitas pedras ainda não é inteiramente conhecida. Há grande variação de estabilidade dos centros de cor, quando submetidos ao calor e à luz ${ }^{[43] .}$

No Intituto de Pesquisas Energéticas e Nucleares (IPEN) existe o Laboratório de Caracterização de Gemas, cujas atividades envolvem:

- Identificação de gemas irradiadas;

- Tratamentos térmicos para beneficiamento de cores em pedras preciosas;

- Desenvolvimento de processos de irradiação para indução e intensificação de cores em pedras preciosas; 
- Beneficiamento de pedras preciosas com o uso de raios gama de uma fonte de ${ }^{60} \mathrm{Co}$ tipo Gamacell;

- Consultoria em beneficiamento de pedras preciosas.

\subsubsection{Química de radiação em polímeros}

A interação da radiação de energias altas com substâncias moleculares envolve a seguinte seqüência de eventos, independentemente da fonte de energia (fótons, prótons, elétrons, nêutrons, etc.): as moléculas são primeiramente excitadas e ionizadas. São emitidos elétrons secundários em velocidades relativamente baixas, que produzem mais íons ao longo de seus caminhos. Dentro de $10^{-12}$ segundos, ocorrem rearranjos moleculares nos íons e nas moléculas excitadas, acompanhados por desativação térmica ou por dissociação das ligações de valência. No que concerne às reações subsequentes, a dissociação de ligações é o fato mais importante. Ela leva à produção de íons ou radicais cuja duração depende de taxas de difusão e que podem ser de semanas ou meses, em sólidos e em temperaturas baixas ${ }^{[44]}$.

Os efeitos visíveis em polímeros surgem quando ocorre a dissociação de ligações de valências primárias (ligações primárias de valência) em radicais, cuja existência pode ser demonstrada por métodos químicos ou por espectroscopia de ressonância paramagnética de elétrons. A dissociação de ligações C-C e C-H leva a resultados diferentes, degradação e reticulação, que podem ocorrer simultaneamente.

Degradação: O maior resultado da radiação é a degradação por cisão de cadeias em polímeros, tais como polimetilmetacrilato e seus derivados, poliisobutileno e polialfa-metilestireno, e em polímeros contendo halógenos, tais como polivinilcloreto, policloreto de vinilideno e politetrafluoroetileno. A tendência à degradação é relacionada à ausêria de átomos de hidrogênio 
terciário, uma ligação mais fraca que a C-C média (temperatura baixa de polimerização) ou à presença de ligações excepcionalmente fortes (tais como C-F) em algum outro local da molécula.

Reticulação: é a reação predominante na irradiação de poliestireno, polietileno e outros polímeros olefínicos, poliacrilatos e seus derivados, e borrachas naturais e sintéticas. É acompanhada pela formação de gel e finalmente pela insolubilização do espécime inteiro. A reticulação por irradiação tem um efeito benéfico sobre as propriedades mecânicas de alguns polímeros e é executada comercialmente para produzir polietileno com estabilidade aumentada e resistência a escorrer em altas temperaturas.

Outras reações: A reticulação por radiação é muitas vezes acompanhada pela formação de insaturação de trans-vinilideno, ambas as reações resultando na formação de gás hidrogênio. No caso da irradiação ser executada na presença de ar, resulta na oxidação de superfície.

A reticulação de polietileno por irradiação com elétrons de altas energias foi usada na produção comercial de filmes, combinando as propriedades típicas de polietileno com estabilidade de forma.

\subsubsection{Obras de arte}

A radiação gama está sendo utilizada em centros avançados de recuperação e conservação de obras de arte, principalmente nas obras de madeira, atacadas por caruncho, cupim ou por bactérias e fungos ${ }^{[45]}$.

A polimerização por radiação de monômeros, que são impregnados 
nesses materiais por pressão em autoclaves, tem feito com que essas obras se conservem bem.

Os objetos "apodrecidos", isto é, atacados por germes, têm sido secos, impregnados e irradiados.

\subsection{Dosimetria de doses altas}

A dosimetria da radiação é fundamental em todos os processos, pois ela acompanha a aplicação da radiação desde o seu desenvolvimento inicial em laboratório até a sua aplicação industrial, onde deve estar presente como controle de rotina, para assegurar que o tratamento por radiação esteja dentro dos parâmetros requeridos de dose. Portanto a dosimetria fornece um meio independente e efetivo de desenvolvimento e controle de processo $^{[1]}$.

Na esterilização de produtos médicos e na irradiação de alimentos, onde o processo de radiação afeta diretamente a saúde pública, as medidas de radiação fornecem os meios oficiais de regulamentação e aprovação do processo. A este respeito espera-se que as condições de operação possibilitem uma medida de dose exata e precisa nos produtos antes de sua liberação para venda.

A dosimetria nos processos por radiação é do interesse da International Commission on Radiation Units and Measurements (ICRU). Com o apoio desta Comissão, um grupo de estudo atualizou a situação presente da dosimetria.

Os conceitos físicos desenvolvidos para dosimetria em radioterapia ou em proteção radiológica são igualmente relevantes para a dosimetria de 
processos por radiação. As questões de rastreabilidade e padronização da determinação da dose absorvida são comparáveis àquelas em outros campos da dosimetria.

Em processamento por radiação, os sistemas dosimétricos estão sujeitos a doses altas, taxas de dose altas e a uma variedade de outras condições. Portanto, os problemas são prováveis e são diferentes daqueles que aparecem em outras aplicações dosimétricas. Além disto, o comissionamento de uma instalação deste tipo, a calibração das taxas de dose da instalação e a validação do processo exigem sistemas dosimétricos específicos e necessários para o processamento por radiação.

\subsubsection{Dose absorvida}

As medidas da radiação aplicada em produtos da indústria, da agricultura e da área médica devem ser feitas com muito cuidado e atenção no que diz respeito à escolha correta da grandeza que se deseja quantificar e de sua unidade ${ }^{[1]}$.

A grandeza mais importante na dosimetria de processamento por radiação é a dose absorvida (D), que é definida como a energia média cedida pela radiação ionizante (d ) a um elemento de volume com massa (dm):

$$
\mathbf{D}=\frac{\mathrm{d}}{\mathrm{dm}}
$$

No Sistema Internacional, a energia é dada em joules (J) e a massa em quilos (kg) e o nome adotado para a unidade de dose absorvida é o gray (Gy). 
Esta unidade recebeu este nome para homenagear L. H. Gray, um dos pioneiros da Medicina, da Biologia e da Física das Radiações.

A dose absorvida por unidade de tempo é expressa como a taxa de dose absorvida:

$$
\dot{D}=\frac{\mathrm{dD}}{\mathrm{dt}}
$$

No Sistema Internacional, a unidade da taxa de dose absorvida é o gray por segundo $(\mathrm{Gy} / \mathrm{s})$, mas ela também pode ser expressa em gray por minuto ou hora dependendo da conveniência.

\subsubsection{Medida da dose absorvida}

A dose absorvida em um ponto de um material pode ser medida usando-se dosímetros de rotina calibrados. Tais dosímetros são geralmente calibrados com fontes de ${ }^{60} \mathrm{Co}$ ou ${ }^{137} \mathrm{Cs}$, em condições muito próximas à do equilíbrio eletrônico. Quando o dosímetro é colocado em um material para monitorar o processamento por radiação, ele constituirá uma descontinuidade ou uma "cavidade" no meio, levando-se em conta que o dosímetro geralmente difere em número atômico e densidade do meio circundante; portanto ele diferirá também nas propriedades de absorção da dose $\mathrm{e}^{[1]}$.

Portanto, a energia absorvida no dosímetro não será a mesma que será absorvida no meio não perturbado. Teorias da cavidade têm sido desenvolvidas para irradiações por fótons para se calcular a relação entre as duas doses. Estas teorias têm se estendido para englobar as irradiações por elétrons. 


\subsubsection{Métodos de dosimetria de doses altas}

\subsubsection{Calorímetros}

Os calorímetros possuem certas vantagens que os fazem extremamente úteis para as aplicações em doses altas. Eles são considerados dosímetros primários, porque não é necessário calibrá-los contra um outro instrumento detector de radiação. A maioria dos dosímetros químicos, de estado sólido e das câmaras de ionização necessita ser calibrada em campos de radiação bem conhecidos; além disso, eles requerem a aplicação de parâmetros que dependem da energia da radiação e das condições ambientais ${ }^{[1]}$.

Os calorímetros, por sua vez, podem ser utilizados em uma extensa faixa de energia, de taxa de dose absorvida e valores altos de dose absorvida. De fato, a sensibilidade da resposta do calorímetro geralmente aumenta em doses altas e em taxas de dose altas. Isto torna possível simplificar a isolação térmica necessária para reduzir a perda de calor e o sistema eletrônico usado em feixes de radiação de alta intensidade de radiação.

O princípio de funcionamento do calorímetro é simples. É medida a quantidade total de energia que é cedida como calor em uma massa isolada termicamente. Esta medida da energia, por unidade de massa, fornece diretamente a dose absorvida. A quantidade de calor depositado nesta massa isolada termicamente (ou absorvedor) é geralmente medida com um termopar pequeno ou um termistor, e a verificação de sua resposta em função do calor absorvido é frequentemente feita pelo uso de um aquecedor elétrico colocado no absorvedor. 
Estas operações parecem simples, mas são geralmente difíceis na prática. Entretanto, muitos calorímetros são construídos pelos próprios usuários para aplicações específicas, tais como para a calibração de campos de radiação de fótons e elétrons, ou para um uso mais rotineiro como medir feixes de elétrons de intensidade e energia altas.

As considerações de projeto são menos rígidas para aplicações em doses altas e um calorímetro relativamente simples em geral terá um desempenho adequado.

Os calorímetros podem ser fabricados em vários formatos, com o objetivo de simular a geometria do objeto em que a dose absorvida será medida.

\subsubsection{Câmaras de ionização}

As câmaras de ionização são largamente utilizadas como padrões primários e secundários e instrumentos de campo, em radioterapia e proteção radiológica, porque eles permitem medidas rápidas e precisas numa faixa grande de doses e taxas de dose. A vantagem de sua utilização vem do fato que sua resposta pode ser determinada convenientemente por meio de eletrodos que são facilmente encontrados no mercado ${ }^{[1]}$.

As câmaras de ionização são construídas em vários tamanhos e formas, dependendo de sua utilização. Muitas câmaras de ionização são muito sensíveis para serem usadas em processamento por radiação, mas uma sensibilidade apropriada para doses altas pode ser conseguida construindo-se câmaras de ionização de volume pequeno. 
A desvantagem das câmaras de ionização é que, como a maioria dos calorímetros, elas necessitam ser conectadas a instrumentos externos para se efetuar as medidas de dose.

Os materiais escolhidos para a construção de uma câmara de ionização que será utilizada para medir doses altas deve ser feita com muito cuidado, porque há a possibilidade de deterioração dos isolantes e das peças plásticas.

Uma câmara de ionização consiste de uma cavidade preenchida com gás e rodeada por paredes condutoras de eletricidade. Dentro da câmara há um eletrodo coletor que pode estar conectado à entrada de um amperímetro. Uma diferença de potencial é mantida entre as paredes da câmara e o eletrodo condutor.

Quando uma câmara de ionização é irradiada por fótons ou elétrons, os elétrons secundários gerados na parede e no gás produzem íons. A produção destes íons é praticamente independente da energia dos elétrons e de fótons incidentes acima de $1 \mathrm{keV}$. A tensão entre as paredes e o eletrodo provoca a liberação de cargas de uma polaridade que serão coletadas pelo eletrodo. Se a irradiação é contínua, será detectado um fluxo de carga (ou corrente) contínuo pelo medidor conectado ao eletrodo.

\subsubsection{Dosímetros químicos}

A maioria dos sistemas dosimétricos utilizados para doses altas são soluções aquosas de reagentes inorgânicos mantidos com pH baixo por meio de ácidos minerais fortes, como por exemplo ácido sulfúrico ou perclórico. Há também certos solventes orgânicos ou uma combinação de solventes contendo solutos ${ }^{[1]}$. 
A maioria das soluções mais recentes são neutras, isto é, elas podem conter somente ácidos fracos ou bases em concentrações baixas. A química da radiação de dosímetros aquosos e orgânicos está bem documentada e isto inclui o entendimento da cinética química de várias reações induzidas pela radiação na água, em soluções químicas e em sistemas moleculares orgânicos.

Quando uma partícula de radiação ionizante, por exemplo um elétron de energia alta, passa através de um meio líquido (que pode ser água, solvente orgânico ou uma solução baseada nestes solventes), a ionização e a excitação ocorrem em escalas atômicas e moleculares ao longo da trajetória e radialmente, devido aos elétrons secundários. Este é um processo altamente heterogêneo ao longo da trajetória de cada partícula e envolve a produção de um número de espécies quimicamente ativadas, tais como íons, radicais livres e radicais íons. Isto torna-se mais uniforme sobre um volume irradiado constantemente quando são utilizadas taxas altas de dose absorvida de radiação de fótons e elétrons.

Entretanto, em uma solução irradiada uniformemente, como uma ampola contendo uma solução dosimétrica, estas espécies intermediárias, reativas, transitórias e últimos produtos, geralmente íons, são produzidas em concentrações relativamente altas e são prontamente mensuráveis.

Cada espécie radiolítica em um dado meio ambiente tem uma duração característica, variando de $10^{-13} \mathrm{~s}$ até segundos, minutos, horas, etc., para certos processos bioquímicos.

A dosimetria química aquosa é baseada na reação de solutos com espécies formadas na radiólise da água. A dose absorvida vem da mudança de 
concentração nos produtos da reação ou no soluto. Um número de solutos restrito é adequado para a dosimetria. A concentração destes solutos se altera proporcionalmente à dose absorvida.

A química da radiação na água é bem entendida e extensamente documentada. Em irradiações com radiação gama e de elétrons, a maior parte dos produtos são $\mathrm{H}_{2} \mathrm{O}_{2}$ e $\mathrm{H}_{2}$, os elétrons hidratados $\left(\mathrm{e}_{\mathrm{aq}}^{-}\right.$), os íons hidrogenados e os radicais $\mathrm{OH}$ e $\mathrm{H}$.

A produção da reação química inicial, antes da reação reversa ocorrer, é independente da taxa de dose absorvida até pelo menos $1 \mathrm{MGy} / \mathrm{s}$. Sua mudança com a temperatura em uma faixa de 20 a $30^{\circ} \mathrm{C}$ e com a adição de solutos até a concentração de $10^{-3} \mathrm{~mol} / \mathrm{dm}^{-3}$ é menor que $5 \%$.

Apesar destas vantagens, há problemas e limitações em dosímetros aquosos. O maior problema é que a água e os reagentes devem ser puros, pois $\mathrm{o} \mathrm{e}_{\mathrm{aq}}^{-}, \mathrm{H}$ e o $\mathrm{OH}$ reagem rapidamente com as impurezas.

Como exemplos de dosímetros aquosos tem-se: sulfato ferroso (Fricke), sulfato ferroso-cúprico, sulfato cérico e dicromato de potássio.

\subsubsection{Sistemas dosimétricos sólidos}

Muitos sólidos usados como dosímetros de doses altas consistem de materiais cristalinos orgânicos, inorgânicos, amorfos ou quase cristalinos. Estas substâncias estão geralmente disponíveis em grandes quantidades para medidas de rotina, mas não são, em muitos casos, suficientemente exatos ou precisos para servirem como dosímetros de referência ${ }^{[1]}$. 
Alguns sólidos produzidos cuidadosamente e em condições controladas têm uma vantagem sobre os dosímetros químicos, que é a possibilidade de possuírem dimensões reduzidas. Por exemplo, tem-se os filmes finos que apresentam boa resolução em medidas de dose absorvida. Outras vantagens podem ser citadas: são mais adequados aos processos industriais e ao manuseio.

Além de poderem ser avaliados nos espectrômetros convencionais, uma variedade de outros métodos de leitura podem ser utilizados, como a espectroscopia por ressonância de elétrons, espectrofluorometria, termoluminescência, etc.

Como exemplo de dosímetros sólidos tem-se: "red perspex", filmes, cristais termoluminescentes $\left(\mathrm{LiF}, \mathrm{CaSO}_{4}\right)$ e cerâmicas.

\subsubsection{Sistemas dosimétricos gasosos}

O estudo dos efeitos da radiação em gases começou logo depois da descoberta da radioatividade e continuou até se tornar uma parte importante da química de radiações. Gases são, pelo menos em princípio, os sistemas mais simples para se investigar; um dos interesses em seu comportamento é a possibilidade de se quantificar todos os eventos do processo que ocorrem quando estes são irradiados. É muito mais fácil prever fisicamente o comportamento de um gás do que de líquidos ou sólidos, devido à complexidade das forças entre átomos e moléculas que ocorrem no estado condensado $^{[1]}$. 
Para muitos gases simples como: $\mathrm{O}_{2}, \mathrm{~N}_{2} \mathrm{O}, \mathrm{CO}_{2}, \mathrm{H}_{2} \mathrm{~S}$, há um bom entendimento de sua resposta à radiação e consequentemente com a dose aplicada, com a taxa de dose e com a temperatura.

Embora a preparação de dosímetros a gás e sua medida requeiram linhas de vácuo e, possivelmente, um espectrômetro ou um cromatógrafo, o bom conhecimento do seu comportamento permite que eles possam ser considerados dosímetros de referência. Os três gases que têm se mostrado como os mais adequados à dosimetria de doses altas são: $\mathrm{N}_{2} \mathrm{O}, \mathrm{H}_{2} \mathrm{~S}_{\text {e }} \mathrm{C}_{2} \mathrm{H}_{4}$.

\subsubsection{Influência de fatores externos sobre dosímetros de doses altas}

A dosimetria em muitas aplicações de processamento por radiação deve ser rastreável a padrões nacionais ou de referência e ter alguma base de exatidão e precisão em termos absolutos. Uma corrente de padronização dosimétrica é normalmente estabelecida para se atingir este objetivo. Padrões de referência de dose absorvida são mantidos por laboratórios nacionais de padrões, e a cadeia de padronização é então estendida do laboratório nacional de padrões para as medidas de dose no processamento ${ }^{[1]}$.

Tanto a incerteza aleatória quanto a sistemática, que podem aparecer em cada elo da corrente de calibração, podem levar a discrepâncias na estimativa da dose na prática.

Um dosímetro pode ser calibrado em um campo de radiação bem definido, com taxa de dose e temperatura constantes, em um período de poucas horas e ser avaliado imediatamente após a irradiação. Na prática o dosímetro deve frequentemente estimar a dose absorvida em um campo de radiação não ideal, com variações da taxa de dose, em diferentes 
temperaturas, durante um período de vários dias, e consequentemente a avaliação do dosímetro ocorrendo várias horas após a sua irradiação.

Neste caso, as fontes de erro são devidas à dependência da resposta do dosímetro com a energia, com a taxa de dose, ou ainda com a variação de temperatura levando ao desvanecimento da resposta.

Os dosímetros de doses altas são frequentemente sensíveis a mudanças das condições do meio ambiente. As diferenças entre as condições de calibração e aquelas encontradas nas aplicações práticas podem levar a sérios erros dosimétricos. As instabilidades em sistemas dosimétricos frequentemente aparecem de uma combinação de vários fatores como temperatura, difusão de oxigênio e taxas de dose. A influência de várias combinações de fatores ambientais deve ser investigada nos estágios de pesquisa e desenvolvimento de um sistema dosimétrico. Entretanto, as condições de umidade relativa e de concentração de oxigênio podem ser otimizadas e portanto evitadas.

Os efeitos provocados pela luz podem ser evitados por uma embalagem e manuseio apropriado. As mudanças na temperatura durante e depois da irradiação não podem ser sempre evitadas, e a temperatura durante a irradiação é provavelmente o fator mais importante que pode gerar um aumento na imprecisão da determinação da dose nas aplicações do processamento por radiação. 


\subsubsection{Incertezas nas análises das leituras de dose}

A estimativa da dose absorvida envolve a medida do dosímetro irradiado e o uso de curvas de calibração da resposta do dosímetro em função da dose absorvida. Independente da confiança da resposta do dosímetro no campo de radiação, as incertezas adicionais na estimativa da dose são introduzidas por erros dos instrumentos de medida, afetando a precisão e/ou a exatidão ${ }^{[1]}$.

Se a curva de calibração do dosímetro é estabelecida utilizando-se os mesmos instrumentos de medida que são usados na dosimetria de rotina, então as falhas podem se originar da operação incorreta dos equipamentos ou da falta de manutenção, mas verificações regulares do funcionamento dos equipamentos e treinamentos dos operadores mantêm estas falhas em um patamar mínimo.

Quando são utilizados diferentes instrumentos de medida na calibração de rotina, as diferenças entre os dois instrumentos podem aumentar as incertezas na estimativa da dose.

\subsection{Calibração}

Para a calibração de dosímetros em doses altas são necessárias fontes de atividade alta de ${ }^{60} \mathrm{Co}$ ou ${ }^{137} \mathrm{Cs}$. As calibrações absolutas podem ser feitas na maioria dos campos de altas taxas de fluxo de raios $\mathrm{X}$ e gama, utilizandose calorímetros ou câmaras de ionização. As taxas de dose em um dado material podem ser determinadas por meio de um calorímetro, de uma câmara de ionização ou ainda pelo dosímetro de Fricke, em uma geometria fixa sob condições aproximadas de equilíbrio eletrônico e, se necessário, em uma 
temperatura controlada. Deste modo a resposta do dosímetro em função da dose absorvida pode ser calibrada com a exatidão e a precisão adequadas ${ }^{[1]}$.

\subsubsection{Calibrações e rastreabilidade.}

Padrões primários nacionais ou internacionais para doses altas não foram ainda estabelecidos, mas alguns laboratórios tais como o "UK National Physical Laboratory" e o "US National Institute of Standards and Technology" desenvolveram padrões de referência para dosimetria de doses altas (calorímetros ou câmaras de ionização) ${ }^{[1]}$.

Um dosímetro de referência é definido como um dosímetro de qualidade metrológica alta, que foi calibrado contra um padrão de referência e que deve satisfazer critérios muito bem estabelecidos para ser usado. Ele deve fornecer uma leitura de radiação precisa e mensurável e proporcional à dose absorvida. Por exemplo, os calorímetros, as câmaras de ionização e o dosímetro de sulfato férrico (Fricke) podem ser utilizados como dosímetros de referência se irradiados em condições onde a resposta destes dosímetros não é influenciada pelas taxas de dose.

Um dosímetro de transferência é definido como sendo um dosímetro suficientemente preciso e estável; consequentemente ele pode ser calibrado contra um padrão ou dosímetro de referência e portanto ser utilizado em instalações de processamento por radiação para uma avaliação da dose ou para a calibração da resposta dos dosímetros de rotina. Sua leitura pode então ser feita na instalação irradiadora ou após o seu retorno para o laboratório de calibração. São exemplos de dosímetros de referência os dosímetros de alanina, de filme radiocrômico e de etanol clorobenzeno. 
Um dosímetro de rotina é geralmente um padrão de trabalho que é usado rotineiramente em uma instalação de processamento, mas que deve ser frequentemente calibrado contra um dosímetro de referência ou de transferência, pois ele pode não ser suficientemente estável como um dosímetro de referência.

\subsubsection{Calibração em laboratório padrão}

Um sistema de dosimetria pode ser calibrado em laboratórios padrões em termos da dose absorvida na água. Se a resposta do dosímetro não for linear, o que acontece às vezes no caso de doses altas, deve-se construir uma curva de calibração, fornecendo ao sistema uma série de doses absorvidas conhecidas com exatidão ${ }^{[1]}$.

Se os dosímetros são avaliados no laboratório padrão, é necessário comparar a precisão e a exatidão dos instrumentos de medida do usuário com os utilizados pelo laboratório padrão, para se minimizar os possíveis erros instrumentais. Se os dosímetros são avaliados no próprio laboratório do usuário, estes erros instrumentais são evitados, mas isto somente pode ser feito quando a resposta pós-irradiação dos dosímetros for suficientemente estável.

\subsubsection{Calibração na instalação do usuário}

Não importa se o usuário utiliza em sua instalação um dosímetro de transferência previamente calibrado ou um conjunto que é enviado a ele para ser irradiado em sua instalação e retorna para o laboratório padrão para avaliação. Deste modo a taxa de dose absorvida da fonte do usuário pode ser determinada com exatidão, sendo rastreada a um padrão de referência ou a um padrão nacional $^{[1]}$. 
A dose recebida pelos dosímetros durante o trânsito da fonte entre a posição de repouso e de exposição, ou durante o trânsito dos dosímetros para ir ou voltar da posição de irradiação, pode ser significativa e deve ser determinada.

\subsubsection{Padronização da avaliação da dose absorvida em produtos}

Os dosímetros de referência podem ser enviados ao usuário e irradiados em sua instalação durante um processamento normal, junto com os dosímetros de rotina do próprio usuário. Os dosímetros de referência retornam para serem avaliados no laboratório padrão e as doses absorvidas determinadas podem ser comparadas com os valores obtidos por meio dos dosímetros de rotina ${ }^{[1]}$.

Este é o modo mais direto para se assegurar que as medidas de dose obtidas pelo usuário em seu processo são rastreáveis a um padrão nacional ou de referência de dose absorvida.

Os dosímetros de alanina, de filmes radiocrômicos, de dicromato e de sulfato cérico são utilizados como dosímetros de transferência para doses altas. Entretanto, a maioria dos dosímetros utilizados para medidas de doses altas é influenciada por fatores ambientais durante e depois da irradiação. Além disso, as condições de processamento da instalação diferem em geral substancialmente das existentes em laboratórios de calibração padrões. Portanto, para uma padronização precisa e exata podem ser requisitadas informações sobre as condições de irradiação (temperatura, taxa de dose, tamanho do dosímetro, etc.), junto com um conhecimento extensivo dos efeitos dos fatores ambientais na resposta dosimétrica. 


\subsubsection{Calibração no local}

Os funcionários dos laboratórios de calibração padrões podem visitar a instalação de radiação para uma calibração no local, utilizando um dosímetro de transferência calibrado. Os dosímetros podem ser avaliados na instalação, mas neste caso os instrumentos na instalação e no laboratório padrão devem ser comparados. Se os dosímetros forem avaliados no laboratório padrão, é necessário um dosímetro de transferência estável e bem calibrado ${ }^{[1]}$.

Uma dosimetria exata no local ainda vai requer um conhecimento detalhado das condições de irradiação da instalação, tais como condições ambientais, limitações da taxa de dose e da geometria do local, onde os dosímetros serão irradiados, pois (se necessário) deverão ser aplicados fatores de correção para as influências externas.

\subsection{Fenômenos observados nos vidros durante a irradiação}

A maioria dos vidros comerciais tem sua estrutura baseada numa cadeia de tetraedros de $\mathrm{SiO}_{4}$. Entretanto, os vidros não se limitam aos silicatos como formadores da rede; outros óxidos como $\mathrm{Na}_{2} \mathrm{O}, \mathrm{K}_{2} \mathrm{O}, \mathrm{CaO}, \mathrm{BaO}, \mathrm{MgO}$, $\mathrm{PbO}$ e os óxidos de terras raras também podem desempenhar este papel. Os vidros comerciais, dependendo do destino de sua utilização (lentes, janelas, recipientes, etc.), apresentarão variações em sua composição para incrementar ou diminuir algumas de suas características, como: índice de refração, cor, dispersão, resistência, etc. ${ }^{[22]}$

Um vidro comercial transparente ao ser irradiado escurecerá devido ao fato que a radiação induz no vidro bandas de absorção óptica que dependem 
de inúmeros fatores, tais como: composição do vidro, tipo e concentração de materiais alcalinos, presença de impurezas, temperatura durante a irradiação, bem como o tipo de radiação. Portanto modificações em um ou mais destes parâmetros acarretarão um escurecimento maior ou menor dos vidros.

A coloração nos vidros é devida a mecanismos de oxidação e redução de seus componentes e à formação de centros de cor. Os processos de oxiredução são fenômenos que ocorrem com fótons com energias da ordem da luz solar e na presença de íons polivalentes na estrutura vítrea.

Um exemplo clássico de oxi-redução é a formação do $\mathrm{Mn}^{3+}$ purpúreo por meio da oxidação do $\mathrm{Mn}^{2+}$ devido à perda de um elétron após ser submetido à radiação. $\mathrm{O}$ centro de cor é definido como uma configuração eletrônica associada com defeitos na rede cristalina, tais como vacâncias e impurezas ou aglomerados destes, que causam a absorção de fótons numa região do espectro para o qual o sólido é normalmente transparente.

Mas pode haver também a emissão de luz de materiais vítreos após a irradiação, por meio de dois fenômenos: a luminescência e a termoluminescência. $\mathrm{O}$ primeiro ocorre quando os elétrons excitados retornam a níveis menos energéticos ou ao seu estado fundamental, emitindo radiação visível com comprimentos de onda bem definidos; o segundo ocorre quando um sólido é aquecido ou exposto à radiação infravermelha emitindo luz visível ou ultravioleta.

Os fenômenos descritos têm sido largamente utilizados em dosimetria, envolvendo uma série de materiais, relacionando a dose absorvida com os eventuais efeitos provocados pela radiação. 
Um sistema dosimétrico de rotina utilizando amostras de vidro comercial comum foi desenvolvido por Quezada ${ }^{[22]}$, onde foram estudadas e comparadas as características dosimétricas de amostras de vidro nacionais e importadas, tais como: uniformidade de lote, repetitividade de resposta, reutilização por tratamento térmico, respostas à dose absorvida entre $30 \mathrm{~Gy}$ e 1,0 kGy, intervalo de detecção, estabilidade da resposta em função da dose absorvida, da temperatura de armazenamento e de tratamentos térmicos pré- e pós-irradiação, pela técnica de absorção óptica. Como uma aplicação, o sistema dosimétrico foi testado num processo de irradiação de flores no IPEN $^{[24]}$. Todos os resultados obtidos mostraram a viabilidade da utilização deste sistema em dosimetria de doses altas. 


\section{3) MATERIAIS e MÉTODOS.}

\subsection{Considerações gerais}

Foram estudadas as características indispensáveis a um dosímetro de rotina que se deseja usar em um irradiador de grande porte:

- uniformidade do lote de amostras

- repetibilidade de resposta

- resposta à dose absorvida entre $5 \mathrm{kGy}$ e $30 \mathrm{kGy}$, que está dentro da faixa de trabalho do dosímetro "red perspex" 4034.

- estabilidade da resposta após a irradiação.

\subsection{Amostras de vidro e dosímetros "red perspex"}

Foram adquiridos, em uma vidraçaria comercial que utiliza placas de vidro para montar espelhos e janelas, 500 amostras de vidro com dimensões próximas às dos dosímetros "red perspex": área de $30 \mathrm{~mm}$ x $10 \mathrm{~mm}$ e espessura de $3 \mathrm{~mm}$, todas cortadas de uma mesma placa translúcida fabricada pela empresa Santa Marina, uma empresa nacional, para serem utilizadas em comparações dosimétricas. A leitura da dose é obtida medindo-se a absorção por unidade de caminho óptico, que um feixe de luz sofre ao atravessar uma amostra de vidro perpendicularmente a sua espessura. Qualitativamente, quanto maior a absorção por unidade de caminho óptico maior é a dose. $\mathrm{Na}$ Figura 3.1 pode-se ver amostras de vidro irradiadas com doses escalonadas. Foi investigada a variação de espessura e da leitura em absorção antes da irradiação destas amostras. 


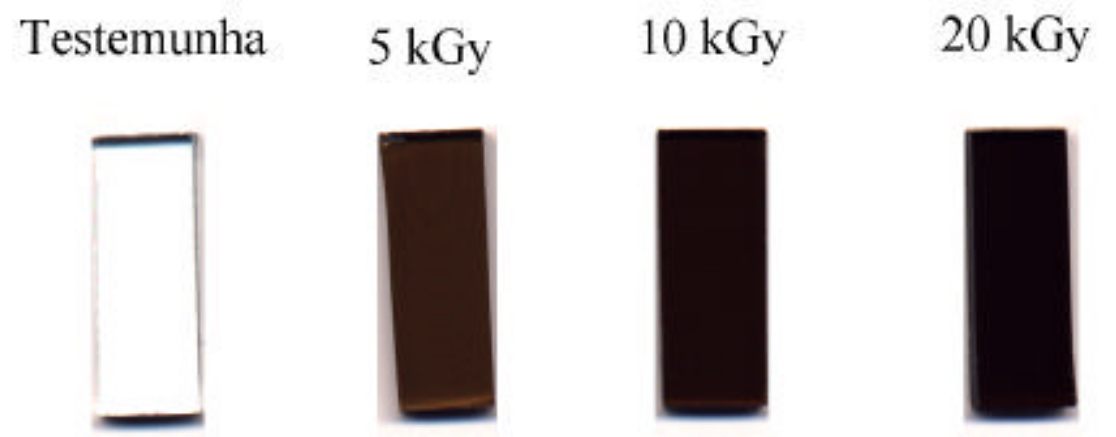

Figura 3.1 Amostras de vidro irradiadas com doses escalonadas

Mediu-se a espessura de $10 \%$ das amostras de vidro por meio de um paquímetro digital, com precisão de centésimo de milímetro, obtendo-se a média de $(3,258 \pm 0,006) \mathrm{mm}$, mostrando uma excelente uniformidade na espessura quando comparada à dos dosímetros "red perspex".

Foi realizada a análise por ativação com nêutrons de uma amostra de vidro, na Divisão de Radioquímica do IPEN. Com exceção de alguns elementos como o $\mathrm{Si}$, para o qual o Laboratório não dispunha de meios para identificar, os resultados são mostrados na Tabela 3.1. 
Tabela 3.1: Resultados da análise por ativação com nêutrons de uma amostra de vidro. Medidas realizadas pela Divisão de Radioquímica do IPEN

\begin{tabular}{cc}
\hline Elemento & Concentração \\
\hline $\mathrm{Ba}$ & $(19,4 \pm 0,5) \mu \mathrm{g} / \mathrm{g}$ \\
\hline $\mathrm{Ca}$ & $(62,9 \pm 2,4) \mathrm{mg} / \mathrm{g}$ \\
\hline $\mathrm{Cr}$ & $(2,08 \pm 0,03) \mu \mathrm{g} / \mathrm{g}$ \\
\hline $\mathrm{Cs}$ & $(3,99 \pm 0,01) \mu \mathrm{g} / \mathrm{g}$ \\
\hline $\mathrm{Fe}$ & $(673,0 \pm 9,2) \mu \mathrm{g} / \mathrm{g}$ \\
\hline $\mathrm{Hf}$ & $(1,59 \pm 0,01) \mu \mathrm{g} / \mathrm{g}$ \\
\hline $\mathrm{Na}$ & $(157,7 \pm 0,4) \mathrm{mg} / \mathrm{g}$ \\
\hline $\mathrm{Sb}$ & $(0,45 \pm 0,10) \mu \mathrm{g} / \mathrm{g}$ \\
\hline $\mathrm{Sc}$ & $(17,1 \pm 0,1) \mathrm{mg} / \mathrm{g}$ \\
\hline $\mathrm{Ta}$ & $(0,40 \pm 0,01) \mu \mathrm{g} / \mathrm{g}$ \\
\hline
\end{tabular}

Os dosímetros "red perspex" tipo 4034, utilizados para monitoração das irradiações, são fabricados na Inglaterra pela empresa Harwell, apresentam-se sob a forma de retângulos de polimetacrilato de metila, cujas dimensões são de aproximadamente $11 \mathrm{~mm}$ x $30 \mathrm{~mm}$ e espessura variando de 2,5 a 3,5 $\mathrm{mm}$. Para se evitar o contato destes com a umidade, à qual são extremamente sensíveis, eles são embalados e selados individualmente em pequenos envelopes de alumínio, sendo que o tempo de prateleira de cada "batch" é de 5 anos. Neste estudo o "batch" utilizado foi o "EL". A Figura 3.2 mostra um dosímetro "red perspex" embalado e outros irradiados com doses escalonadas. 

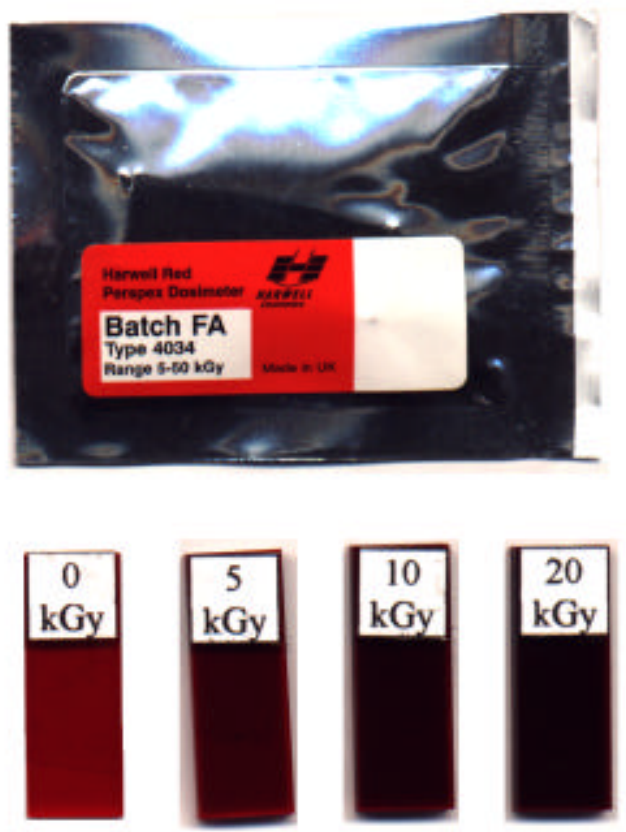

Figura 3.2 Dosímetro "red perspex" tipo 4034, em seu envelope de alumínio e irradiado com doses escalonadas.

Cada novo "batch" adquirido (geralmente um por ano) é acompanhado por um conjunto de calibração composto por cinco pacotes, contendo cada um quatro dosímetros "red perspex" do "batch" em questão, onde cada pacote foi irradiado com uma dose diferente $(5,15,25,35$ e $45 \mathrm{kGy})$ pelo "UK National Physical Laboratory"; no caso do "batch" EL enviado a EMBRARAD o certificado de irradiação é identificado pela data de 19/10/97.

Para cada dosímetro de um pacote mede-se a absorbância em 640 nm e a espessura, divide-se a primeira pela segunda, obtendo-se a absorção por 
unidade de comprimento. Calcula-se a média destes valores para cada pacote e consequentemente para cada dose, o que possibilita a construção de uma curva de calibração.

Para se estudar a resposta das amostras de vidro em função da dose absorvida, o procedimento adotado foi formar conjuntos contendo dois dosímetros "red perspex" (para servirem de referência) e três amostras de vidro, de modo que todos os componentes do conjunto estivessem paralelos entre si e próximos uns dos outros, para todos estarem à mesma distância da fonte, durante as irradiações.

Estes conjuntos foram então irradiados estaticamente e dinamicamente (percorrendo um trajeto em torno da fonte de radiação) com doses escalonadas em um irradiador de grande porte que utiliza radiação gama de ${ }^{60}$ Co. Após a irradiação, a absorção óptica das amostras de vidro foi medida em intervalos regulares de tempo utilizando um fotocolorímetro, descontando a absorção óptica antes da irradiação, e estes valores foram divididoss pela espessura da amostra de vidro correspondente, para o estudo do desvanecimento de sua resposta. Com estes dados foram feitas curvas da variação da absorção óptica $(\Delta \mathrm{AO})$ dividida pela espessura (1) das amostras de vidro por dose, fornecida pelos dosímetros "red pespex", para vários intervalos de tempo após a irradiação. Por meio do método dos mínimos quadrados foi possível descrevê-las por meio de equações polinomiais, ou seja, por equações do tipo: 


$$
f(x)=\sum_{i} a_{i} \cdot x^{i}
$$

onde: $\mathrm{f}(\mathrm{x})=$ dose em $\mathrm{kGy}$

$\mathrm{x}=$ variação da absorção óptica pela espessura da amostra de vidro em $\mathrm{mm}^{-1}$

$\mathrm{a}_{\mathrm{i}}=$ coeficientes da equação que serão obtidos pelo método dos mínimos quadrados

A finalidade de se descrever estas curvas por meio deste tipo de equação é obter tabelas de "x" por " $\mathrm{f}(\mathrm{x})$ " e assim dispensar o uso das curvas de calibração para a determinação da dose, tornando este processo mais fácil, rápido e menos sujeito a erros, o que é primordial em um processo industrial.

Após cada irradiação, as amostras de vidro e os dosímetros "red perspex" foram guardados em locais sem a incidência direta de luz solar, para não acelerar o desvanecimento das amostras de vidro e dos dosímetros "red perspex", embora a sensibilidade destes últimos à luz solar seja pequena quando comparados aos primeiros.

$\mathrm{Na}$ irradiação estática, os conjuntos foram alinhados paralelamente à fonte, mas nas irradiações dinâmicas (percorrendo um trajeto em torno da fonte) o alinhamento dos conjuntos em relação à fonte variou entre modo paralelo e modo perpendicular. 


\subsection{Fonte de radiação}

As irradiações foram realizadas no irradiador de grande porte (modelo JS 7500, marca Nordion) da Embrarad ${ }^{[46]}$, Cotia, S. Paulo (registrada na Comissão Nacional de Energia Nuclear sob o número 103.345/75) na posição estática do canal experimental ("research loop"), que se situa a 1,5m perpendicularmente à fonte, e na linha de produção (dinâmica), cujo trajeto se dá em torno da fonte variando a distância de irradiação de alguns centímetros a 1 metro.

O irradiador JS 7500 é composto basicamente por três partes: a blindagem biológica, o sistema de transporte dos materiais para e da câmara de irradiação e a fonte de ${ }^{60} \mathrm{Co}$, cuja atividade é certificada após cada recarga pelo fornecedor do ${ }^{60} \mathrm{Co}$; neste trabalho a atividade é rastrável aos certificados: IR 106 1998/06/01 e 97/08/01. Na Figura 3.3 é mostrado um esquema do irradiador.

A blindagem biológica é feita pelo prédio com paredes espessas de concreto, que atenuam a radiação proveniente das fontes para níveis de radiação de fundo.

O sistema de transporte dos materiais para a e da câmara de irradiação é composto basicamente por esteiras rolantes de entrada e saída, que fazem um trajeto em forma de "S", chamado de labirinto, cuja finalidade é absorver a radiação espalhada, de forma a atenuá-la a valores da radiação de fundo. 


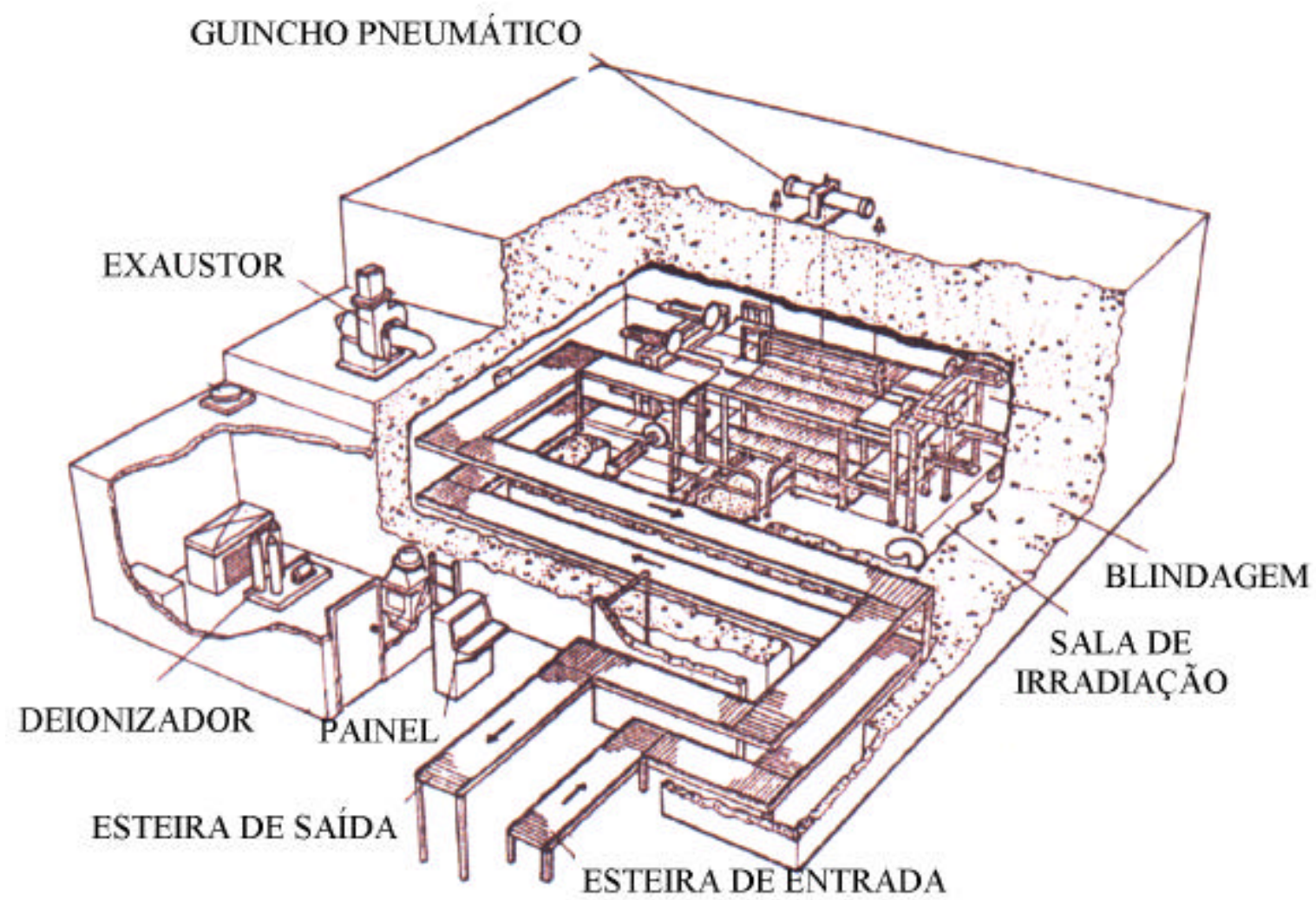

Figura 3.3: Irradiador de grande porte tipo JS 7500 da EMBRARAD, fabricado pela Nordion (Canadá); figura extraída do manual de instruções.

O material a ser irradiado é acondicionado dentro de caixas de alumínio com $90 \mathrm{~cm}$ de altura, $60 \mathrm{~cm}$ de comprimento e $50 \mathrm{~cm}$ de profundidade (Figura 3.4) e estes são continuamente colocados na esteira de entrada para serem levados à câmara de irradiação (Figura 3.5), onde percorrem um trajeto em torno da fonte de ${ }^{60} \mathrm{Co}$ de aproximadamente $29 \mathrm{~m}$, e voltam pela esteira de saída. 


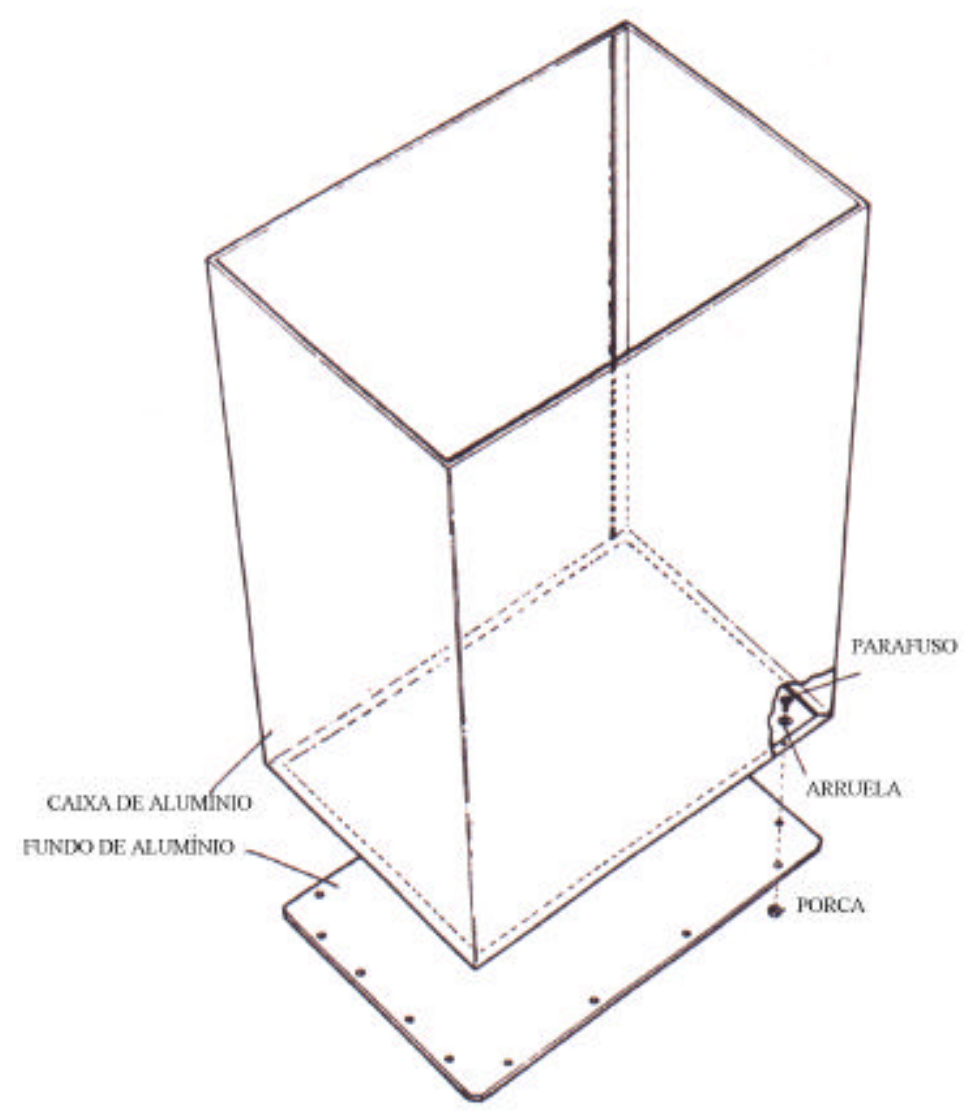

Figura 3.4: Caixa de alumínio com $90 \mathrm{~cm}$ de altura, $60 \mathrm{~cm}$ de comprimento e $50 \mathrm{~cm}$ de profundidade, do irradiador de grande porte tipo JS 7500, da EMBRARAD, para acondicionamento do material a ser irradiado; figura extraída do manual de instruções. 


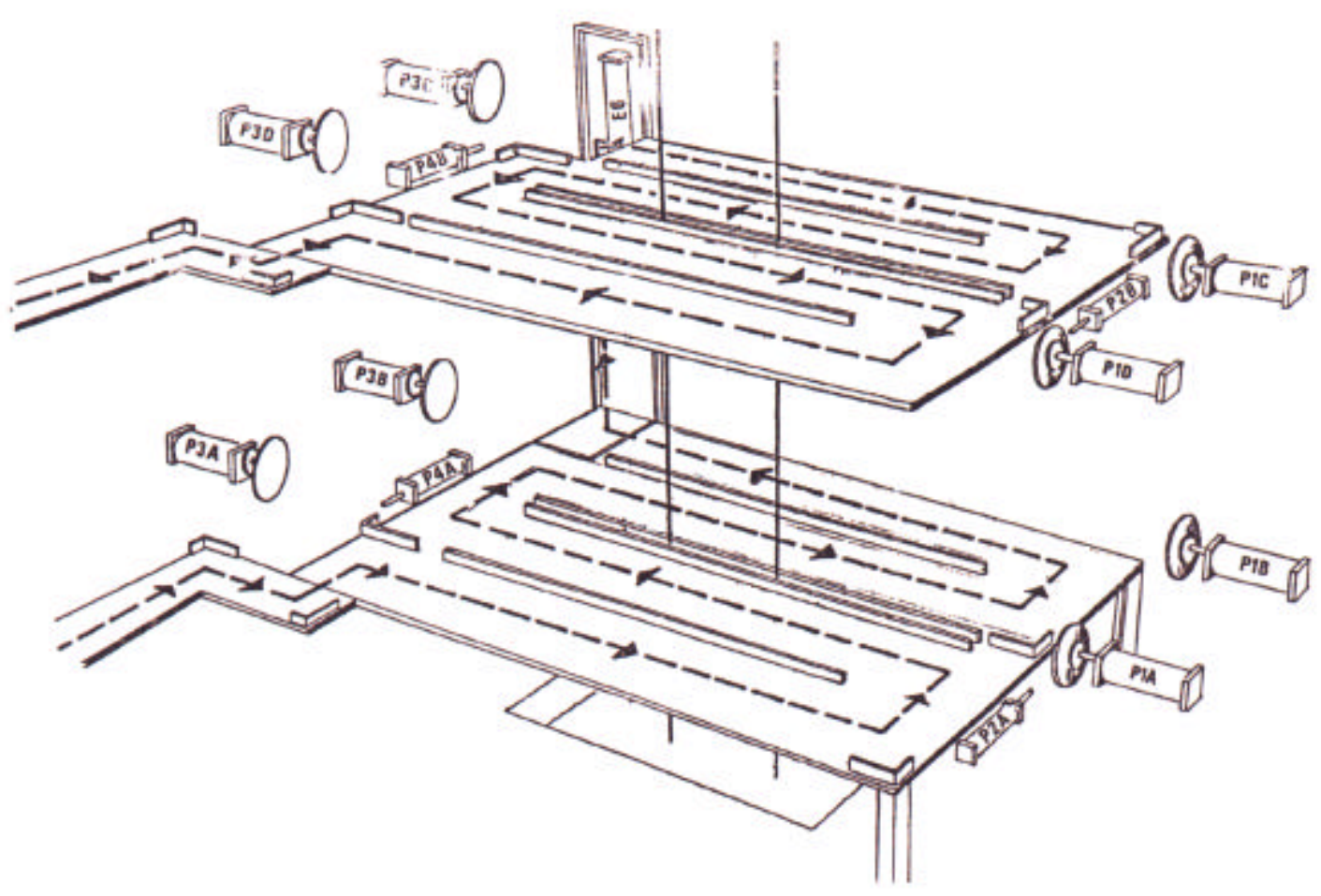

Figura 3.5: Câmara de irradiação do irradiador de grande porte tipo JS 7500, da EMBRARAD; figura extraída do manual de instruções.

Este trajeto em torno da fonte é composto de 48 posições, sendo 24 no plano inferior de irradiação (chamado bandeja inferior) e 24 no plano superior de irradiação (chamado bandeja superior), e a dose recebida pelo material é diretamente proporcional ao tempo em que a caixa de alumínio permanecer em cada uma destas posições. Este tempo é ajustado por meio do painel de controle e é chamado de ciclo ou passo da máquina.

Em todo o trajeto percorrido pela caixa de alumínio dentro do irradiador, este não sofre qualquer movimento de rotação, ocorre somente translação. 
A unidade que forma a fonte radioativa é composta por pastilhas de ${ }^{60} \mathrm{Co}$ encapsuladas duplamente em tubos de aço inoxidável com $45,2 \mathrm{~cm}$ de comprimento e $1,11 \mathrm{~cm}$ de diâmetro. Cada tubo é identificado individualmente por um número gravado em uma de suas extremidades.

Quarenta e dois tubos colocados lado a lado formam um módulo e no caso do JS 7500 oito módulos, acomodados em uma moldura de duas fileiras e quatro colunas, formam a fonte (Figura 3.6). Uma característica desta fonte é que sua altura é aproximadamente igual à altura da caixa de alumínio.

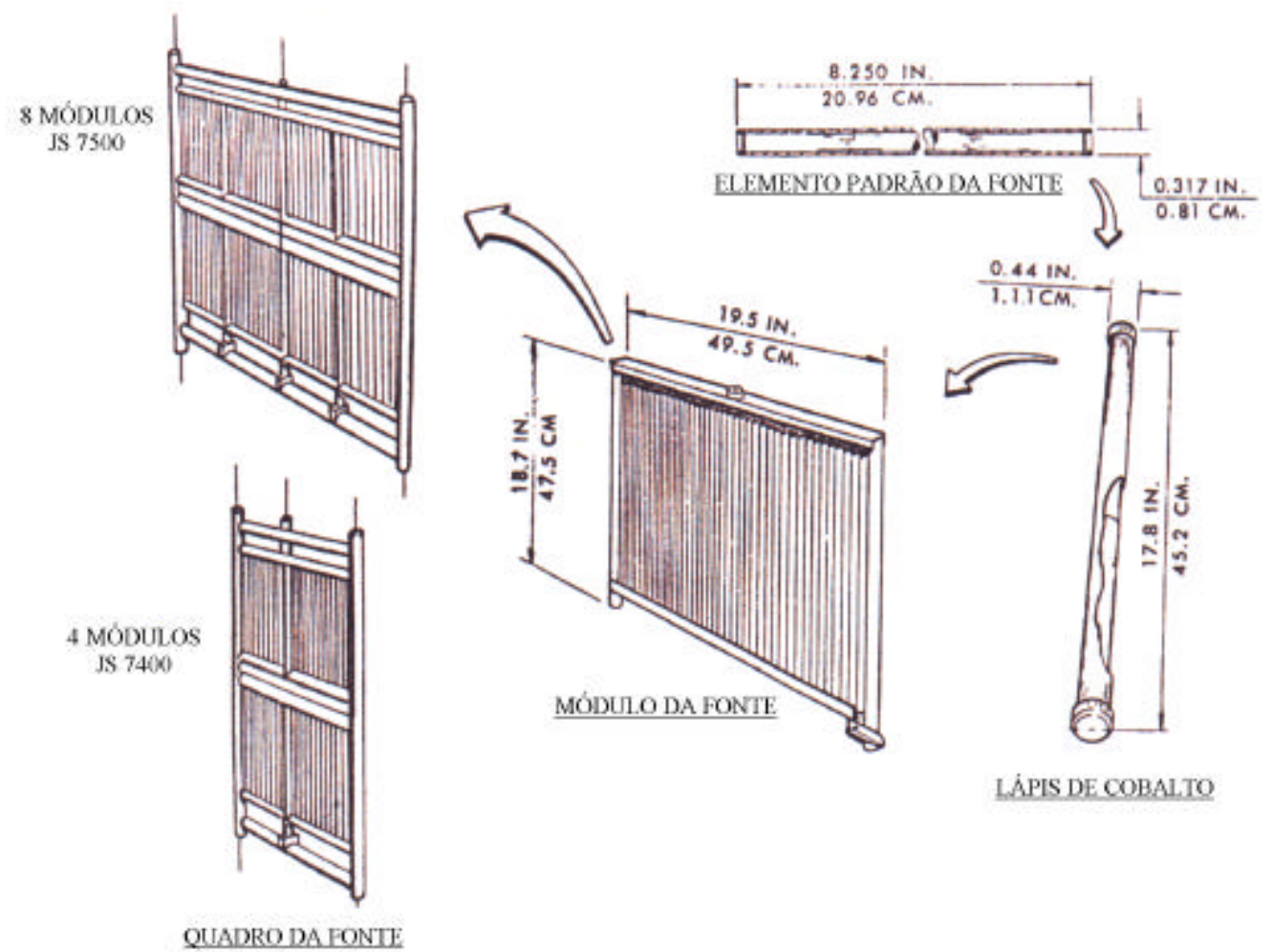

Figura 3.6: Estrutura da fonte plana de ${ }^{60} \mathrm{Co}$ do irradiador de grande porte tipo JS 7500, da EMBRARAD; figura extraída do manual de instruções. 
A fonte possui duas posições: a de repouso e a de exposição. $\mathrm{Na}$ posição de repouso, a fonte está no fundo de um tanque de seis metros de profundidade cheio de água, cuja função é a de blindar a radiação proveniente da fonte, no caso de haver a necessidade de se entrar na câmara de irradiação, por exemplo para efetuar algum reparo no sistema de transporte das caixas de alumínio em torno da fonte. Na posição de exposição, a fonte é içada pelo meio dos planos de irradiação até a posição em que a metade dos módulos da fonte está acima do plano superior de irradiação e a outra metade abaixo, com o propósito de irradiar majoritariamente a parte superior das caixas de alumínio, quando estes percorrem o plano inferior e majoritariamente a parte inferior quando estes percorrem o plano superior. Os lados da caixa de alumínio que ficam paralelos à fonte durante todo o percurso são os lados de $90 \mathrm{~cm} \times 60 \mathrm{~cm}$.

Por estas características de irradiação, a distribuição da dose dentro das caixas de alumínio será inomogênea, como mostra a Figura 3.7, onde as curvas de isodose são vistas pelo lado da caixa de alumínio de $90 \mathrm{~cm}$ x $50 \mathrm{~cm}$, que fica perpendicular à fonte durante todo o percurso. Nas irradiações dinâmicas foram colocados até 3 conjuntos em posições diferentes de uma mesma caixa de alumínio. Isto explica porque a Tabela 4.3 , no item 4.4 referente aos parâmetros observados destas irradiações, apresenta os mesmos dados para doses diferentes. 


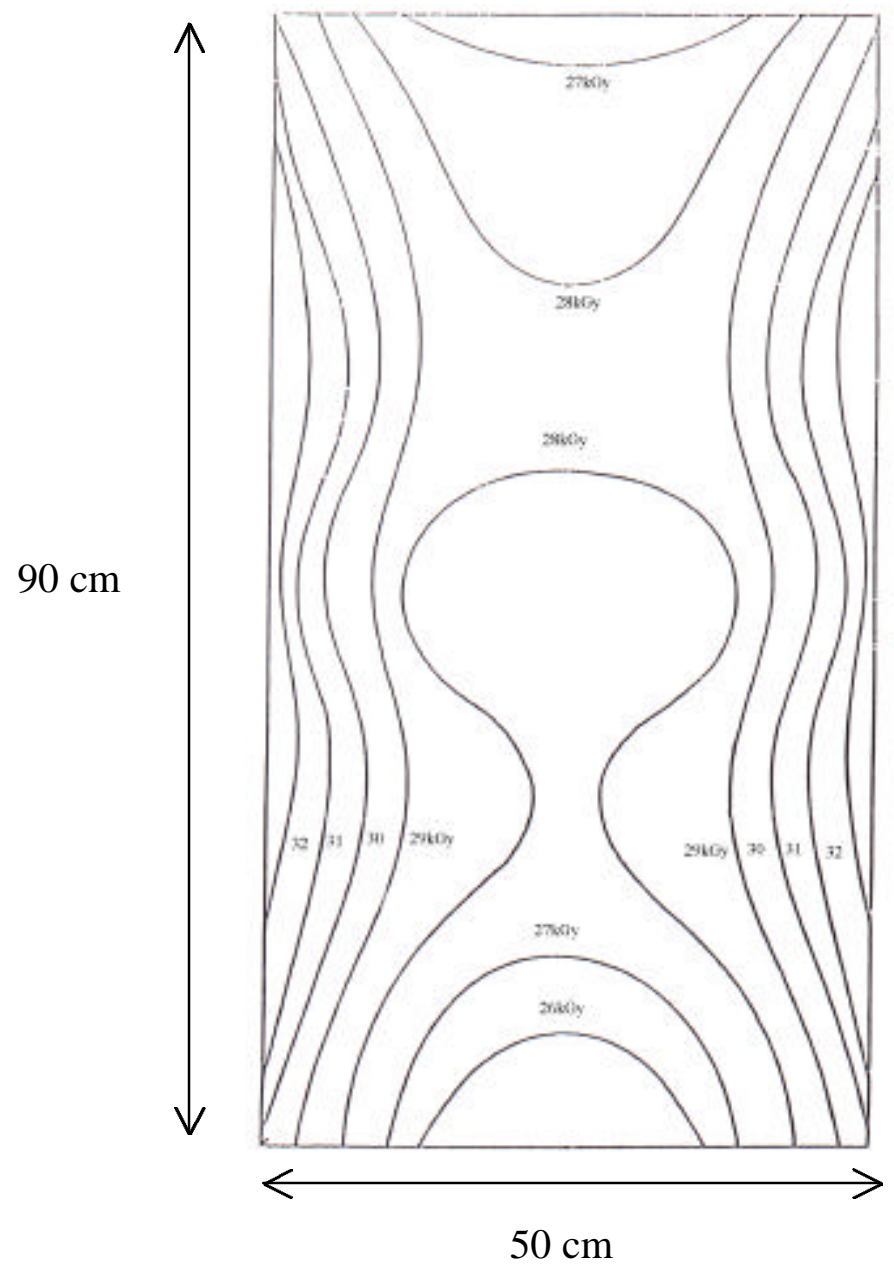

Figura 3.7: Curvas de isodose características na caixa de alumínio, vistas pelo lado de $90 \mathrm{~cm}$ x $50 \mathrm{~cm}$, usada no processamento de mercadorias no irradiador de grande porte tipo JS 7500, da EMBRARAD; figura extraída do manual de instruções.

O canal experimental ("research loop") é um equipamento que permite a irradiação de amostras sem interferir com o funcionamento normal da máquina. O sistema é composto por uma caixa de alumínio com paredes de aproximadamente $2 \mathrm{~mm}$ de espessura e com capacidade para 20 litros, cuja função, além da sustentação mecânica dos conjuntos a serem irradiados, é proporcionar o equilíbrio eletrônico. A caixa de alumínio é suspensa por 
trilhos que permitem o seu movimento através do labirinto até a sua posição de irradiação estática (Figura 3.8).

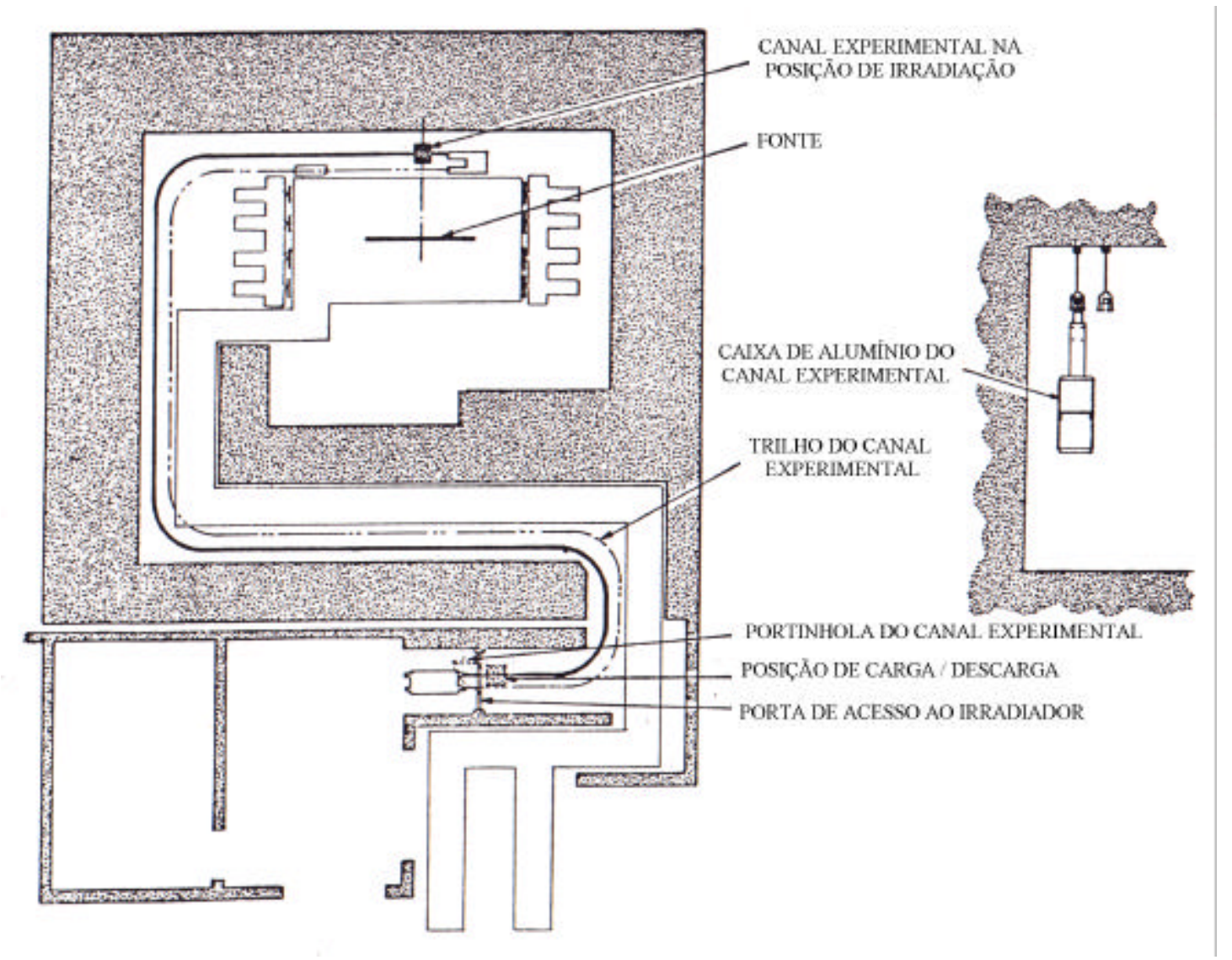

Figura 3.8: Trajeto do canal experimental até a câmara de irradiação do irradiador de grande porte tipo JS 7500, da EMBRARAD; figura extraída do manual de instruções.

A radiação proveniente da fonte de ${ }^{60} \mathrm{Co}$ atravessa primeiro o material que estiver passando pelo plano inferior de irradiação antes de atingir a caixa de alumínio do canal experimental. A Figura 3.9 mostra esquematicamente a irradiação no canal experimental e a Figura 3.10 mostra o canal experimental em sua posição de irradiação. 


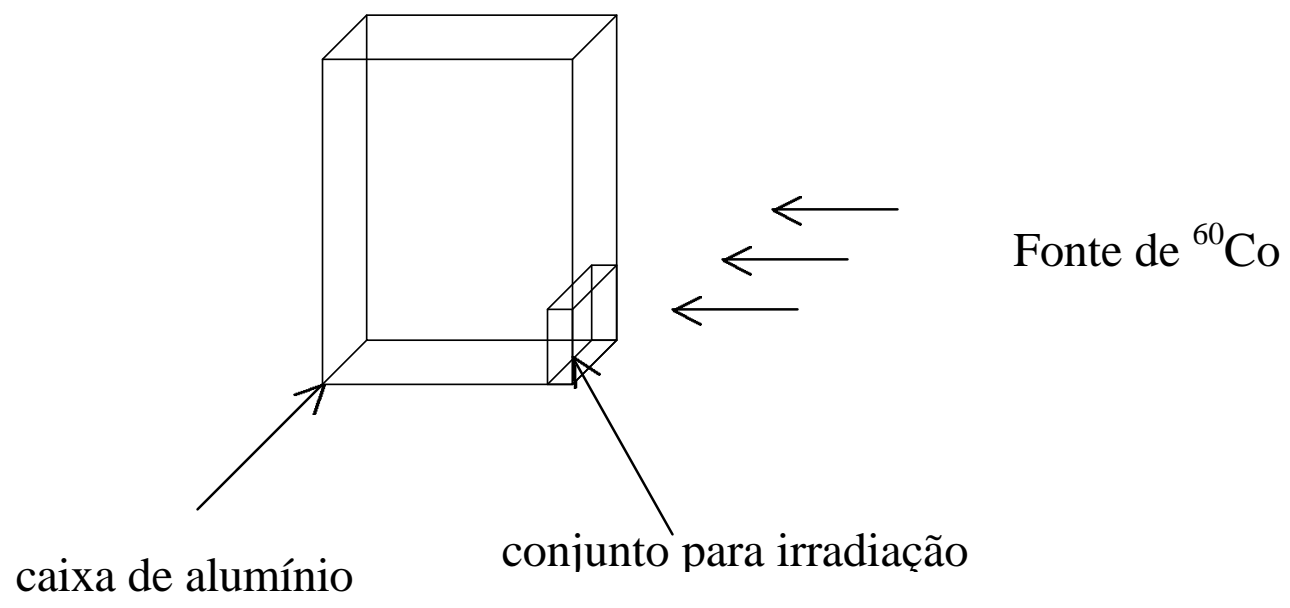

Figura 3.9: Esquema do arranjo experimental da posição de irradiação estática do irradiador de grande porte JS 7500, da EMBRARAD.

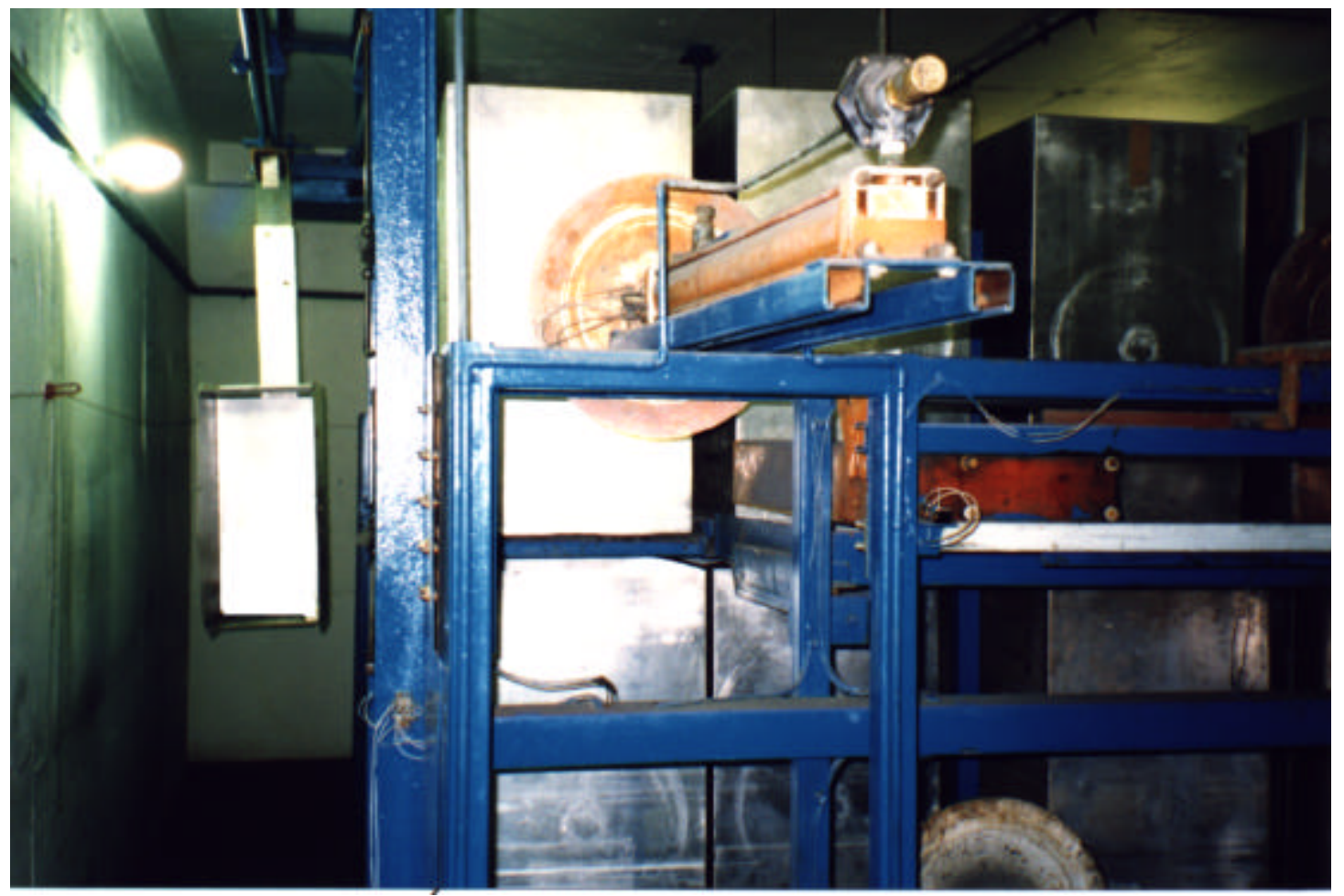

Figura 3.10: Canal experimental em sua posição de irradiação na câmara de irradiação do irradiador de grande porte tipo JS 7500, da EMBRARAD. 


\subsection{Sistema de medida}

Foi utilizado um fotocolorímetro marca Tecnow, modelo 7000, Brasil, no modo de absorbância e ajustado para $640 \mathrm{~nm}$ para a avaliação tanto dos dosímetros "red perspex" como das amostras de vidro, antes e após as irradiações. 


\section{4) RESULTADOS}

Neste capítulo serão apresentados os resultados dos experimentos realizados com as amostras de vidro, utilizando um fotocolorímetro para verificar a resposta destas à radiação e a sua viabilidade como dosímetro e indicador SIM / NÃO para doses altas.

\subsection{Caracterização das amostras de vidro com relação à espessura e à absorção.}

Para verificar qual seria a variação da espessura e da absorção óptica antes da irradiação das amostras de vidro, foram escolhidas aleatoriamente 50 amostras de vidro.

No caso das medidas da espessura das cinquenta amostras de vidro foi obtida uma espessura média de $3,258 \mathrm{~mm}$ e um desvio padrão de $\pm 0,006 \mathrm{~mm}$, o que representa um desvio padrão percentual de $\pm 0,2 \%$.

No caso das leituras em absorção óptica em $640 \mathrm{~nm}$ das cinquenta amostras não irradiadas foi obtida uma absorção média de 39 e um desvio padrão de \pm 1 , o que representa um desvio padrão percentual de $\pm 2,6 \%$.

Estes dados mostram a uniformidade das amostras de vidro com relação à absorção antes da irradiação e à espessura, que se repetiram nas medidas antes da irradiação realizadas nas aproximadamente 130 amostras de vidro utilizadas neste trabalho. 


\subsection{Irradiação estática das amostras}

As irradiações estáticas foram realizadas utilizando-se o canal experimental, descrito no item 3.3.

Os resultados apresentados referem-se à irradiação de 15 conjuntos de amostras e os dados referentes a cada irradiação são mostrados na Tabela 4.1.

Tabela 4.1: Dados referentes às 15 irradiações estáticas das amostras de vidro, com ${ }^{60} \mathrm{Co}$ com atividade de $54,7 \mathrm{PBq}(1,48 \mathrm{MCi}) \mathrm{em}$ março de 1999.

\begin{tabular}{cccccccccccccccc}
\hline $\begin{array}{c}\text { Dose } \\
\text { (kGy) }\end{array}$ & $\mathbf{5 , 4}$ & 6,0 & $\mathbf{6 , 5}$ & 8,2 & $\mathbf{8 , 3}$ & 11,8 & $\mathbf{1 1 , 9}$ & 15,6 & $\mathbf{1 5 , 7}$ & 16,2 & $\mathbf{2 3 , 3}$ & 23,4 & $\mathbf{2 3 , 8}$ & 26,3 & $\mathbf{2 7 , 7}$ \\
\hline $\mathrm{A}$ & $\mathbf{0 , 9 8}$ & 1,55 & $\mathbf{1 , 7 2}$ & 1,53 & $\mathbf{1 , 5 8}$ & 3,27 & $\mathbf{3 , 1 7}$ & 4,45 & $\mathbf{4 , 3 5}$ & 5,02 & $\mathbf{5 , 0 7}$ & 6,32 & $\mathbf{6 , 4 8}$ & 8,03 & $\mathbf{6 , 6}$ \\
\hline $\mathrm{B}$ & $\mathbf{0}$ & 0 & $\mathbf{8}$ & 0 & $\mathbf{0}$ & 0 & $\mathbf{1 9}$ & 17 & $\mathbf{3 3}$ & 4 & $\mathbf{0}$ & 3 & $\mathbf{5 7}$ & 14 & $\mathbf{5 3}$ \\
\hline $\mathrm{C}$ & $\mathbf{5 , 5}$ & 3,9 & $\mathbf{4 , 1}$ & 5,4 & $\mathbf{5 , 2}$ & 3,6 & $\mathbf{4 , 2}$ & 3,7 & $\mathbf{4 , 1}$ & 3,3 & $\mathbf{4 , 6}$ & 3,7 & $\mathbf{4 , 3}$ & 3,4 & $\mathbf{4 , 8}$ \\
\hline
\end{tabular}

$\mathrm{A}=$ Tempo total de irradiação (h).

$\mathrm{B}=$ Tempo total de interrupção da irradiação (min).

$\mathrm{C}=$ Taxa de dose média $(\mathrm{kGy} / \mathrm{h})$.

As condições em que as irradiações estáticas foram realizadas nunca foram exatamente as mesmas para todas as irradiações, como pode ser visto na Tabela 4.1, devido às características de projeto de um irradiador de grande porte descritas no item 3.3. Por exemplo, tem-se a taxa de dose, que varia de uma irradiação para a outra e também durante uma irradiação, devido à variação da densidade do material dentro das caixas de alumínio, que passam entre a posição de irradiação estática e a fonte. Nestas irradiações, a maior densidade chegou a $0,26 \mathrm{~g} / \mathrm{cm}^{3}$ e a menor a $0,11 \mathrm{~g} / \mathrm{cm}^{3}$. 
As leituras em absorção referentes a um conjunto de amostras de vidro irradiado diminuem exponencialmente com o tempo, como pode ser visto na Figura 4.1. Na mesma figura foram representados os dados obtidos com os dosímetros "red perspex" para comparação. Estes apresentaram um comportamento constante em função do tempo após a irradiação até um total de 2 dias, tendo por esta razão sido utilizados como sistema de referência neste trabalho.

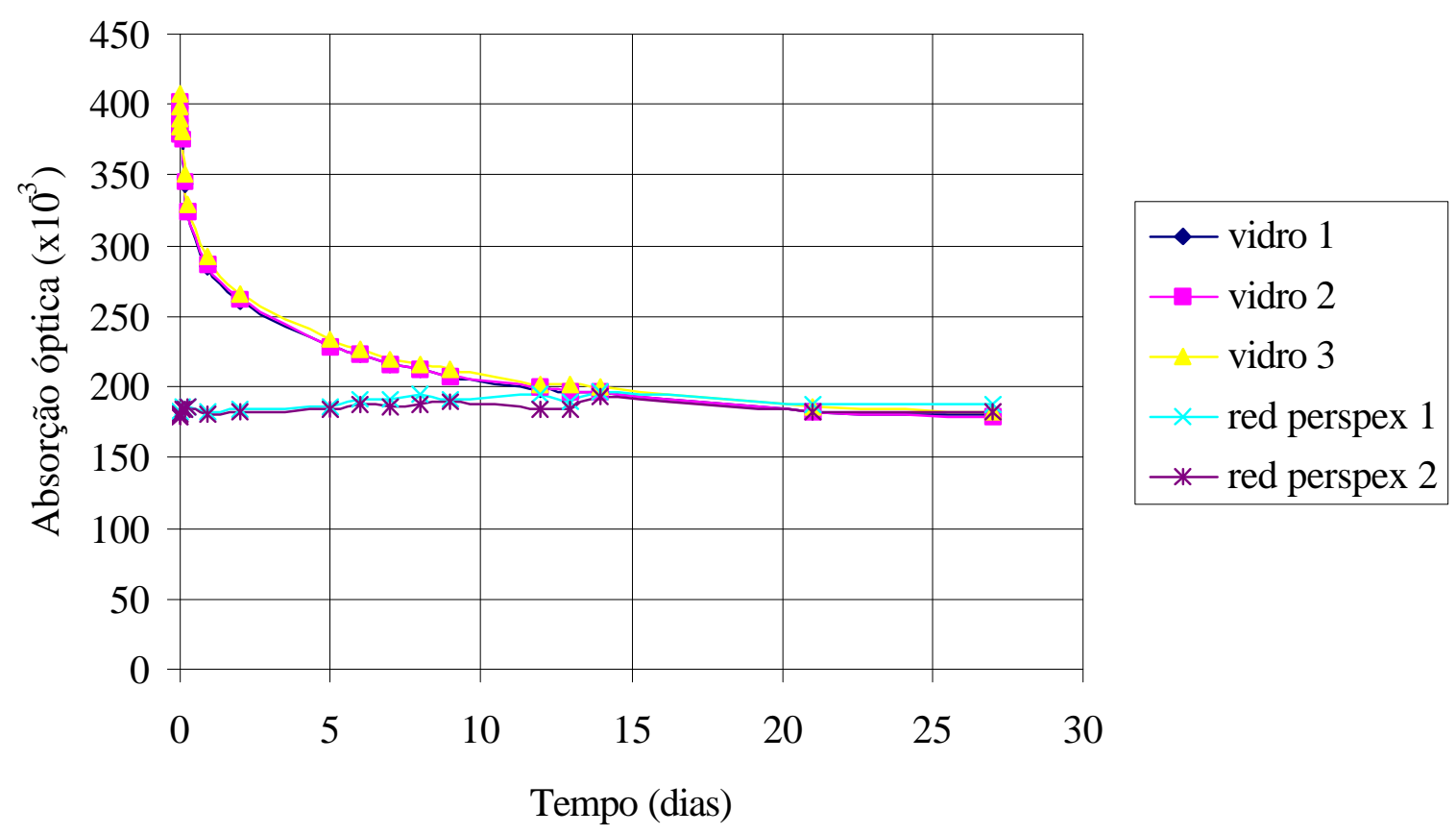

Figura 4.1: Variação das leituras em absorção dos dosímetros "red perspex" e das amostras de vidro em relação ao tempo após a irradiação $(6,5$ kGy).

Devido às amostras de vidro apresentarem este rápido desvanecimento após a irradiação, não se pode desprezar o tempo decorrido entre o término da irradiação e a leitura da absorção óptica. 


\subsection{Curvas de calibração: irradiação estática}

Foram obtidas curvas de calibração para $1 \mathrm{~h}, 2 \mathrm{~h}, 7 \mathrm{~h}, 1$ dia, 2 dias e 3 dias após a irradiação estática e são apresentadas respectivamente nas Figuras 4.2 a 4.7 e na Figura 4.8 que mostra todas as curvas em um único gráfico. O desvio padrão das medidas foi sempre menor que $1 \%$.

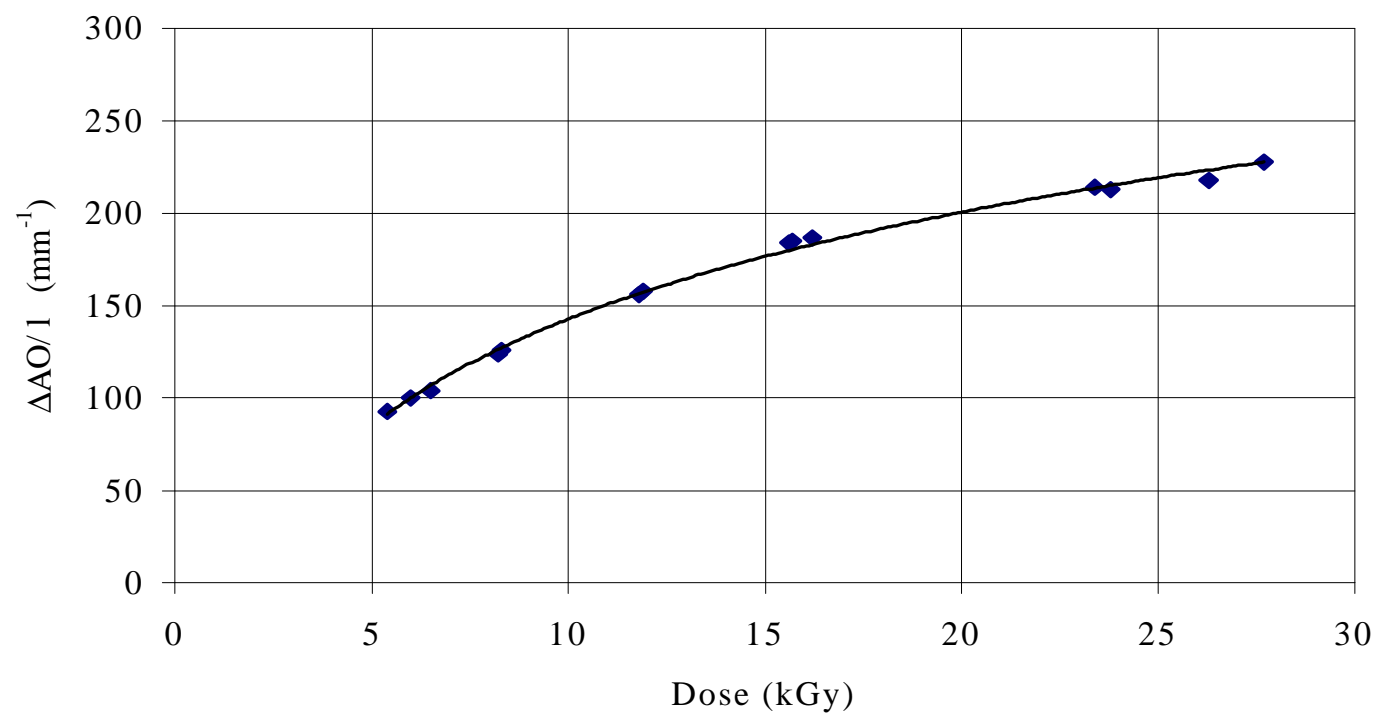

Figura 4.2: Curva de calibração das amostras de vidro em função da dose, medidas 1 hora após a irradiação estática. 


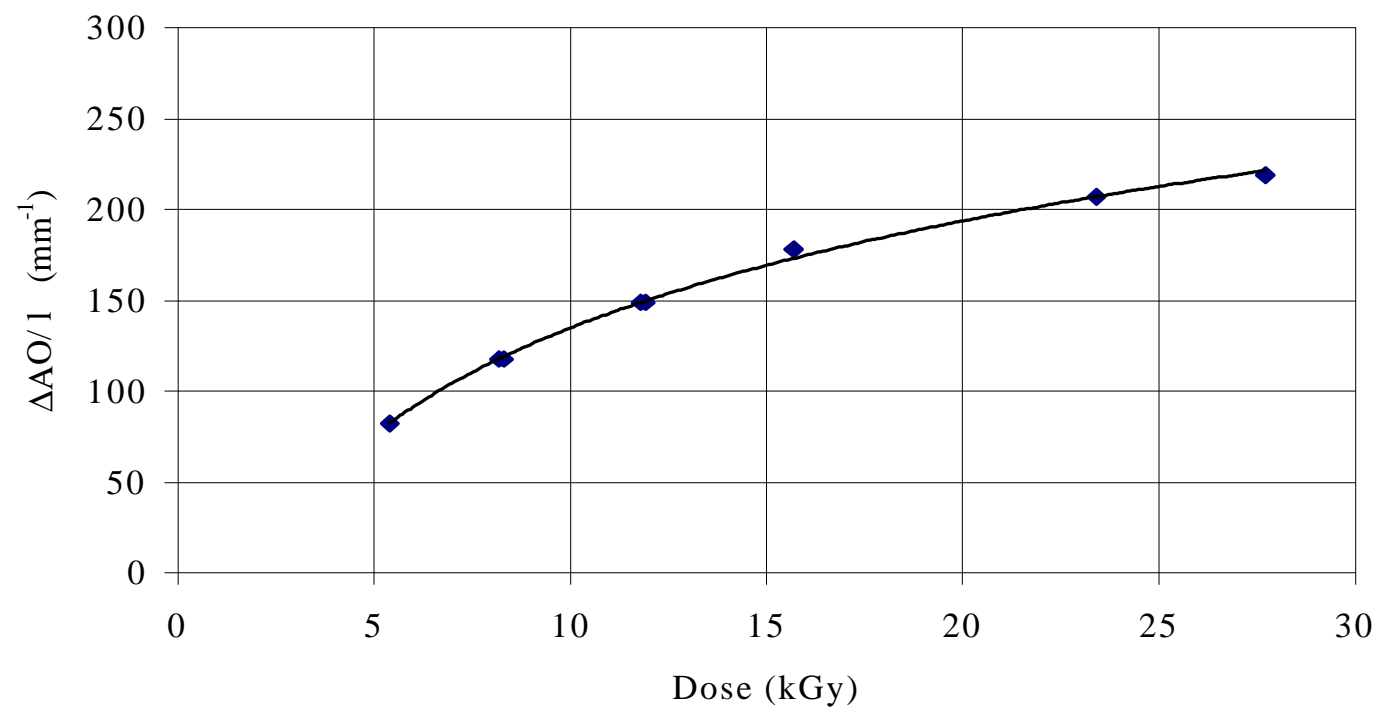

Figura 4.3: Curva de calibração das amostras de vidro em função da dose, medidas 2 horas após a irradiação estática.

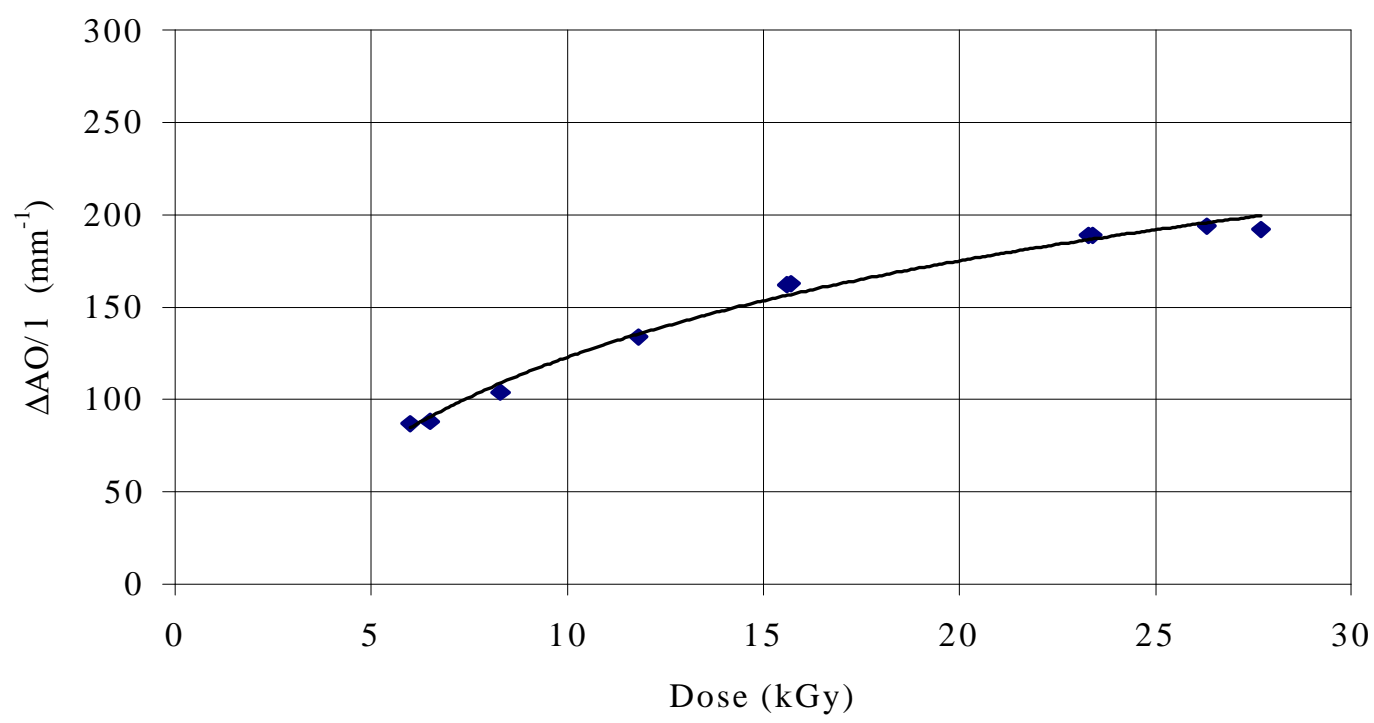

Figura 4.4: Curva de calibração das amostras de vidro em função da dose, medidas 7 horas após a irradiação estática. 


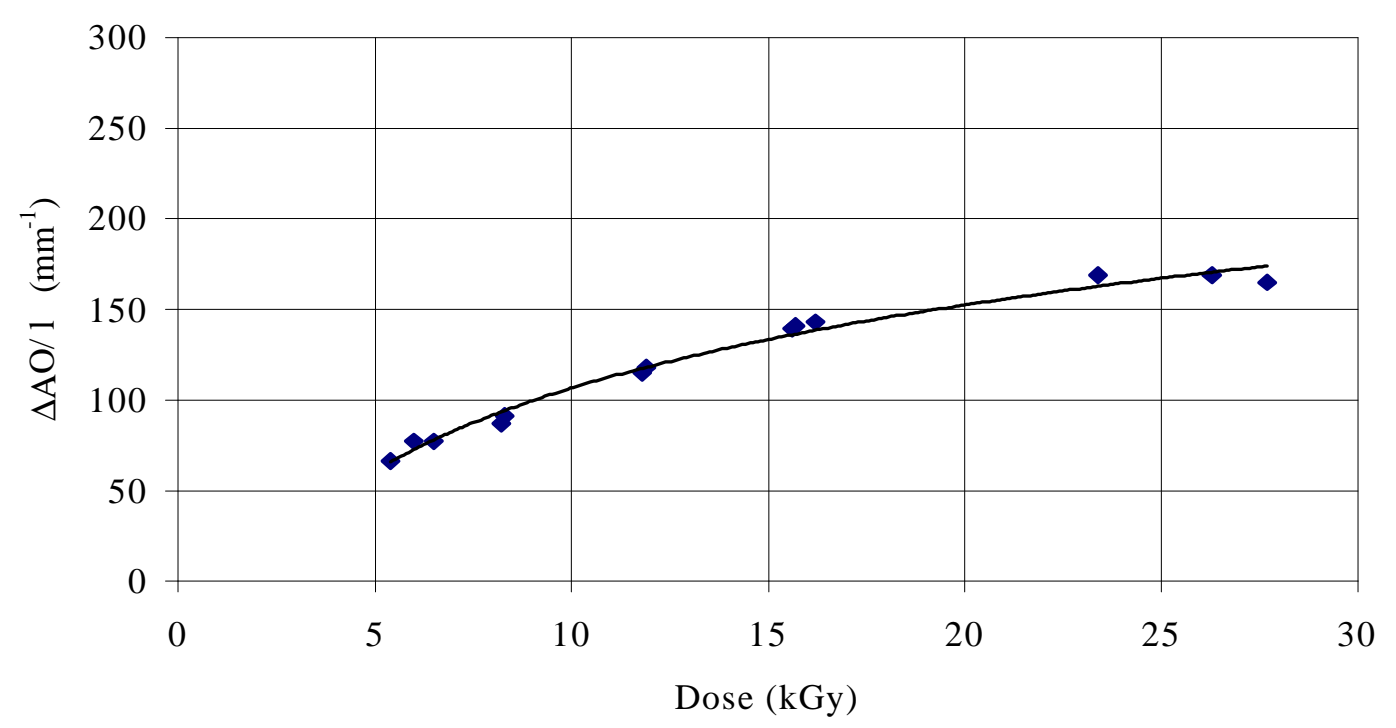

Figura 4.5: Curva de calibração das amostras de vidro em função da dose, medidas 1 dia após a irradiação estática.

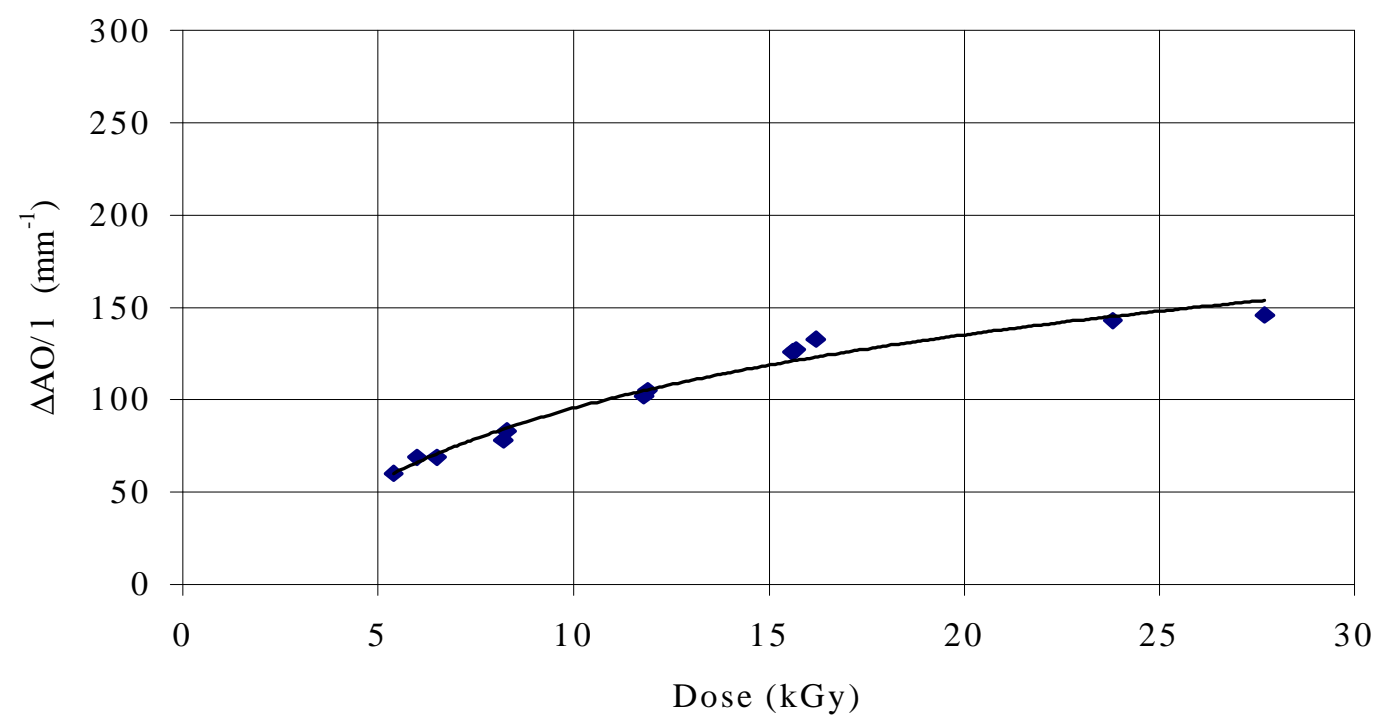

Figura 4.6: Curva de calibração das amostras de vidro em função da dose, medidas 2 dias após a irradiação estática. 


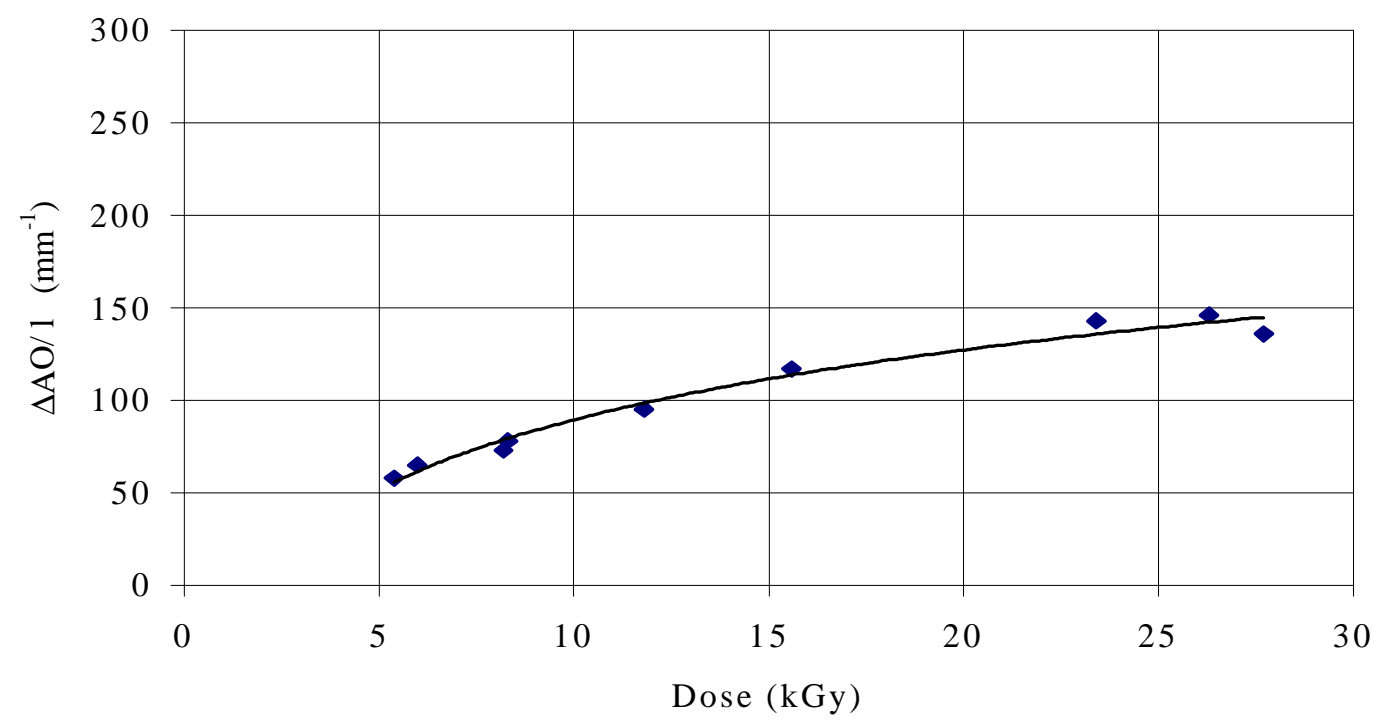

Figura 4.7: Curva de calibração das amostras de vidro em função da dose, medidas 3 dias após a irradiação estática.

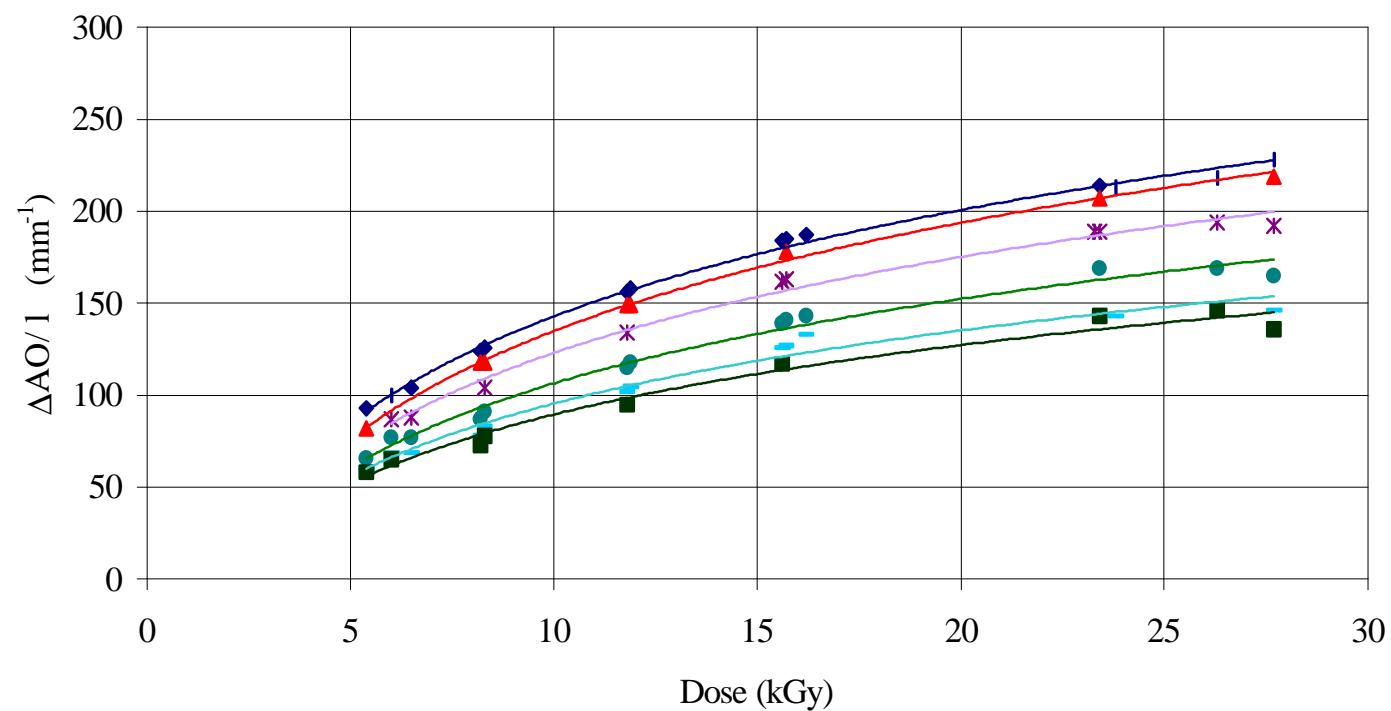

- 1h após a irradiação estática $\quad \Delta$ 2h após a irradiação estática $* 7$ h após a irradiação estática

- 1 dia após a irradiação estática - 2 dias após a irradiação estática - 3 dias após a irradiação estática

Figura 4.8: Curvas de calibração das amostras de vidro em função da dose, medidas 1, 2 e 7 horas e 1, 2 e 3 dias após as irradiações estáticas. 
As Figuras 4.2 a 4.7 mostram que na irradiação estática a variação da absorção óptica pela espessura $(\Delta \mathrm{AO} / \mathrm{l})$ das amostras de vidro apresenta um comportamento crescente com a dose, que variou de 5,4 kGy a 27,7 kGy, mesmo com as interrupções durante as irradiações e com a variação da taxa de dose mostradas respectivamente nas linhas B e C da Tabela 4.1.

$\mathrm{Na}$ Tabela 4.2 são mostradas as equações polinomiais obtidas para cada curva de calibração por meio do método dos mínimos quadrados, os parâmetros e a avaliação de cada ajuste. Pode-se ver que quanto maior o tempo após a irradiação, maior o erro estimado para se obter um bom ajuste, o que significa que a precisão na determinação das doses das amostras de vidro diminui com o tempo após a irradiação estática. Mesmo assim, pode-se considerar um erro de $8 \%$ aceitável para um dosímetro de rotina. 
Tabela 4.2 Equações obtidas pelo método dos mínimos quadrados e os respectivos parâmetros de ajuste e da verificação do ajuste para cada uma das curvas das irradiações estáticas.

\begin{tabular}{|c|c|c|c|c|c|}
\hline \multirow[b]{2}{*}{$\begin{array}{l}\text { Número } \\
\text { da Figura }\end{array}$} & \multirow[b]{2}{*}{$\begin{array}{c}\text { Equação } \\
f(x)\end{array}$} & \multicolumn{2}{|c|}{$\begin{array}{c}\text { Parâmetros } \\
\text { de Ajuste }\end{array}$} & \multicolumn{2}{|c|}{$\begin{array}{l}\text { Verificação } \\
\text { do Ajuste }\end{array}$} \\
\hline & & $\begin{array}{l}\mathrm{N}^{\mathrm{o}} \mathrm{de} \\
\text { pontos }\end{array}$ & $\begin{array}{c}\text { Erro } \\
\text { estimado }\end{array}$ & $\chi^{2}$ & $\chi_{\text {reduzido }}^{2}$ \\
\hline $4.2(1 \mathrm{~h})^{*}$ & $8,29-0,1 \cdot x+8,00 \cdot 10^{-4} \cdot x^{2}$ & 15 & $5 \%$ & 12,94 & 1,1 \\
\hline $4.3(2 \mathrm{~h})^{*}$ & $6,85-0,08 \cdot x+7,56 \cdot 10^{-4} \cdot x^{2}$ & 9 & $4 \%$ & 7,48 & 1,3 \\
\hline $4.4(7 \mathrm{~h})^{*}$ & $10,48-0,15 \cdot x+1,15 \cdot 10^{-3} \cdot x^{2}$ & 10 & $7 \%$ & 7,82 & 1,1 \\
\hline $4.5(24 \mathrm{~h})^{*}$ & $6,66-0,10 \cdot x+1,22 \cdot 10^{-3} \cdot x^{2}$ & 15 & $8 \%$ & 12,80 & 1,1 \\
\hline $4.6(48 \mathrm{~h})^{*}$ & $5,39-0,08 \cdot x+1,34 \cdot 10^{-3} \cdot x^{2}$ & 15 & $8 \%$ & 15,80 & 1,3 \\
\hline $4.7(72 \mathrm{~h})^{*}$ & $1,93-0,02 \cdot x+1,26 \cdot 10^{-3} \cdot x^{2}$ & 10 & $8 \%$ & 9,94 & 1,4 \\
\hline
\end{tabular}

* tempo após a irradiação estática.

$\mathrm{f}(\mathrm{x})=$ dose em $\mathrm{kGy}$

$\mathrm{x}=$ variação da absorção óptica pela espessura da amostra de vidro em $\mathrm{mm}^{-1}$

$\chi^{2}=$ Verifica se a distribuição dos pontos experimentais em relação à curva é verossímil; seu valor deve ser próximo ao número de graus de liberdade ${ }^{[47,48]}$.

$\chi_{\text {reduzido }}^{2}=$ verifica se a função ajustada é verossímil; seu valor deve ser próximo ao número " 1 " [47,48].

\subsection{Irradiação dinâmica das amostras}

$\mathrm{Na}$ irradiação dinâmica, os conjuntos são acondicionados dentro das caixas de alumínio, junto com os materiais (dos clientes) a serem irradiados. A caixa de alumínio é então colocada na esteira rolante que a leva à câmara de irradiação, para percorrer um trajeto em torno da fonte de ${ }^{60} \mathrm{Co}$, como descrito no item 3.3 . 
Os resultados apresentados baseiam-se na irradiação dinâmica de 25 conjuntos de amostras e os dados referentes a cada irradiação são apresentados na Tabela 4.3.

Tabela 4.3: Dados referentes às 25 irradiações dinâmicas das amostras de vidro com ${ }^{60} \mathrm{Co}$ com atividade de 54,7PBq $(1,48 \mathrm{MCi})$, março de 1999.

\begin{tabular}{ccccccccccccccc}
\hline $\begin{array}{c}\text { Dose } \\
\text { kGy) }\end{array}$ & $\mathbf{5 , 5}$ & 6,6 & $\mathbf{6 , 9}$ & 8,0 & $\mathbf{8 , 5}$ & 8,6 & $\mathbf{1 0 , 9}$ & 11,8 & $\mathbf{1 2 , 1}$ & 13,1 & $\mathbf{1 5 , 1}$ & 20,0 & $\mathbf{2 0 , 0}$ & 21,0 \\
\hline A & $\mathbf{2 , 1 7}$ & 2,25 & $\mathbf{2 , 2 5}$ & 2,17 & $\mathbf{2 , 2 5}$ & 2,17 & $\mathbf{2 , 2 5}$ & 2,17 & $\mathbf{2 , 2 5}$ & 2,17 & $\mathbf{2 , 2 5}$ & 4,58 & $\mathbf{4 , 7 5}$ & 5,08 \\
\hline B & $\mathbf{5}$ & 4 & $\mathbf{4}$ & 23 & $\mathbf{4}$ & 5 & $\mathbf{1 1}$ & 23 & $\mathbf{1 1}$ & 23 & $\mathbf{1 1}$ & 17 & $\mathbf{7}$ & 29 \\
\hline C' & $\mathbf{0 , 3}$ & 0,3 & $\mathbf{0 , 3}$ & 0,27 & $\mathbf{0 , 3}$ & 0,3 & $\mathbf{0 , 3}$ & 0,27 & $\mathbf{0 , 3}$ & 0,27 & $\mathbf{0 , 3}$ & 0,17 & $\mathbf{0 , 2 5}$ & 0,24 \\
\hline
\end{tabular}

\begin{tabular}{cccccccccccc}
\hline $\begin{array}{c}\text { Dose } \\
\text { (kGy) }\end{array}$ & $\mathbf{2 1 , 2}$ & 23,1 & $\mathbf{2 3 , 2}$ & 23,6 & $\mathbf{2 4 , 0}$ & 24,7 & $\mathbf{2 5 , 7}$ & 26,3 & $\mathbf{2 7 , 3}$ & 28,3 & $\mathbf{2 8 , 9}$ \\
\hline $\mathrm{A}$ & $\mathbf{4 , 5 5}$ & 4,55 & $\mathbf{5 , 9 2}$ & 4,58 & $\mathbf{4 , 7 5}$ & 5,08 & $\mathbf{4 , 5 8}$ & 5,92 & $\mathbf{4 , 7 5}$ & 5,08 & $\mathbf{4 , 5 5}$ \\
\hline $\mathrm{B}$ & $\mathbf{2}$ & 2 & $\mathbf{5 0}$ & 17 & $\mathbf{7}$ & 29 & $\mathbf{1 7}$ & 50 & $\mathbf{7}$ & 29 & $\mathbf{2}$ \\
\hline $\mathrm{C}^{\prime}$ & $\mathbf{0 , 2 5}$ & 0,25 & $\mathbf{0 , 1 7}$ & 0,17 & $\mathbf{0 , 2 5}$ & 0,24 & $\mathbf{0 , 1 7}$ & 0,17 & $\mathbf{0 , 2 5}$ & 0,24 & $\mathbf{0 , 2 5}$ \\
\hline
\end{tabular}

$A=$ Tempo total de irradiação (h).

$\mathrm{B}=$ Tempo total de interrupção da irradiação (min).

$\mathrm{C}^{\prime}=$ Densidade do material existente dentro da caixa de alumínio $\left(\mathrm{g} / \mathrm{cm}^{3}\right)$.

Nas irradiações dinâmicas foram colocados até 3 conjuntos em posições diferentes de uma mesma caixa de alumínio, mas a dose não é a mesma para todos os pontos da caixa, como pode ser visto na Figura 3.7. Isto explica porque a Tabela 4.3 apresenta os mesmos dados para doses diferentes.

Como no caso da irradiação estática, também na irradiação dinâmica as condições de irradiação nem sempre foram as mesmas para todas as irradiações, como pode ser visto na Tabela 4.3, devido às características de projeto de um irradiador de grande porte descritas no item 3.3. 


\subsection{Curvas de calibração: irradiação dinâmica}

Foram obtidas as curvas de calibração para $1 \mathrm{~h}, 2 \mathrm{~h}, 3 \mathrm{~h}$ e 1 dia após a irradiação dinâmica e são apresentadas respectivamente nas Figuras 4.9 a 4.12 e na Figura 4.13 que mostra todas as curvas em um único gráfico. O desvio padrão das medidas foi sempre menor que $1 \%$.

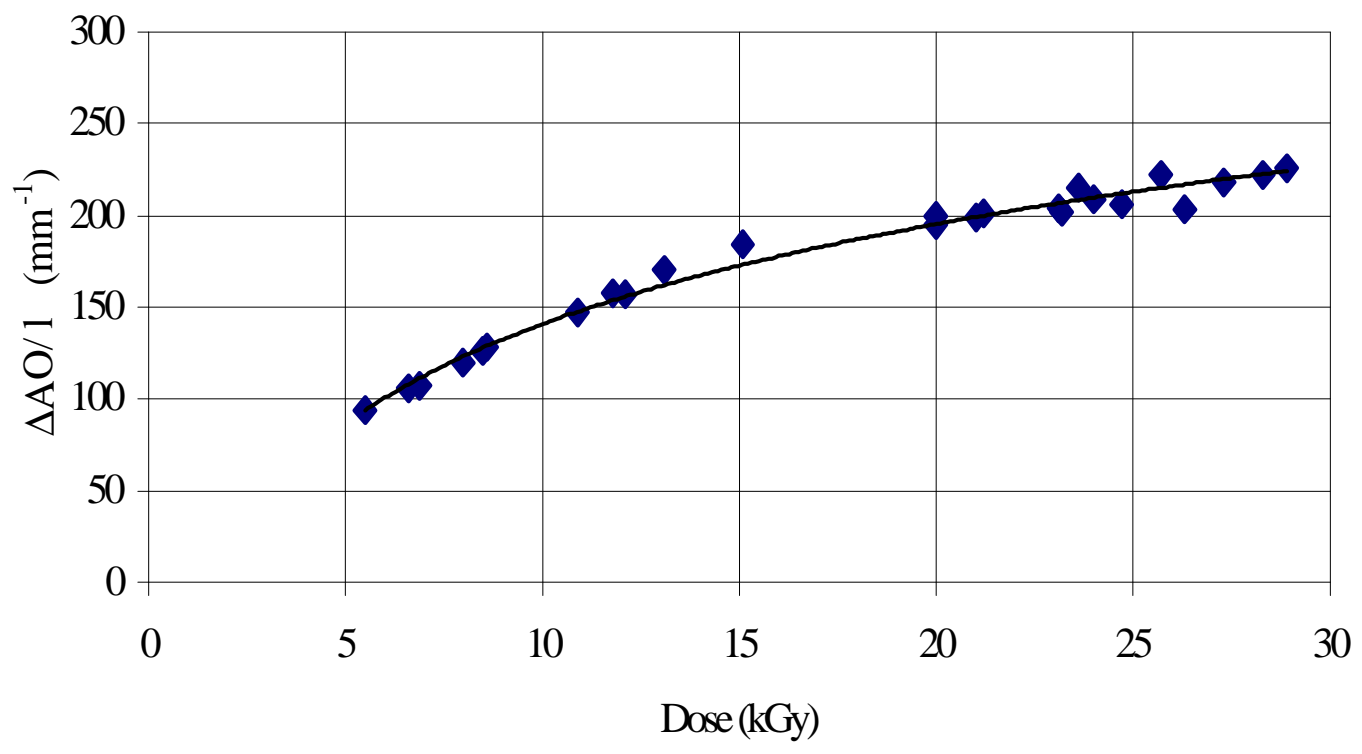

Figura 4.9: Curva de calibração das amostras de vidro em função da dose, medidas 1 hora após a irradiação dinâmica. 


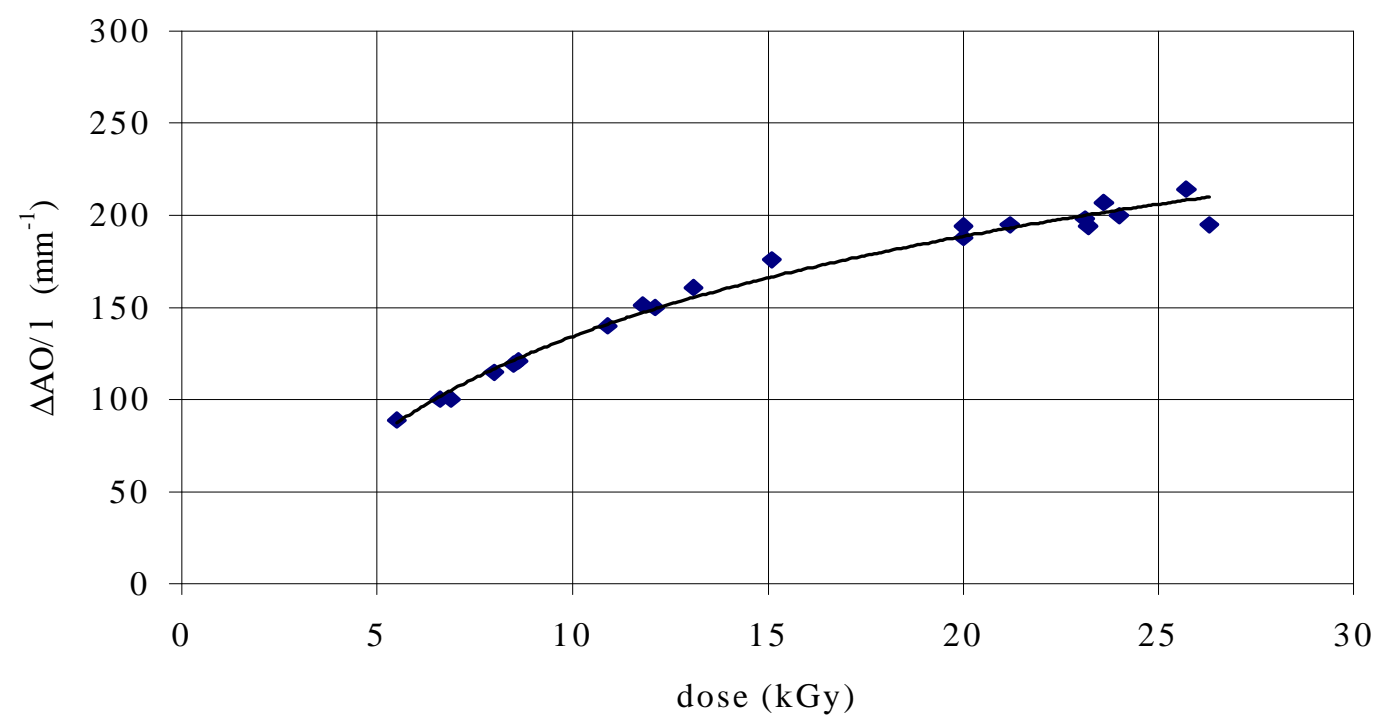

Figura 4.10: Curva de calibração das amostras de vidro em função da dose, medidas 2 horas após a irradiação dinâmica.

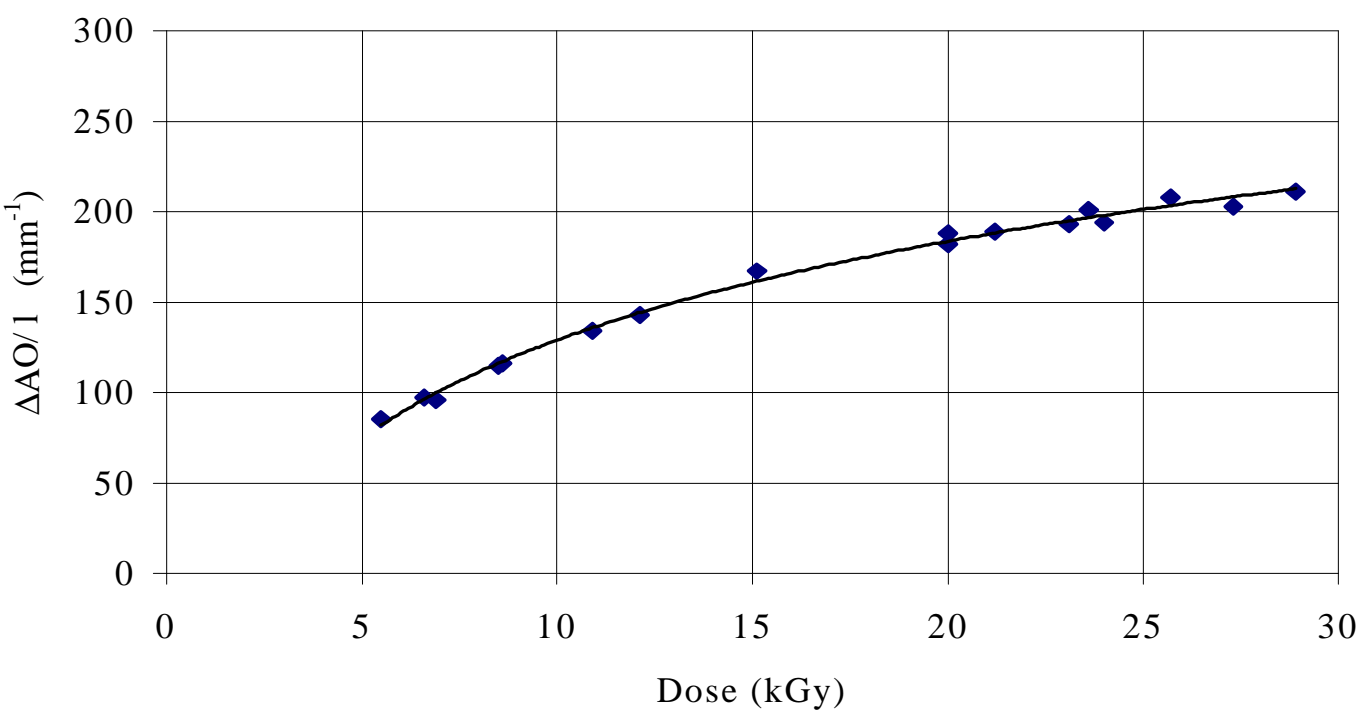

Figura 4.11: Curva de calibração das amostras de vidro em função da dose, medidas 3 horas após a irradiação dinâmica. 


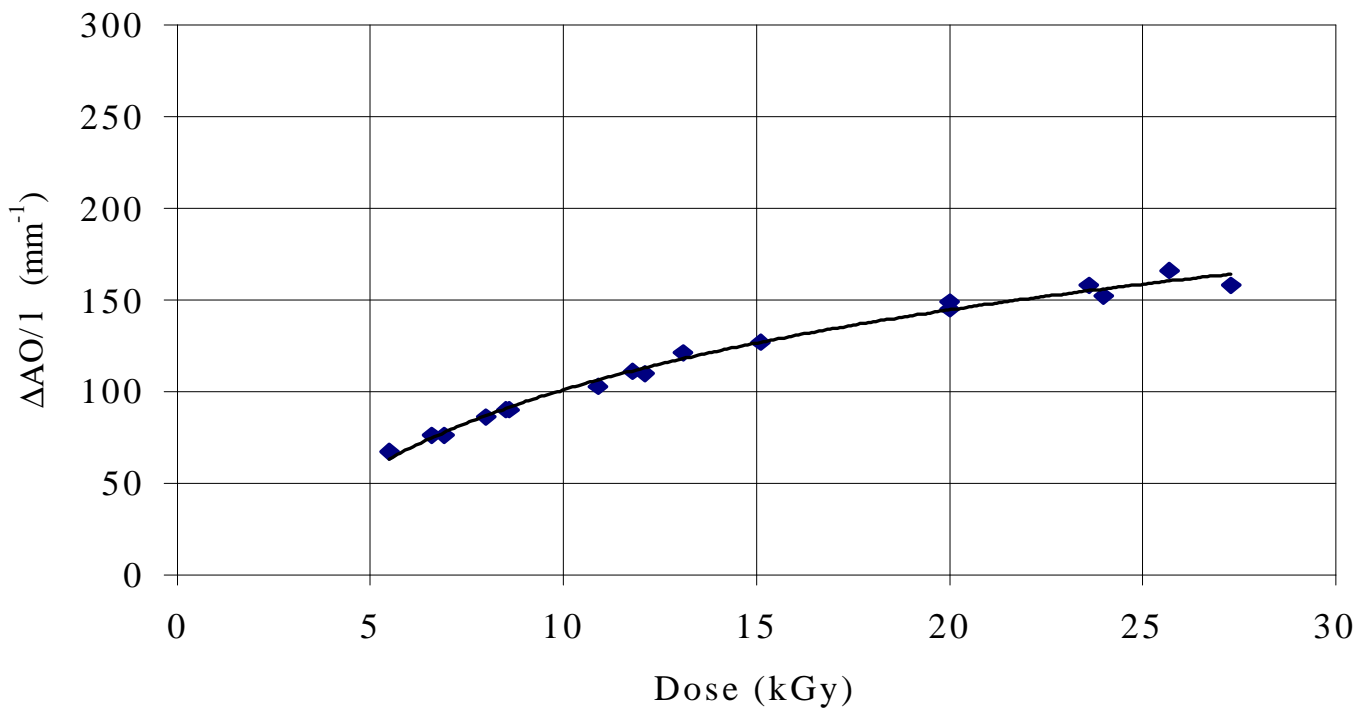

Figura 4.12: Curva de calibração das amostras de vidro em função da dose, medidas 1 dia após a irradiação dinâmica.

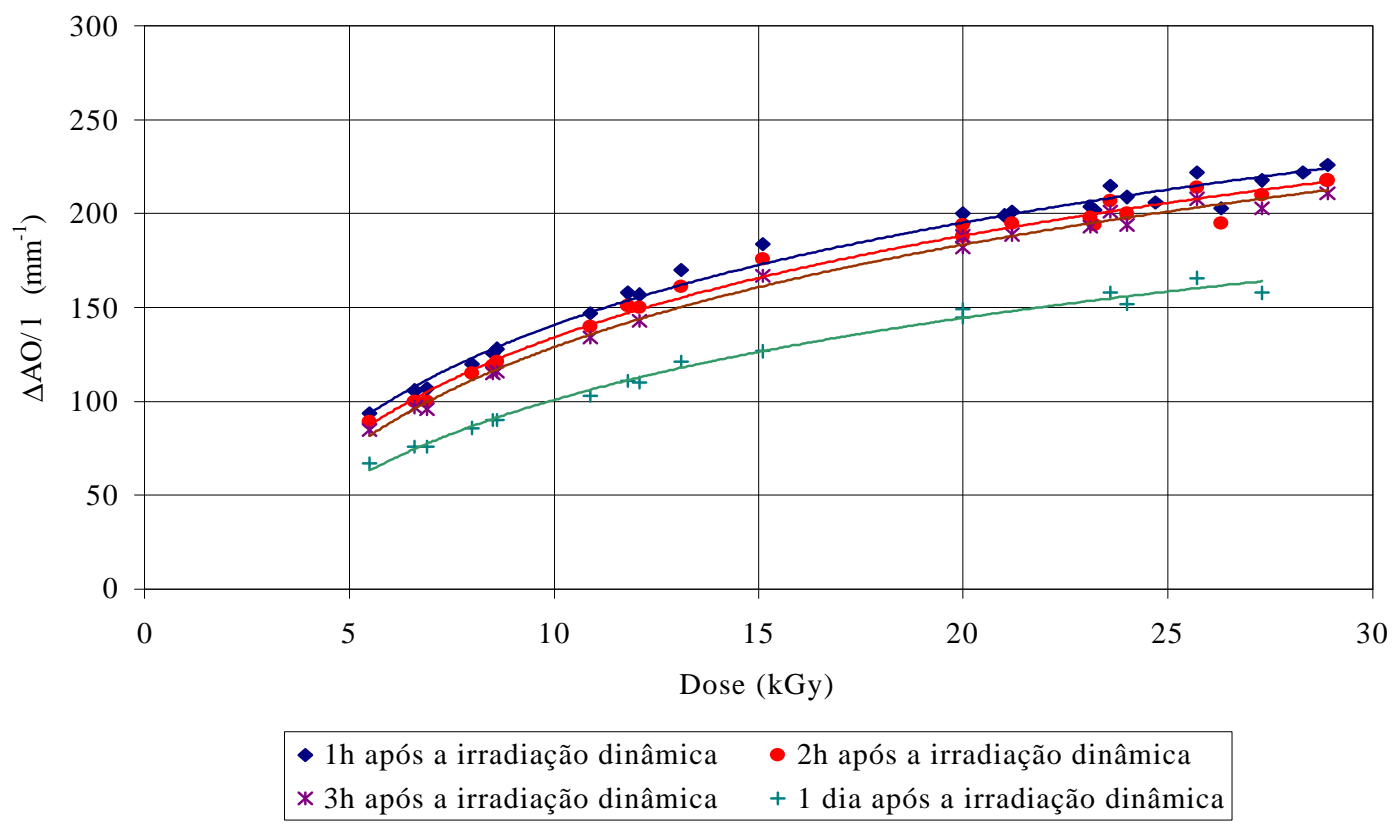

Figura 4.13: Curvas de calibração das amostras de vidro em função da dose, medidas 1,2 e 3 horas e 1 dia após as irradiações dinâmicas. 
As Figuras 4.9 a 4.12 mostram que também na irradiação dinâmica a variação da absorção pela espessura $(\Delta \mathrm{AO} / \mathrm{l})$ das amostras de vidro apresenta um comportamento crescente com a dose, que variou de 5,5 kGy a 28,9 kGy, mesmo com as interrupções durante as irradiações e com a variação da taxa de dose inerente a este tipo de irradiação mostradas respectivamente nas linhas B e C' da Tabela 4.3.

$\mathrm{Na}$ Tabela 4.4 são mostradas as equações polinomiais obtidas para cada curva de calibração por meio do método dos mínimos quadrados, os parâmetros e a avaliação de cada ajuste. O erro estimado variou de forma diferente ao da irradiação estática, diminuindo com o tempo após a irradiação. Isto pode ser explicado pelo fato de nas irradiações dinâmicas para 1 e 2 horas após a irradiação haver muitos pontos acima de $15 \mathrm{kGy}$, que não responderam proporcionalmente à dose e como o ajuste da equação levou em conta estes pontos, o erro estimado teve que ser da ordem de 6 a $8 \%$ para poder englobálos. Se o ajuste fosse feito somente com os pontos abaixo de $15 \mathrm{kGy}$ o erro estimado seria menor. Apesar disto um erro de $8 \%$ pode ser considerado aceitável para um dosímetro de rotina. 
Tabela 4.4 Equações obtidas pelo método dos mínimos quadrados e os respectivos parâmetros de ajuste e da verificação do ajuste para cada uma das curvas das irradiações dinâmicas.

\begin{tabular}{|c|c|c|c|c|c|}
\hline & & \multicolumn{2}{|c|}{$\begin{array}{c}\text { Parâmetros } \\
\text { de Ajuste }\end{array}$} & \multicolumn{2}{|c|}{$\begin{array}{l}\text { Verificação } \\
\text { do Ajuste }\end{array}$} \\
\hline $\begin{array}{l}\text { Número } \\
\text { da Figura }\end{array}$ & $\begin{array}{c}\text { Equação } \\
f(x)\end{array}$ & $\begin{array}{l}\mathrm{N}^{\mathrm{o}} \mathrm{de} \\
\text { pontos }\end{array}$ & $\begin{array}{c}\text { Erro } \\
\text { estimado }\end{array}$ & $\chi^{2}$ & $\chi_{\text {reduzido }}^{2}$ \\
\hline $4.8(1 \mathrm{~h})^{*}$ & $11,47-0,16 \cdot x+1,02 \cdot 10^{-3} \cdot x^{2}$ & 25 & $6 \%$ & 27,99 & 1,3 \\
\hline $4.9(2 \mathrm{~h})^{*}$ & $7,48-0,10 \cdot x+8,79 \cdot 10^{-4} \cdot x^{2}$ & 22 & $8 \%$ & 19,12 & 1,0 \\
\hline $4.10(3 \mathrm{~h})^{*}$ & $7,07-0,09 \cdot x+8,82 \cdot 10^{-4} \cdot x^{2}$ & 17 & $5 \%$ & 14,20 & 1,0 \\
\hline $4.11(24 \mathrm{~h})^{*}$ & $4,90-0,07 \cdot x+1,20 \cdot 10^{-3} \cdot x^{2}$ & 17 & $5 \%$ & 15,52 & 1,1 \\
\hline
\end{tabular}

* tempo após a irradiação dinâmica.

$\mathrm{f}(\mathrm{x})=$ dose em $\mathrm{kGy}$

$\mathrm{x}=$ variação da absorção óptica pela espessura da amostra de vidro em $\mathrm{mm}^{-1}$

$\chi^{2}=$ Verifica se a distribuição dos pontos experimentais em relação à curva é verossímil; seu valor deve ser próximo ao número de graus de liberdade ${ }^{[47,48]}$.

$\chi_{\text {reduzido }}^{2}$ Verifica se a função ajustada é verossímil; seu valor deve ser próximo ao número " 1 " [47,48]".

\subsection{Comparação entre os resultados}

A resposta das amostras de vidro em função da dose absorvida para os dois tipos de irradiação foi comparada por meio do comportamento das equações (obtidas pelo método dos mínimos quadrados) das curvas de calibração para diferentes intervalos de tempo pós-irradiação estática e dinâmica. Devido às características de um irradiador de grande porte, este não permite reproduzir exatamente todas as variáveis de uma irradiação para outra e portanto as doses não são exatamente iguais. Mas na avaliação dos dados a diferença entre as doses foi levada em consideração. 
Foram escolhidos os mesmos valores de " $\Delta \mathrm{AO} / \mathrm{l}$ " para as equações das curvas para os intervalos de tempo após a irradiação comum às irradiações estáticas e dinâmicas, ou seja, os de $1 \mathrm{~h}, 2 \mathrm{~h}$ e 1 dia.

\subsubsection{Uma hora após a irradiação}

Das Tabelas 4.2 e 4.4, tem-se as seguintes equações para a comparação entre as curvas de calibração estática e dinâmica:

equação para irradiação estática:

$f(x)=8,29-0,10 \cdot x+8,00 \cdot 10^{-4} \cdot x^{2}$

equação para irradiação dinâmica:

$f(x)=11,47-0,16 \cdot x+1,02 \cdot 10^{-3} \cdot x^{2}$

onde:

$\mathrm{f}(\mathrm{x})=$ dose em $\mathrm{kGy}$

$\mathrm{x}=$ variação da absorção óptica pela espessura da amostra de vidro em $\mathrm{mm}^{-1}$

Nesta comparação fez-se " $x$ " variar de 94 a 226 mm$^{-1}$ em intervalos de $2 \mathrm{~mm}^{-1}$. O resultado é mostrado na Figura 4.14. 


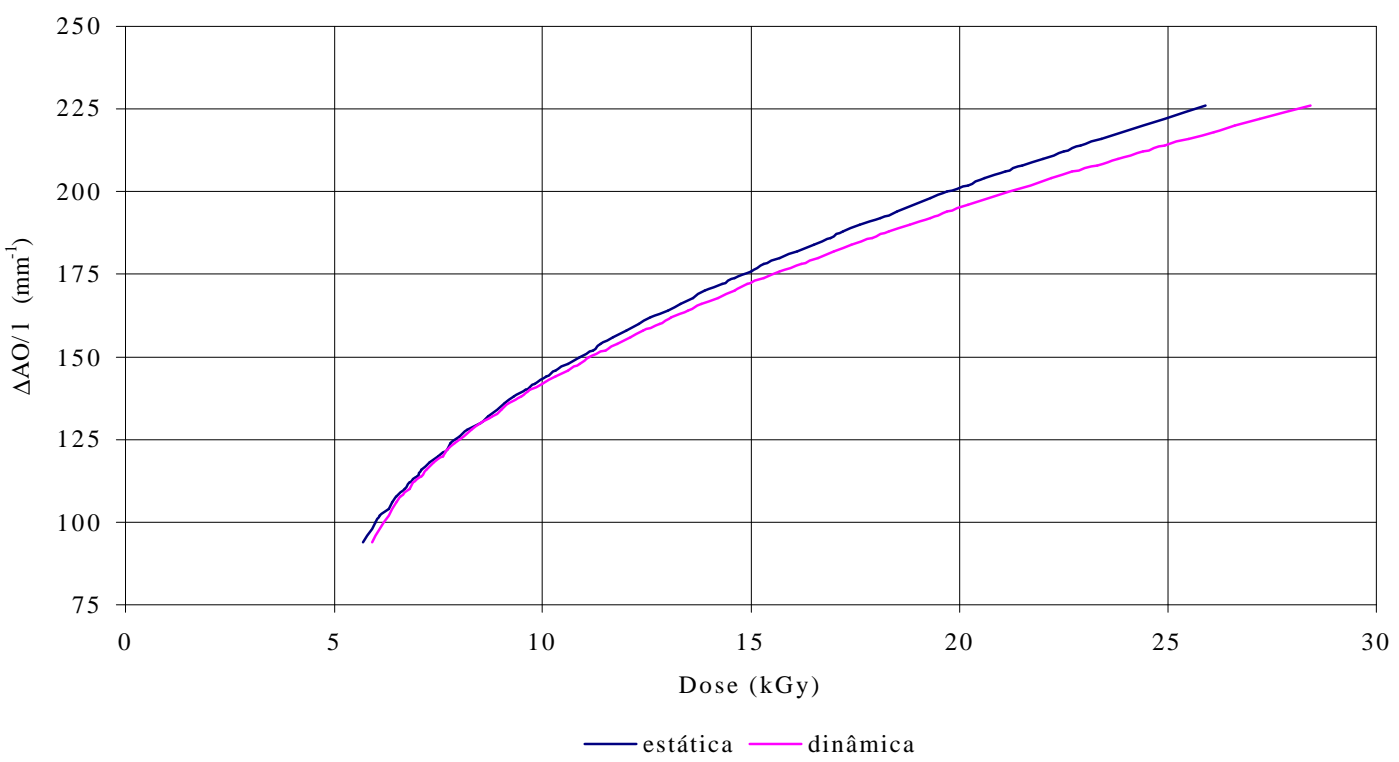

Figura 4.14: Comparação entre os comportamentos das equações obtidas pelo método dos mínimos quadrados para 1 hora após a irradiação estática e dinâmica das amostras de vidro. 
Fazendo-se a comparação das curvas ajustadas pelo métodos dos mínimos quadrados com os pontos experimentais das irradiações estáticas e dinâmicas, foram obtidas respectivamente as Figuras 4.15 e 4.16.

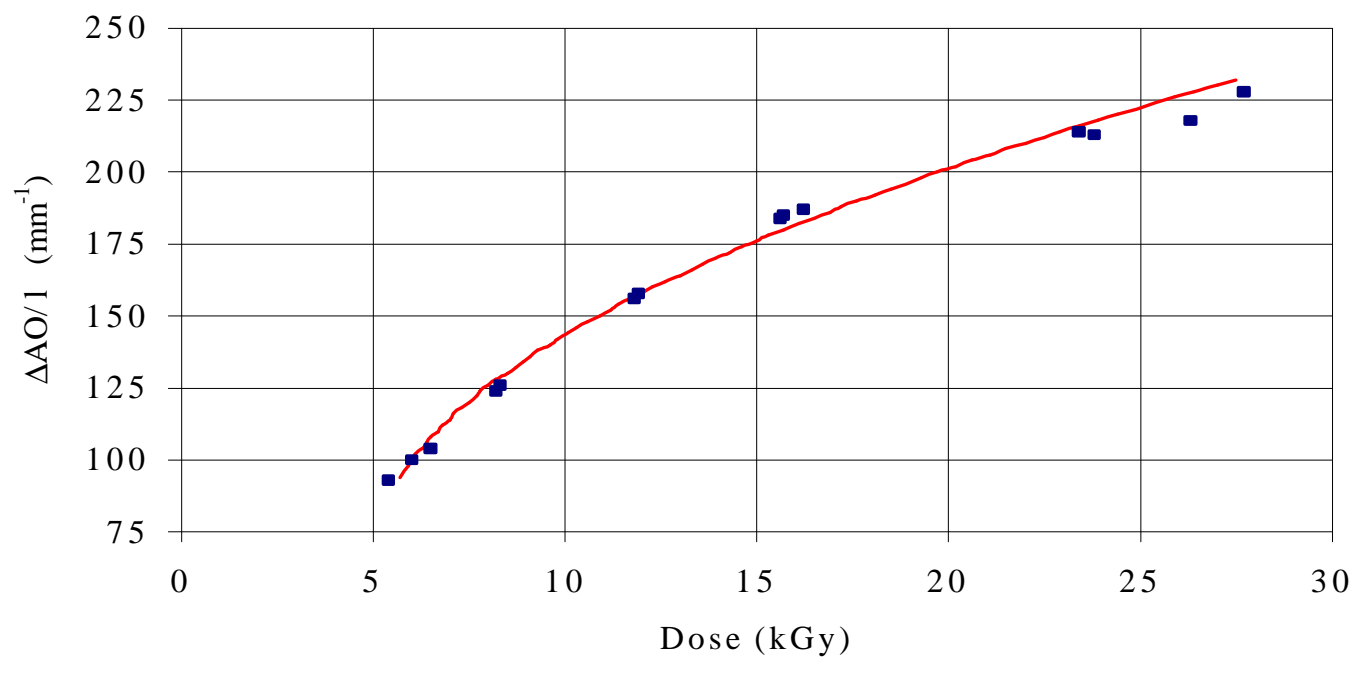

- pontos experimentais —estática, curva ajustada

Figura 4.15: Comparação entre o comportamento da curva ajustada pelo método dos mínimos quadrados com a distribuição dos pontos experimentais em torno da mesma, para 1 hora após a irradiação estática das amostras de vidro. 


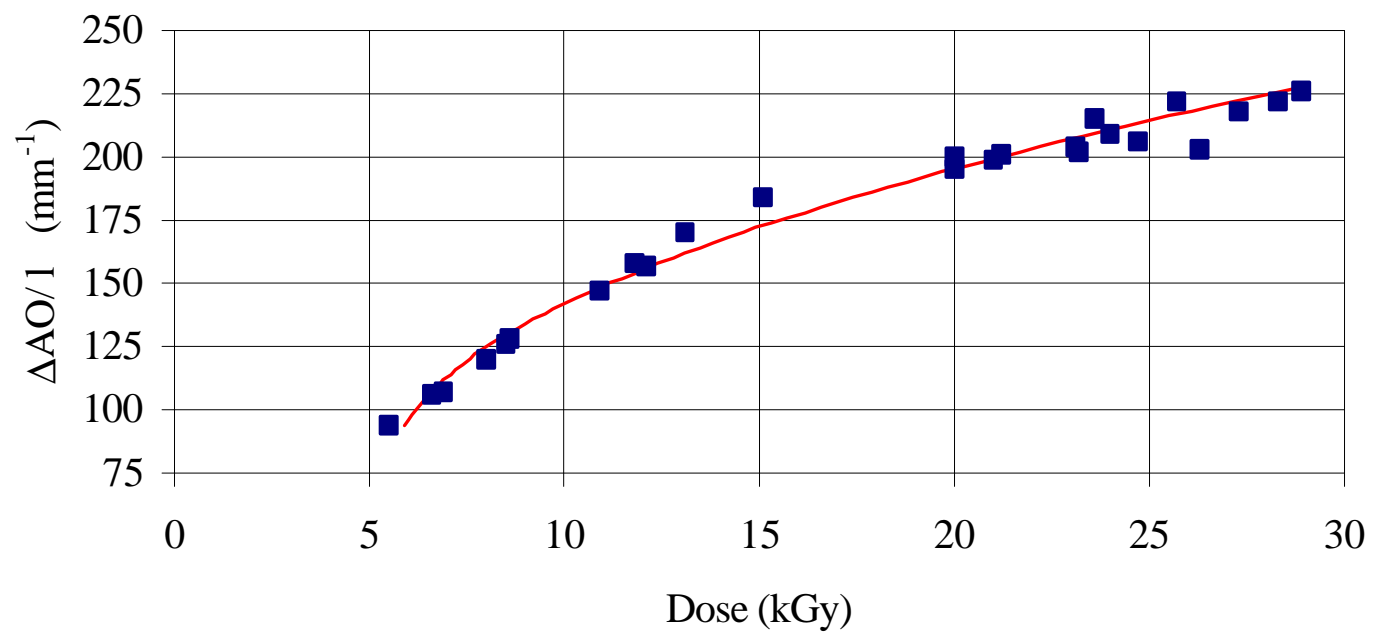

- pontos experimentais — dinâmica, curva ajustada

Figura 4.16: Comparação entre o comportamento da curva ajustada pelo método dos mínimos quadrados com a distribuição dos pontos experimentais em torno da mesma, para 1 hora após a irradiação dinâmica das amostras de vidro.

Observando-se as Figuras 4.15 e 4.16, verifica-se que há concordância entre o comportamento da curva ajustada e da distribuição dos pontos experimentais em torno da mesma, para 1 hora após a irradiação estática ou dinâmica, o que valida o ajuste.

O mesmo estudo foi realizado com os dados relativos a duas horas e um dia após a irradiação. 


\subsubsection{Duas horas após a irradiação}

Das Tabelas 4.2 e 4.4, tem-se as seguintes equações para a comparação entre as curvas de calibração estática e dinâmica:

equação para irradiação estática:

$f(x)=6,85-0,08 \cdot x+7,56 \cdot 10^{-4} \cdot x^{2}$

equação para irradiação dinâmica:

$$
f(x)=7,48-0,10 \cdot x+8,79 \cdot 10^{-4} \cdot x^{2}
$$

Nesta comparação fez-se "x" variar de 89 a 213 mm$^{-1}$ em intervalos de $2 \mathrm{~mm}^{-1}$. O resultado é mostrado na Figura 4.17. 


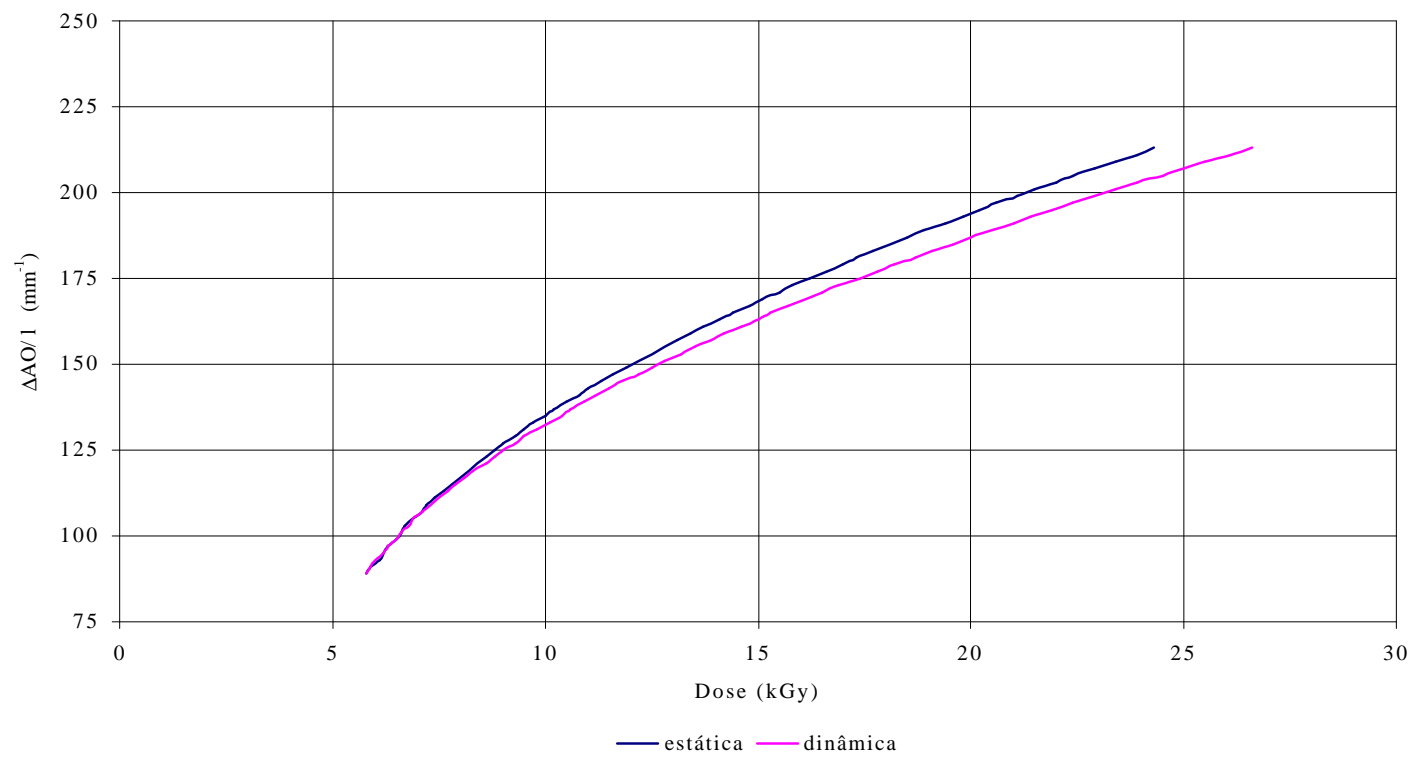

Figura 4.17: Comparação entre os comportamentos das equações obtidas pelo método dos mínimos quadrados para 2 horas após a irradiação estática e dinâmica das amostras de vidro. 
Fazendo-se a comparação das curvas ajustadas pelo métodos dos mínimos quadrados com os pontos experimentais das irradiações estáticas e dinâmicas, foram obtidas respectivamente as Figuras 4.18 e 4.19.

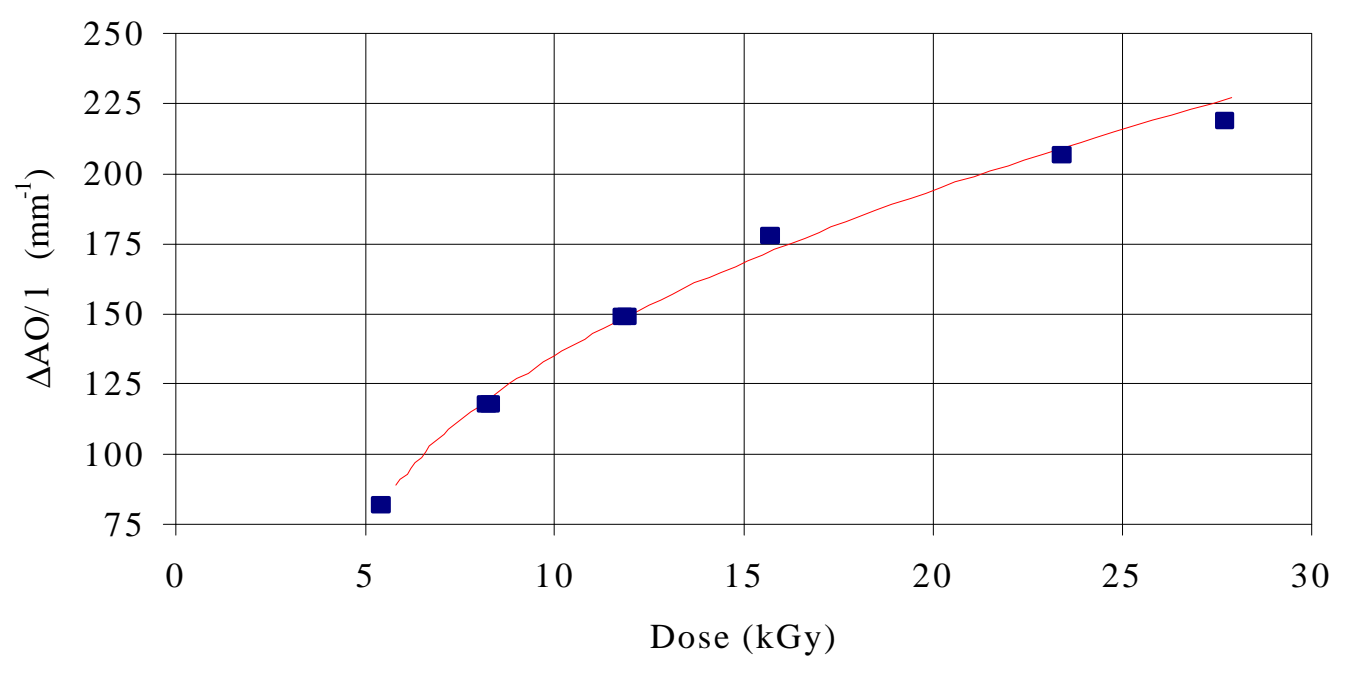

- pontos experimentais - estática, curva ajustada

Figura 4.18: Comparação entre o comportamento da curva ajustada pelo método dos mínimos quadrados com a distribuição dos pontos experimentais em torno da mesma, para 2 horas após a irradiação estática das amostras de vidro. 


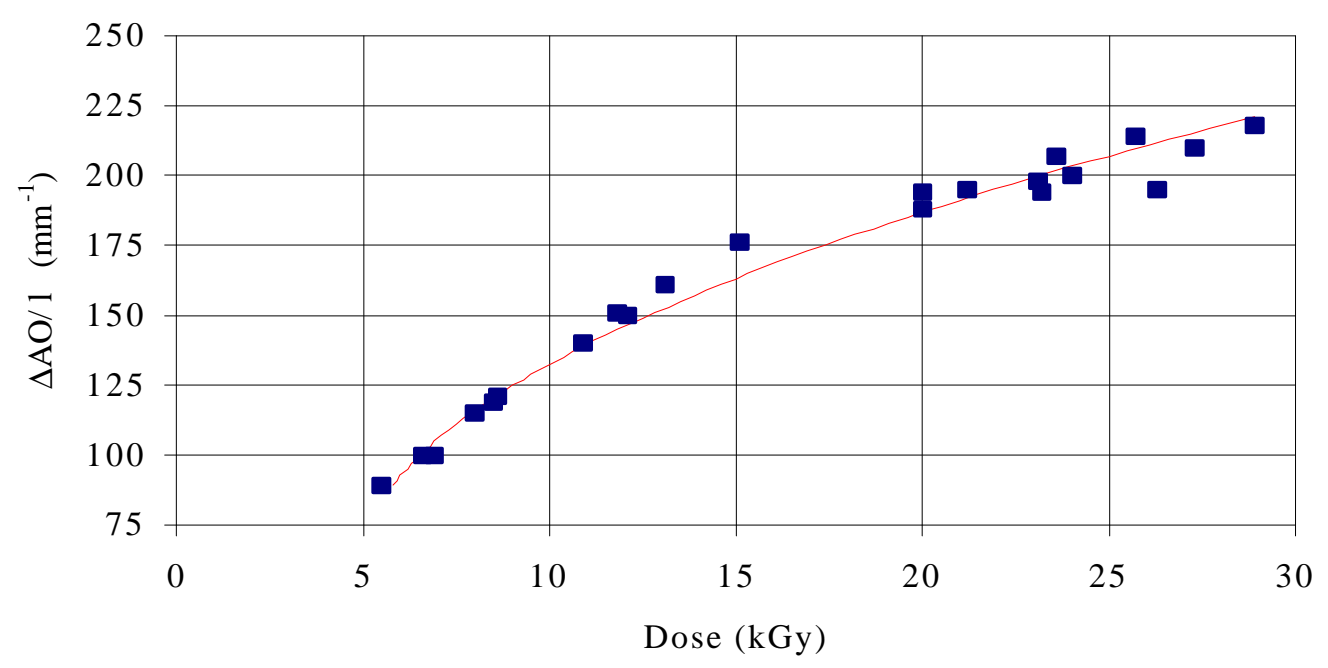

- pontos experimentais — dinâmica, curva ajustada

Figura 4.19: Comparação entre o comportamento da curva ajustada pelo método dos mínimos quadrados com a distribuição dos pontos experimentais em torno da mesma, para 2 horas após a irradiação dinâmica das amostras de vidro.

Observando-se as Figuras 4.18 e 4.19, verifica-se que há concordância entre o comportamento da curva ajustada e da distribuição dos pontos experimentais em torno da mesma, para 2 horas após a irradiação estática ou dinâmica, como no caso de 1 hora após a irradiação. 


\subsubsection{Um dia após a irradiação}

Das Tabelas 4.2 e 4.4, tem-se as seguintes equações para as devidas comparações entre as curvas de calibração estática e dinâmica:

equação para irradiação estática:

$f(x)=6,66-0,10 \cdot x+1,22 \cdot 10^{-3} \cdot x^{2}$

equação para irradiação dinâmica:

$f(x)=4,90-0,07 \cdot x+1,20 \cdot 10^{-3} \cdot x^{2}$

Nesta comparação fez-se " $x$ " variar de 67 a $159 \mathrm{~mm}^{-1}$ em intervalos de $2 \mathrm{~mm}^{-1}$. O resultado é mostrado na Figura 4.20. 


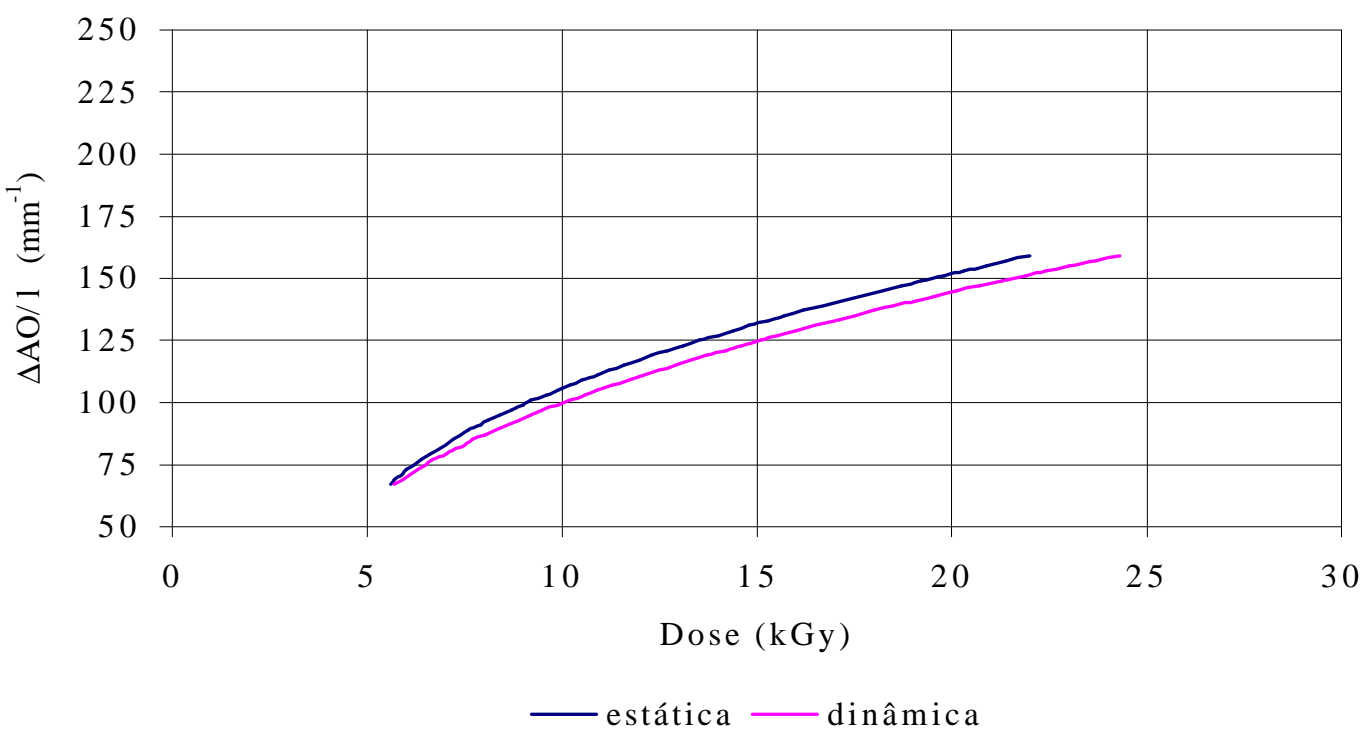

Figura 4.20: Comparação entre os comportamentos das equações obtidas pelo método dos mínimos quadrados para 1 dia após a irradiação estática e dinâmica das amostras de vidro. 
Fazendo-se a comparação das curvas ajustadas pelo métodos dos mínimos quadrados com os pontos experimentais das irradiações estáticas e dinâmicas, foram obtidas respectivamente as Figuras 4.21 e 4.22.

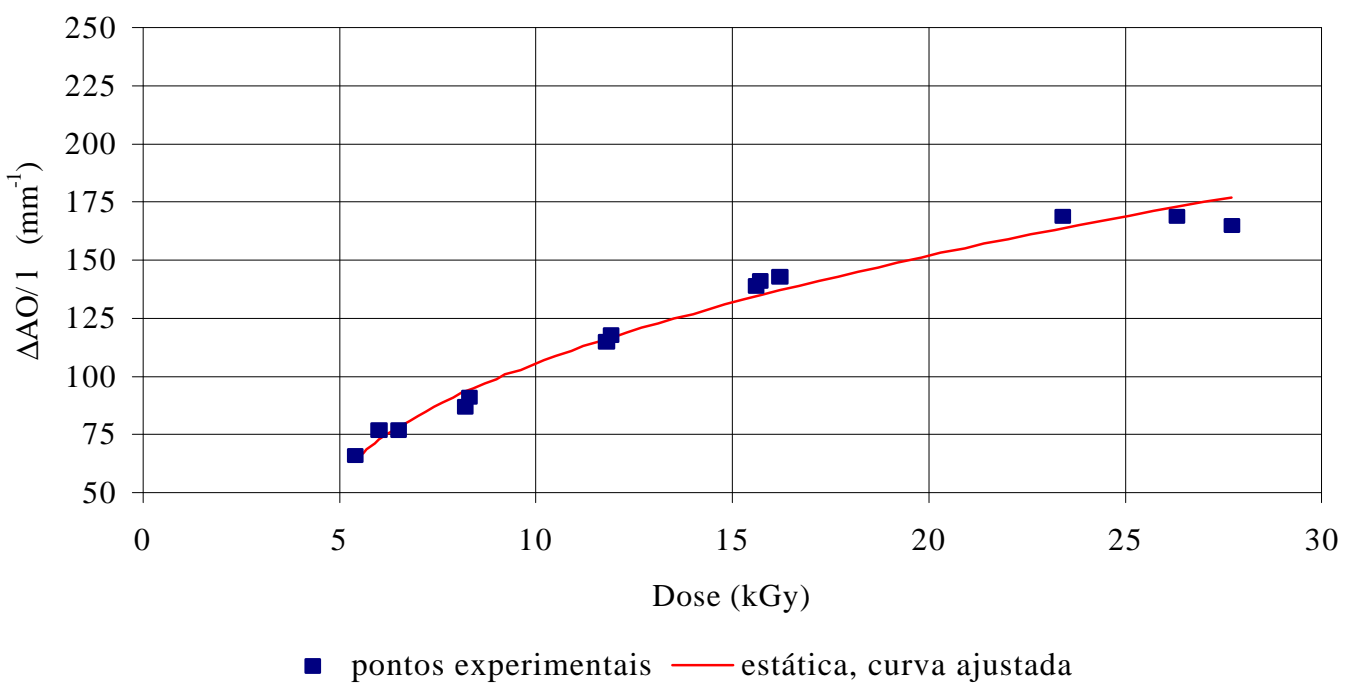

Figura 4.21: Comparação entre o comportamento da curva ajustada pelo método dos mínimos quadrados com a distribuição dos pontos experimentais em torno da mesma, para 1 dia após a irradiação estática das amostras de vidro. 


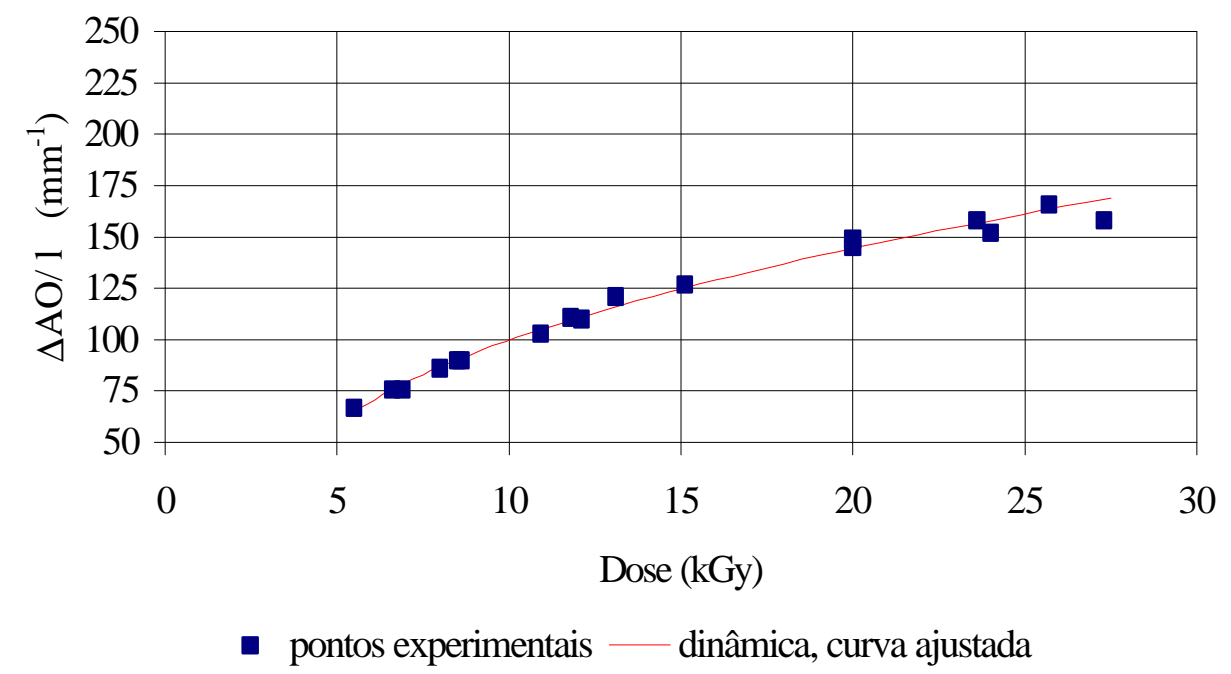

Figura 4.22: Comparação entre o comportamento da curva ajustada pelo método dos mínimos quadrados com a distribuição dos pontos experimentais em torno da mesma, para 1 dia após a irradiação dinâmica das amostras de vidro.

Observando-se as Figuras 4.21 e 4.22, verifica-se que há neste caso também concordância entre o comportamento da curva ajustada e da distribuição dos pontos experimentais em torno da mesma, para 1 dia após a irradiação estática ou dinâmica.

Até aproximadamente $12 \mathrm{kGy}$ as equações das curvas de calibração para 1 e 2 horas após as irradiações estática e dinâmica apresentam o mesmo comportamento, o que demonstra a independência da resposta com o modo de irradiação. No caso de 1 dia após a irradiação as duas curvas já divergem desde a dose mais baixa (Figura 4.20). 


\subsection{Estudo de repetibilidade}

Devido às características de projeto de um irradiador de grande porte, descritas no item 3.3, este não permite reproduzir exatamente todas as variáveis de uma irradiação para outra. Isto torna difícil a realização de um estudo experimental de repetibilidade da resposta das amostras de vidro irradiadas estaticamente ou dinamicamente.

Normalizando-se os dados para 7 e 14 kGy, no caso da irradiação estática e para 7 e 12 kGy no caso da irradiação dinâmica, foi possível reunir dados para um estudo de repetibilidade. Todos os resultados referem-se a uma hora após as irradiações. No caso dos dados da irradiação estática, a variação percentual no estudo de repetibilidade foi sempre menor que $6,3 \%$ e no caso da irradiação dinâmica, de 5,5 \%. Estes valores estão perfeitamente dentro dos limites aceitáveis.

\subsection{Detector de irradiação Sim/Não}

Devido à grande facilidade de escurecimento dos vidros pela irradiação gama com as doses utilizadas num irradiador de grande porte, os vidros são excelentes detectores de irradiação do tipo Sim/Não, bastando-se constatar seu escurecimento ao fim do processo.

Não há preocupação com o tempo de medida após a irradiação, que leva ao desvanecimento; mesmo um ano e meio após a irradiação, ainda foi possível constatar a olho nu que as amostras, guardadas protegidas da luz e do calor para este fim, não haviam perdido toda a cor, isto é não se apresentavam totalmente transparentes. 
Por isto este tipo de material de baixíssimo custo pode substituir qualquer outro tipo de detector Sim/Não importado ou nacional.

\subsection{Proposta de um circuito detector}

Os vidros apresentam uma desvantagem que é o desvanecimento de sua resposta após a irradiação. Para a utilização dos vidros como dosímetros, este fato pode ser contornado pela utilização de curvas de calibração construídas nas condições de operação e por um mecanismo de detecção da saída das caixa de alumínio da câmara de irradiação.

No caso específico do irradiador de grande porte em que este estudo foi desenvolvido, este mecanismo poderia funcionar da seguinte maneira: em uma das bordas superiores da caixa de alumínio, onde fosse colocado a amostra de vidro, seria acoplada uma pequena haste, cuja função seria acionar um contato elétrico para acionar um relê, que dispararia dois relês de tempo, sendo por exemplo um ajustado para 60 minutos e o outro para 45 minutos.

O relê de tempo ajustado para 60 minutos acionaria ao término deste tempo um aviso sonoro, informando que se passou 1 hora do término da irradiação e que a amostra de vidro deve ser lida imediatamente.

O relê de tempo ajustado para 45 minutos ligaria ao término deste tempo o fotocolorímetro onde será realizada a leitura da absorção da amostra de vidro, pois este necessita de no mínimo 15 minutos de aquecimento antes de se realizar a medida.

O esquema de blocos do sistema elétrico do mecanismo proposto é mostrado na Figura 4.23. 
$110 \mathrm{VCA}$

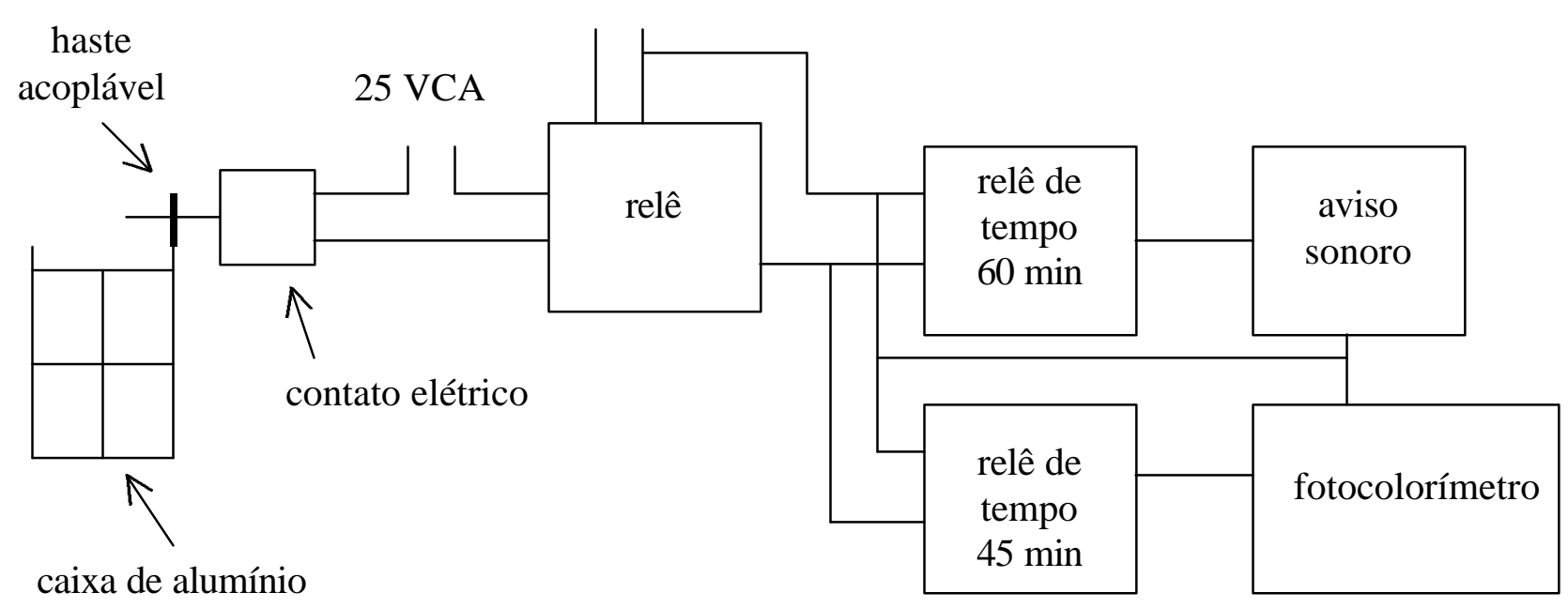

Figura 4.23: Esquema de blocos do sistema elétrico de mecanismo de detecção da saída da caixa de alumínio da sala de irradiação, para o irradiador JS 7500 da EMBRARAD.

\subsection{Análise de custo vidro versus "red perspex"}

Uma das grandes vantagens do sistema de vidros é o seu custo baixo, gerando uma economia considerável, pois cada dosímetro "red perspex" tipo 4034 custa cerca de 1 dólar, já inclusos todos os impostos, enquanto que 10 amostras de vidro com as mesmas dimensões do "red perspex" 4034 custam cerca de 8 centavos de real ou 5 centavos de dólar em uma vidraçaria comum de Cotia. Além disto, seriam evitados os processos de importação.

Uma outra forma de utilização deste tipo de material é o de detector de irradiação Sim/Não, devido ao escurecimento que apresenta após a irradiação. Também neste caso o sistema de vidros apresenta uma evidente vantagem 
econômica, pois cada detector Sim/Não nacional custa cerca de 5 centavos de real, o que daria para comprar aproximadamente 6 amostras de vidro.

Apesar deste aspecto não ter sido estudado neste trabalho, a literatura fornece evidências que os vidros podem ser reutilizados após tratamento térmico, tanto como dosímetros como indicadores Sim/Não ${ }^{[22,23,28]}$. 


\section{5) CONCLUSÕES}

Foi estudada e demonstrada a possibilidade da utilização de vidro transparente comum nacional como dosímetro de rotina em um irradiador de grande porte, com fonte de ${ }^{60} \mathrm{Co}$, comparando-se sua resposta com a do dosímetro "red perspex", que é o dosímetro de rotina mais utilizado no mundo para este tipo de aplicação.

A utilização das curvas de calibração das amostras de vidro permite uma determinação da dose absorvida até $12 \mathrm{kGy}$, independente do modo de irradiação (estático ou dinâmico), para até pelo menos 2 horas após a irradiação.

Utilizando-se curvas de calibração específicas para o modo de irradiação estático ou dinâmico, é possível a determinação da dose absorvida até aproximadamente $30 \mathrm{kGy}$, pelo menos até 1dia após a irradiação.

A utilização de vidros como dosímetros apresenta uma vantagem econômica considerável, pois com o valor pago por um dosímetro "red perspex" (importado) ou por um indicador Sim/Não (nacional) é possível comprar respectivamente 200 ou 6 amostras de vidro aproximadamente.

O desvanecimento dos vidros após a irradiação representa o principal obstáculo ao seu uso como dosímetros em um irradiador de grande porte, mas por meio do circuito detector proposto neste trabalho, torna-se possível contornar este obstáculo, pois se poderá saber com precisão e exatidão quando ocorreu o término da irradiação da caixa de alumínio que contém o dosímetro de vidro. 


\section{6) REFERÊNCIAS.}

1. MCLAUGHLIN, W.L.; BOYD, A.W.; CHADWICK, K.H.; MCDONALD, J.C.; MILlER, A. Dosimetry for Radiation Processing, Taylor \& Francis, London, 1989.

2. KOVÁCS, A.; WOJNÁROVITS, L.; EL-ASSY, N.B.; AFFEFY, H.Y.; AL-SHEIKHLY, M.; WALKER, M.L.; McLAUGHLIN, W.L. Alcohol solutions of triphenyl-tetrazolium chloride as high-dose radiochromic dosimeters. Radiat. Phys. Chem., v.46, n. 4-6, p. 1217-1225, 1995.

3. MAI, H.H.; DUONG, N.G.D.; KOJIMA, T. $\gamma$-ray dose intercomparison in absorbed dose range, 5-50kGy, using dicromate and alanine dosimeters. Appl. Radiat. Isot., v.47, n. 2, p 259-261, 1996.

4. BUXTON, G.V.; DJOUIDER, F. Use of the dichromate solution as a dosimeter for high dose and high dose rate. Radiat. Phys. Chem., v.48, n. 6, p. 799-804, 1996.

5. KOVÁCS, A.; WOJNÁROVITS, L. Large-scale dosimetry using dilute methylene blue dye in aqueous solution. Radiat. Phys. Chem., v.52, n. 1-6, p. 539-542, 1998.

6. STENGER, V.; TORDAY, Z.; HORVÁTH, I.; FALVI, L.; PAPP, Z. Long term experience in using the ethanol chlorobenzene dosimeter sistem. In: INTERNATIONAL SYMPOSIUM ON HIGH-DOSE DOSIMETRY FOR RADIATION PROCESSING, November 5-9, 1990, Vienna. Proceedings ... Vienna: IAEA, 1991. p. 277-288. 
7. FERNANDEZ, J.; CASTILLO-RODRIGUES E. A ceric sulphate dosimetric system. In: INTERNATIONAL SYMPOSIUM ON HIGHDOSE DOSIMETRY FOR RADIATION PROCESSING, November 5-9, 1990, Vienna. Proceedings ... Vienna: IAEA, 1991. p. 225-233.

8. McLAUGHLIN, W.; FARAHANI M.; LIANG, J. 2-deoxy-d-ribose aqueous solution as a gamma ray dosimeter. In: INTERNATIONAL SYMPOSIUM ON HIGH-DOSE DOSIMETRY FOR RADIATION PROCESSING, November 5-9, 1990, Vienna. Proceedings ... Vienna: IAEA, 1991. p. 159-171.

9. YUNUSOV, M.S.; AKHMADALIEV, A.; BEGMATOV, K.A. Semiconductor detector as ionising radiation dosimeter. Radiat. Phys. Chem., v. 46, n. 4-6, p. 1287-1290, 1995.

10. LITOVCHENKO, P.G.; BARABASH, L.I.; KUTS, V.I.; ROSENFELD, A.B.; MARUSAN, I.A. P-Channel mos sensor for measurement of emergency gamma and neutron irradiation. Radiat. Prot. Dosim., v. 66, n. 1-4, p.225-228, 1996.

11. MUSILEK, L.; GERNDT, J. Radiation response and dosimetric possibilities of photocouplers. Radiat. Prot. Dosim., v. 66, n. 1-4, p.209-212, 1996.

12. ONORI, S.; BORTOLIN E.; LAVALLE, M.; FUOCHI, P.G. $\mathrm{CaSO}_{4}: \mathrm{Dy}$ Phosphor as a suitable material for EPR high dose assesment. Radiat. Phys. Chem., v. 52, n. 4-6, p. 1199-1202, 1998. 
13. McLAUGHLIN, W.L. Color centres in LiF for measurement of absorbed doses up to 100MGy. Radiat. Prot. Dosim., v. 66, n. 1-4, p.197-200, 1996.

14. LEWANDOWSKI, A.C.; MATHUR, V.K. High dose and phototransferred thermoluminescence in $\mathrm{CaSO}_{4}$ : Dy and $\mathrm{CaSO}_{4}$ : Tm. Radiat. Prot. Dosim., v. 66, n. 1-4, p.213-216, 1996.

15. OSVAY, M. Measurements on shielding experiments using $\mathrm{Al}_{2} \mathrm{O}_{3}: \mathrm{Mg}, \mathrm{Y}$ TL detectors. Radiat. Prot. Dosim., v. 66, n. 1-4, p.217-219, 1996.

16. WIESER, A.; REGULLA D. Cellulose for high level dosimetry. In: INTERNATIONAL SYMPOSIUM ON HIGH-DOSE DOSIMETRY FOR RADIATION PROCESSING, November 5-9, 1990, Vienna. Proceedings ... Vienna: IAEA, 1991. p. 203-212.

17. ABDEL-FATTAH, A.A.; EL-KELANI, M.; ABDEL-REHIM, F. Developement of a radiation-sensitive indicator. Radiat. Phys. Chem., v. 48, n. 4, p. 497-503, 1996.

18. GLOVER, K.M.; KING, M.; WATTS M. F. Calibration and intercomparison of red 4034 perspex dosimeters. In: INTERNATIONAL SYMPOSIUM ON HIGH-DOSE DOSIMETRY, 1984, Proceedings ... Vienna: IAEA, 1985. p. 373-395. 
19. WHITTAKER, B.; WATTS M.F.; MELLOR, S.; HENEGHAN, M. Some parameters affecting the radiation response and post-irradiation stability of red 4034 perspex dosimeters. In: INTERNATIONAL SYMPOSIUM ON HIGH-DOSE DOSIMETRY, 1984, Proceedings ... Vienna: IAEA, 1985. p. 293-305.

20. AL-SHEIKHLY, M.; CHAPPAS, W.J.; McLAUGHLIN, W.L.; HUMPHREYS, J., C. Effects of absorbed dose rate, irradiation temperature and post-irradiation temperature on the gamma ray response of red perspex dosimeters. In: INTERNATIONAL SYMPOSIUM ON HIGH-DOSE DOSIMETRY FOR RADIATION PROCESSING, November 5-9, 1990, Vienna. Proceedings ... Vienna: IAEA, 1991. p. 419-434.

21. AMIN, M.R.; SIDDIQUE, A.K.; CHOWDHURY, N.A.; RAHMAN, S. Evaluation of locally available white perspex as a dosimeter in radiation processing. In: INTERNATIONAL SYMPOSIUM ON HIGH-DOSE DOSIMETRY FOR RADIATION PROCESSING, November 5-9, 1990, Vienna. Proceedings ... Vienna: IAEA, 1991. p. 57-63.

22. QUEZADA, V. A. C., Estabelecimento de um sistema dosimétrico para doses altas, Dissertação de Mestrado, Instituto de Pesquisas Energéticas e Nucleares, São Paulo, Brasil, 1997.

23. CALDAS, L. V. E., Utilização de vidros como detectores de radiação para altas doses, IPEN-PUB-261, São Paulo, Brasil, 1989. 
24. QUEZADA, V.A.C.; CALDAS, L.V.E. Glass detectors for dose determination in a flower irradiation process. In $12^{\text {th }}$ INTERNATIONAL CONFERENCE ON SOLID STATE DOSIMETRY, July 5-10, 1998, Burgos, Spain, Radiat. Prot. Dosim., v. 85, n. 1-4, p. 473-475, 1999.

25. ZHENG, Z.; HONG-GUI, D.; SHANG-ZE, H.; JIAN L. , An optical fibre-type silicate glass thermoluminescent detector, Nucl. Instrum. Meth. Phys. Res., A301, p. 337-340, 1991.

26. ERKOL, A. Y.; YASAR, S.; KARAKELLE, B.; YASAR, D. Investigation of TLD properties of metal alloy oxides, glass, ceramics and various papers. Radiat. Phys. Chem., v. 46, n. 4-6, p. 1199-1202, 1995.

27. KHAN, H.M.; ALI, S.W. Environmental effects on dosimetric properties of commercially available window glass sheets. Radiat. Phys. Chem., v. 46, n. 4-6, p. 1203-1206, 1995.

28. CALDAS L.V.E.; DE SOUZA C.N. High dose dosimetry using glass detectors in electron beams . In: INTERNATIONAL SYMPOSIUM ON HIGH-DOSE DOSIMETRY FOR RADIATION PROCESSING, November 5-9, 1990, Vienna. Proceedings ... Vienna: IAEA, 1991. p. 93-99.

29. ZHENG, Z.; HOENGGUI, D.; JIE, F.; DAOCHUAN, Y. Window glass as a routine dosimeter for radiation processing, Radiat. Phys. Chem., v. 31, n. 4-6, p. 419-423, 1988. 
30. ZHENG, Z.; JIANSHENG.; JIATING, Z.; HOENGGUI, D.; YONGFU, Z.; SHANGZE, H; JIE, F. Study on the possibility of reading two kinds of data from one glass detector, Radiat. Phys. Chem., v. 50, n.3, p. 303-305, 1997.

31. RODRIGUES JÚNIOR, A. A.; CALDAS L.V.E. Vidro comercial testado como detector de radiação num irradiador de grande porte. IN: VII CONGRESSO GERAL DE ENERGIA NUCLEAR, Anais, 31 ago.3 set., 1999, Belo Horizonte, Brasil.

32. ASANO, Y.; SASAMOTO, N.; NAKANE Y.; NAKASHIMA, H.; SAKAMOTO, Y.; TANAKA, S.; NAMITO, Y.; BAN, S.; HIRAYAMA, H.; NARIYAMA, N. Measurement of glass dosimeter response for low energy photon using synchrotron radiations. In INTERNATIONAL CONGRESS ON RADIATION PROTECTION, april 14-19, 1996, Vienna. Proceedings ... v.4, 1996, p.253-255.

33. CHARITIDIS, C; KITS, G; CHARALAMBOUS, S. Supralinearity of synthetic quartz at different irradiation temperatures. Radiat. Prot. Dosim., v. 65, n. 1-4, p. 347-350, 1996.

34. JUSTUS, B.L.; RYCHNOVSKY S.; HUSTON A.L. Optically stimulated luminescence dosymetry using doped fused quartz glass. In $12^{\text {th }}$ INTERNATIONAL CONFERENCE ON SOLID STATE DOSIMETRY, July 5-10, 1998, Burgos, Spain. Radiat. Prot. Dosim., v. 84, n. 1-4, p. 189-192, 1999. 
35. OTHMAN, I.E.; CHARLES, M.W. Thermoluminescence properties of novel thin clear fused quartz (CFQ) dosemeters. In INTERNATIONAL CONFERENCE ON SOLID STATE DOSIMETRY, July 5-10, 1998, Burgos, Spain. Radiat. Prot. Dosim., v. 84, n. 1-4, p. 193-196, 1999.

36. MANSY, M.; HUSSEIN, A.; HIGAZY, A.A. The $\mathrm{MgO}-\mathrm{P}_{2} \mathrm{O}_{5}$ glasses as thermoluminescent gamma dosimeters. Radiat. Eff. \& Def. in Sol., v.145, p. 115-121, 1998.

37. ZANOTTO, E.D., Os vidros das catedrais fluem ?. Ciência Hoje, v. 23, n. 136, p.6-7, 1998

38. VIZEU, D.M. O crescimento da indústria de processamento por radiação. BOLETIM EMBRARAD, nº 21, São Paulo, Brasil, 1996.

39. VIZEU, D.M. Esterilização por radiação. BOLETIM EMBRARAD, n 2 2, São Paulo, Brasil, 1981.

40. VIZEU, D.M. Irradiação de alimentos. BOLETIM EMBRARAD, $\mathrm{n}^{\circ} 6$, São Paulo, Brasil, 1983.

41. VIZEU, D.M. Irradiação de alimentos BOLETIM EMBRARAD, $\mathrm{n}^{\mathrm{o}} 10$, São Paulo, Brasil, 1986.

42. VIZEU, D.M. Esterilização industrial. BOLETIM EMBRARAD, $\mathrm{n}^{\circ} 14$, São Paulo, Brasil, 1989.

43. VIZEU, D.M. Irradiação de pedras preciosas. BOLETIM EMBRARAD, nº 5, São Paulo, Brasil, 1983. 
44. VIZEU, D.M. Química de polímeros. BOLETIM EMBRARAD, ${ }^{\circ} 14$, São Paulo, Brasil, 1989.

45. VIZEU, D.M. Obras de arte. BOLETIM EMBRARAD, $n^{0} 15$, São Paulo, Brasil, 1990.

46. EMBRARAD EMPRESA BRASILEIRA DE RADIAÇÕES LTDA, Plano de Radioproteção, Cotia, Brasil, 1998.

47. HELENE, O., A., M.; VANIN, V., R. Tratamento de dados em física experimental. ed. Edgar Blücher Ltda., São Paulo, 1981.

48. VUOLO, J., V. Fundamentos da teoria dos erros. ed. Edgar Blücher Ltda., São Paulo, 1992. 